Final Report

FHWA/IN/JTRP-2006/28

\title{
Lab Testing and Field Implementation of Soil Flushing
}

\author{
by \\ Linda S. Lee \\ Professor \\ Dept. of Agronomy \\ Purdue University \\ and \\ Xihong Zhai \\ Jaesun Lee \\ Graduate Research Assistants \\ School of Civil Engineering \\ Purdue University \\ Joint Transportation Research Program \\ Project No. C-36-68H \\ File No. 4-7-8 \\ SPR-2335 \\ Prepared in Cooperation with the \\ Indiana Department of Transportation and the \\ U.S. Department of Transportation \\ Federal Highway Administration
}

The contents of this report reflect the views of the author who is responsible for the facts and the accuracy of the data presented herein. The contents do not necessarily reflect the official views or policies of the Indiana Department of Transportation or the Federal Highway Administration at the time of publication. This report does not constitute a standard, specification, or regulation.

Purdue University

West Lafayette, Indiana 47907

December 2006 
TECHNICAL REPORT STANDARD TITLE PAGE

\begin{tabular}{|c|c|c|}
\hline $\begin{array}{l}\text { 1. Report No. } \\
\text { FHWA/IN/JTRP-2006/28 }\end{array}$ & 2. Government Accession No. & 3. Recipient's Catalog No. \\
\hline \multirow{2}{*}{\multicolumn{2}{|c|}{$\begin{array}{l}\text { 4. Title and Subtitle } \\
\text { Lab Testing and Field Implementation of Soil Flushing }\end{array}$}} & $\begin{array}{l}\text { 5. } \quad \text { Report Date } \\
\text { December } 2006\end{array}$ \\
\hline & & 6. Performing Organization Code \\
\hline $\begin{array}{l}\text { 7. Author(s) } \\
\text { Linda S. Lee, Xihong Zhai, and Jaesun Lee }\end{array}$ & & $\begin{array}{l}\text { 8. Performing Organization Report No. } \\
\text { FHWA/IN/JTRP-2006/28 }\end{array}$ \\
\hline \multirow{2}{*}{\multicolumn{2}{|c|}{$\begin{array}{l}\text { 9. Performing Organization Name and Address } \\
\text { Joint Transportation Research Program } \\
\text { Purdue University } \\
\text { West Lafayette, IN 47907-1284 }\end{array}$}} & 10. Work Unit No. \\
\hline & & $\begin{array}{l}\text { 11. Contract or Grant No. } \\
\text { SPR-2335 }\end{array}$ \\
\hline \multirow{2}{*}{\multicolumn{2}{|c|}{$\begin{array}{l}\text { 12. Sponsoring Agency Name and Address } \\
\text { Indiana Department of Transportation, State Office Bldg, } 100 \text { N Senate Ave., } \\
\text { Indianapolis, IN } 46204\end{array}$}} & $\begin{array}{l}\text { 13. Type of Report and Period Covered } \\
\text { Final Report }\end{array}$ \\
\hline & & 14. Sponsoring Agency Code \\
\hline
\end{tabular}

\section{Abstract}

Many of the Indiana Department of Transportation (INDOT) sites are contaminated with aromatic hydrocarbons and chlorinated solvents; these contaminants often occur in the form of light non-aqueous phase liquids (LNAPLs) or dense non-aqueous phase liquids (DNAPLs). Considerable effort has recently been focused on developing in-situ technologies for removing or destroying NAPL source zones, and several potentially viable methods have emerged including cosolvent-enhanced source zone removal. Most recently, site-specific remedial designs involving a combination of in-situ methods (often referred to as a treatment train) have been proposed for which data are still sparse.

The primary goal of the laboratory experiments is to assess the utility and effectiveness of a biofriendly cosolvent ethyl lactate for source zone flushing through enhanced dissolution mechanisms followed by assessing enhanced biological removal of contaminant residuals by cosolvent residuals. Ethyl lactate residuals after source zone remediation can serve as a substrate for indigenous microorganisms to induce anaerobic conditions and enhance in-situ reductive dehalogenation, but whether or not this process would further facilitate complete mineralization or if it too would stall at undesirable metabolites is unknown. Results from these lab evaluations involving batch tests and one-dimensional (1-D) and two-dimensional (2-D) flow systems will contribute to assessing the value of this treatment train approach for relevant INDOT sites and to developing an effective strategy for using this approach under field conditions. Ethyl lactate was found to be very efficient in recovering DNAPL mass in source zone. The residual amount of EL not only poses no harm to indigenous microbial population in a DNAPL contaminated site, but also serves as electron donor to promote the microbial dehalogenation of chlorinated contaminants, such as perchloroethene (PCE) and trichloroethylene (TCE) in the down gradient plume. Therefore, the flushing agent, EL, can be left behind at low concentrations to facilitate biodegradation in the plume.

The soils used were from INDOT sites selected based on input from INDOT staff regarding amenability to future site remediation via the proposed treatment train. Site selection and assessment required travel by senior personnel to evaluate the nature and extent of contamination and by research assistants to collect soil samples for laboratory experiments.

\section{Key Words}

In-situ enhanced dissolution, remediation, source zone, NAPLs, perchloroethene, toluene, enhanced microbial dehalogenation

\section{Distribution Statement}

No restrictions. This document is available to the public through the National Technical Information Service, Springfield, VA 22161

\begin{tabular}{|c|c|c|c|}
\hline $\begin{array}{c}\text { 19. Security Classif. (of this report) } \\
\text { Unclassified }\end{array}$ & 20. Security Classif. (of this page) & 21. No. of Pages \\
70
\end{tabular}

Form DOT F 1700.7 (8-69) 


\section{Table of Contents}

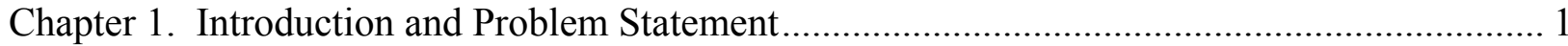

1.1 Background Information and Problem Statement......................................................... 1

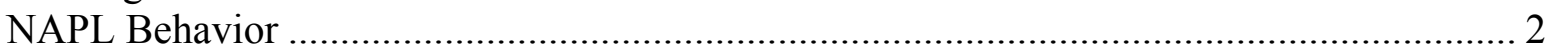

Optimizing Cosolvent Enhanced NAPL Solubilization ................................................. 3

Benefits of Ethyl Lactate as the Biofriendly Solvent of Choice ...................................... 4

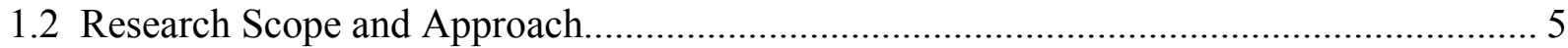

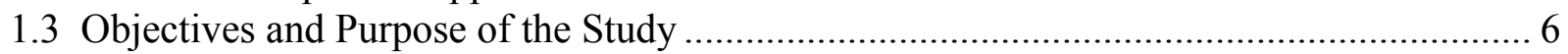

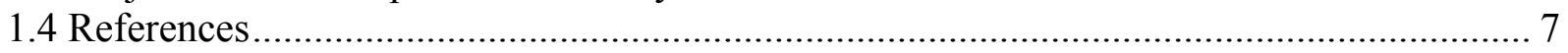

Chapter 2. Flux-mass Relationship with Sequential DNAPL Release Events .......................... 9

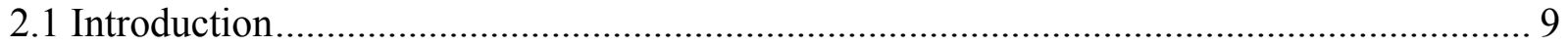

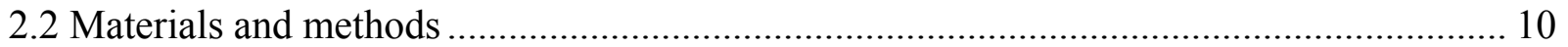

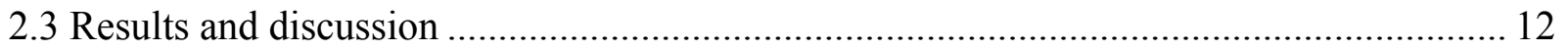

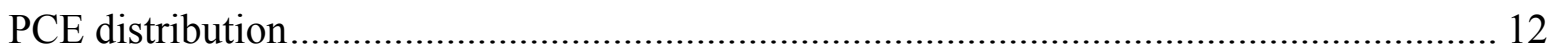

Flux versus mass relationship .......................................................................... 13

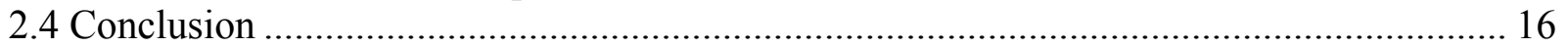

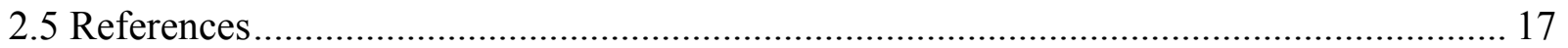

Chapter 3. In-Situ Flushing for DNAPL Mass Depletion Using Ethyl lactate.......................... 22

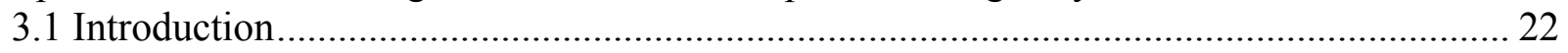

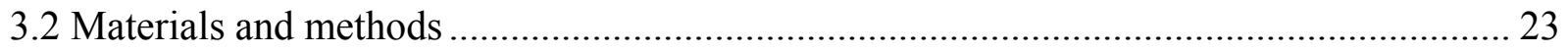

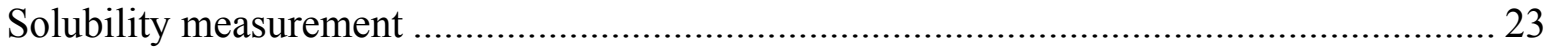

DNAPL mobilization experiment gradient flushing in 1-D column ............................... 24

Flushing PCE-conatminated 1-D column with 50\% ethyl lactate .................................. 24

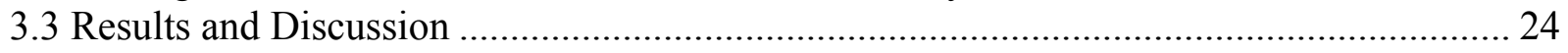

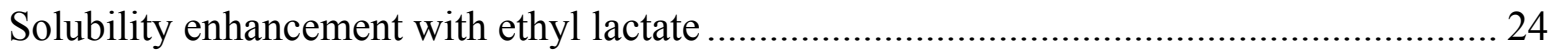

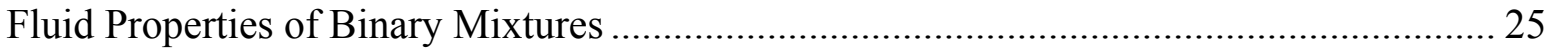

NAPL Mobilization \& Total Trapping Number .................................................... 26

Enhanced PCE Solubilization by Flushing with Ethyl Lactate .................................... 28

Modeling of PCE elution with EL/water flushing in the column ................................... 29

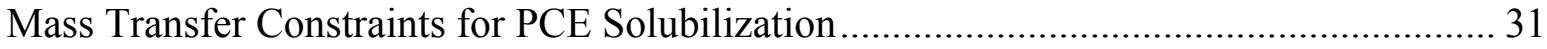

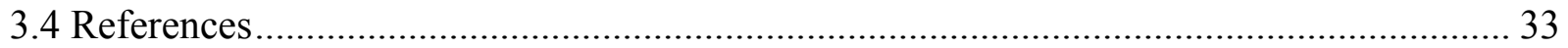

Chapter 4. Impact on Ethyl Lactate Residuals on Biodegradation of a PCE Plume .................. 43

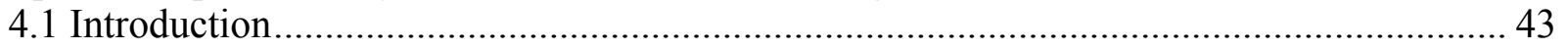

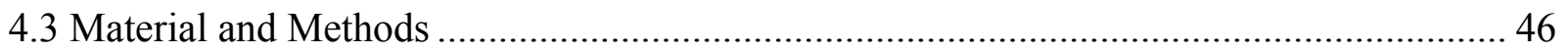

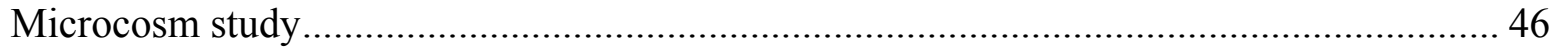

PCE biodegradation in 1-D column ................................................................... 47

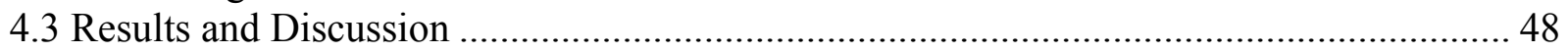

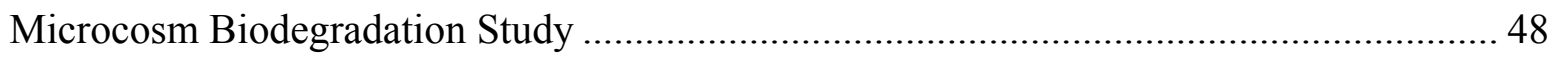

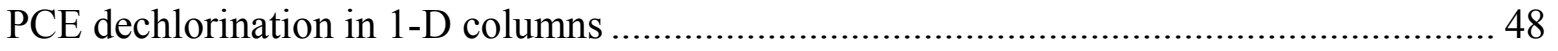

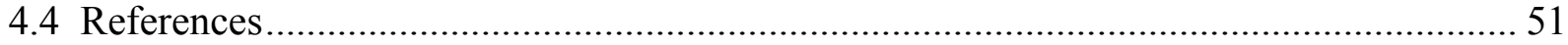

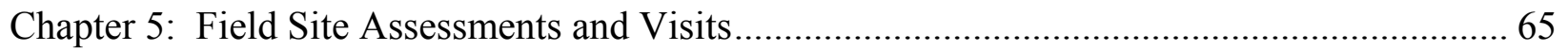

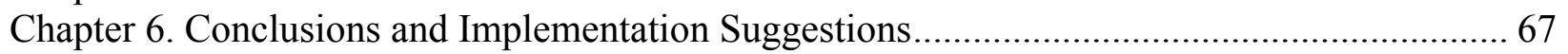

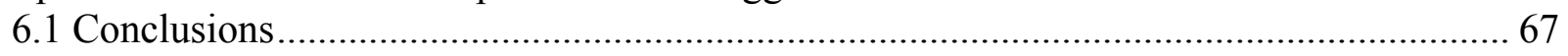

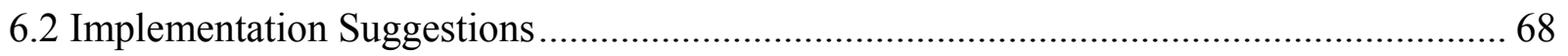

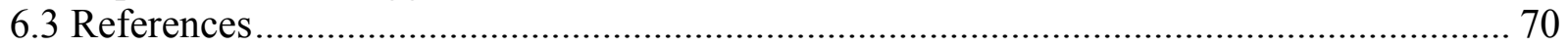




\section{List of Tables}

Table 2-1. Volumes of PCE released (mL) at each injection ports during each injection event. . 19

Table 3-1. Experimental parameters of PCE mobilization in 1-D column.................................37

Table 3-2. Experimental conditions for PCE dechlorination in 1-D columns .............................37

Table 3-3. PCE solubilization power of several cosolvents for PCE reported in literature..........37

Table 3-4. Calculated and model fitted mass transfer rate constants.......................................37

Table 4-1. Summary of PCE reductive dehalogenation of pure cultures .................................54

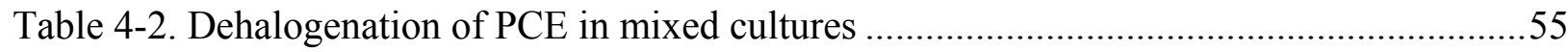

Table 4-3. Summary of PCE dechlorination in 1-D columns ..............................................56

Table 5-1. Potential Sites for the EL-Treatment Train Field Test/Study in Indiana...................66 


\section{List of Figures}

Figure 2-1. Distribution of PCE injection ports in the flow chamber. Picture was taken after the fourth DNAPL spill event.

Figure 2-2. PCE DNAPL in the flow chamber (a) 3 hours after first spill, (b) 16 hours after first spill, and (c) one day after second spill 20

Figure 2-3. PCE effluent concentration and remaining mass versus time after first spill, modeled with power function with $\Gamma=2,2.33$, and 4 . 21

Figure 3-1. Experimental set up of PCE mobilization in 1-D columns.................................... 38

Figure 3-2. Log normalized solubility $\left(\mathrm{C}_{\mathrm{m}}{ }^{\mathrm{s}} / \mathrm{C}_{\mathrm{w}}{ }^{\mathrm{s}}\right)$ versus ethyl lactate cosolvent fraction............ 38

Figure 3-3. Log normalized interfacial tension $\left(\mathrm{IFT}_{\mathrm{N}, \mathrm{m}} / \mathrm{IFT}_{\mathrm{N}, \mathrm{w}}\right)$ between ethyl lactate/water mixture and NAPL (PCE and toluene) versus ethyl lactate volume fraction, $\mathrm{f}_{\mathrm{c}}$. 39

Figure 3-4. Viscosity of binary solvent systems of water and TBA (Kipkemboi and Easteal, 1994), acetone (Ovchinnikova, 1982), EL (this study), or ethanol (Belda et al., 2004) as a function of organic cosolvent volume fraction. 39

Figure 3-5. Density of binary solvent systems of water and TBA (Kipkemboi and Easteal, 1994), acetone (Ovchinnikova, 1982), EL (this study), or ethanol (Belda et al., 2004) as a function of organic cosolvent volume fraction. 40

Figure 3-6. Inverse relationship between log normalized interfacial tension $\left(\mathrm{IFT}_{\mathrm{N}}, \mathrm{m} / \mathrm{IFT}, \mathrm{N}\right.$ ) versus log normalized solubility $\left(\mathrm{C}_{\mathrm{m}}{ }^{\mathrm{s}} / \mathrm{C}_{\mathrm{w}}{ }^{\mathrm{s}}\right)$ of PCE in different binary solvent systemz. TBA and acetone data are from Zhai et al. (2005), ethanol data are from Van Valkenburg and Annable (2002), surfactant data are from Sabatini et al. (2000)

Figure 3-7. Viscosity of binary solvent systems of water and TBA (Kipkemboi and Easteal, 1994), acetone (Ovchinnikova, 1982), EL (this study), or ethanol (Belda et al., 2004) versus the $\log$ normalized solubility $\left(\mathrm{C}_{\mathrm{m}}^{\mathrm{s}} / \mathrm{C}_{\mathrm{w}}{ }^{\mathrm{s}}\right)$ of correspondent system.

Figure 3-8. PCE residual saturation after flushing relative to initial PCE residual saturation $\left(\mathrm{S}_{\mathrm{n}} / \mathrm{S}_{\mathrm{n}}{ }^{\circ}\right.$, ) versus total trapping number $\left(\mathrm{N}_{\mathrm{T}}\right)$ with different volume fraction (data label) of ethyl lactate for three media.

Figure 3-9. PCE concentration relative to solubility in $50 \%$ ethyl lactate $\left(\mathrm{C} / \mathrm{C}_{\mathrm{m}}{ }^{\mathrm{s}}\right)$ and average PCE residual saturation ( $\mathrm{S}_{\mathrm{n}}$, calculated based on PCE mass) during the cosolvent flushing. 
Figure 4-1. Metabolic pathway for the anaerobic degradation of ethyl lactate ..... .57

Figure 4-2. Microbial dechlorination pathway of PCE to ethene..... .57

Figure 4-3. Schematic of 1-D column biodegradation experiment set up. Blue dashed lines indicate the sectioning scheme of the columns at the end of the experiment. 58

Figure 4-4. Mass distribution of chlorinated solvents after 8 days in the soil microcosms. .58

Figure 4-5. Concentration of PCE in the feeding solution in (a) NoED column, (b) EL column, and (c) EtOH column. 59

Figure 4-6. Breakthrough of cis-DCE (open triangles) and PCE (filled squares) in the middle sampling ports of (a) NoED column, (b) EL column, and (c) EtOH column, and at the end sampling ports of (d) NoED column, (e) EL column, and (f) EtOH column

Figure 4-7. Mass of cis-DCE, TCE, and PCE extracted from the soil in (a) NoED column, (b) EL column, and (c) EtOH column.

Figure 4-8. Ethanol and ethyl lactate concentration (average over time) along the columns in (a) EL column and (b) EtOH column, error bars show one standard deviation. .62

Figure 4-9. Mass of cis-DCE, TCE and PCE as (a) recovered in the aqueous phase at the end sampling ports (integration of area under the curve in Figure 4-6 d, e and f), and (b) extracted from the soil (summation of Figure 4-7 a, b and c). .63

Figure 4-10. Appearance of the three column couples post biodechlorination. .64

Figure 4-11. DGGE analysis of the soil from the three column couples at the end of the biodegradation experiment. 


\title{
Chapter 1. Introduction and Problem Statement
}

\author{
Linda S. Lee and Xihong Zhai
}

\subsection{Background Information and Problem Statement}

Many of the Indiana Department of Transportation (INDOT) sites are contaminated with aromatic (e.g., gasoline) and aliphatic (e.g., diesel fuel) hydrocarbons and chlorinated solvents; these contaminants often occur in the form of light non-aqueous phase liquids (LNAPLs) or as dense non-aqueous phase liquids (DNAPLs). After a NAPL enters the subsurface (e.g., after a spill or leaky underground storage tank), the NAPL migrates through the subsurface, capillary forces within the porous media will cause a portion of the organic liquid to be retained within soil pores as discrete globules or ganglia. Under normal flow regimes, this residual NAPL phase is immobile and often represents a long-term source of aquifer contamination (Pennell et al., 1996). As such, it is now widely acknowledged that pump-and- treat remediation technologies are ineffective and costly in restoring aquifers with NAPLs present (MacDonald, J.A., 1994).

Several potentially viable in-situ technologies for removing or destroying NAPL source have emerged. Emphasis on source zone treatment is appropriate as an integral component of contaminated site management because even small sources can sustain extensive dissolved plumes. Most of the new in-situ methods involve removal of the NAPL through enhanced evaporation (air sparging/soil vapor extraction; steam stripping, electrical heating), enhanced dissolution (surfactant, cosolvent and cyclodextrin flushing), separate phase mobilization (steam, surfactant, and cosolvent flooding), enhanced biological degradation, or in-situ chemical oxidation (ISCO). The goal for the latter two options is conversion of the NAPLs to potentially innocuous by-products, but this may not always be the case. Most recently, site-specific remedial designs involving a combination of in-situ methods (often referred to as a treatment train) have been proposed for which data are still sparse. All in-situ methods offer advantages over more conventional techniques, such as pump-and-treat or excavation. In terms of enhanced dissolution technologies, recent focus has been on the use of biofriendly solvents to remove the NAPL source and if solvents left in the subsurface may enhance subsequent microbial degradation of any NAPL residuals remaining. The use of only a biological treatment of a NAPL can be limited, because concentrations of organi.zhc contaminants in the presence of the NAPL 
(at their effective solubility limits) are often toxic to indigenous microbial populations (Cherry et al., 1992; NRC, 1999; Distefano et al., 1992).

\section{NAPL Behavior}

When NAPLs are released to the subsurface, the actual area contaminated will be a function of a number of factors, including the volume of NAPL released, the area of infiltrated, the duration of release, NAPL fluid properties, media properties, and subsurface flow condition (Mercer and Cohen, 1990). An LNAPL contamination may sink through the unsaturated zone until it reaches the water table resulting in a thin floating layer of LNAPL (Otten et al., 1997). As the water table rises and falls with recharge, LNAPL residuals will be trapped in pores above the water table. Therefore, both percolating rain water and horizontal groundwater flow will result in development of a dissolved plume (Lowe et al., 1999). The DNAPL problem is much more complex because DNAPL can move downward; DNAPLs by definition are denser, thus heavier, than water. A DNAPL can sink through the unsaturated zone until it reaches the groundwater table. Once the gravity force exceeds buoyancy forces, the DNAPL will penetrate the saturated zone. DNAPLs can penetrate to depth via preferential pathways or viscous fingering through small seams or fractures (Kueper and Frind, 1998). DNAPL will continue to move until stopped by an impervious lens or the aquitard after which it will travel in the direction of the slope. The pressure in a DNAPL pool can cause the DNAPL to enter even very small pores and fractures in the subsurface (Lowe et al., 1999).

NAPL contaminated sites are characterized by a source zone that clearly has a nonaqueous phase present in pools or at residual saturation (USEPA 2003), and a plume located down-gradient of the source zone, which contains only the dissolved, adsorbed, or volatilized contaminant. The plume from the source zone results from in a mass discharge over time from the source, which is referred to as source strength and is defined as the rate of mass discharge out of the control plane perpendicular to the groundwater flow direction and just down-gradient of the source zone. When using a realistic flux-based evaluation of risks and performance, the site remediation goal is removal of a sufficient NAPL mass from the source zone to achieve a reduction in source strength that results in either stabilization or shrinkage of the dissolved plume (Kavanaugh and Rao, 2003). Most studies in assessing how much NAPL mass must be

removed have focused on the period after which a single contamination event occurred, and remediation or natural attenuation has been occurring. Most industrial sites may have had more 
than one spill event, or even chronic periodic spills, at various locations, which will change NAPL distribution at a site, and thus, affect how source strength evolves and how it changes with partial NAPL removal.

\section{Optimizing Cosolvent Enhanced NAPL Solubilization}

In-situ cosolvent flushing has been evaluated both under laboratory and field conditions as an effective strategy for enhanced removal of NAPLs from source zones; NAPL mass depletion is achieved either by solubilization or by mobilization (AATDF 1997; ITRC 2003). However, solubilization is typically preferred in that it minimizes the potential for off-site or downward transport of NAPL globules, which contain large amounts of contaminant mass compared to the dissolved plume. NAPL mass recovery effectiveness from in-situ flushing in the source zone has been reported to cover a wide range (0 to 99\%) (AATDF 1997). The maximum efficiency of a cosolvent is a function of the solubilization or cosolvency power (Banerjee and Yalkowsky 1988; Rao et al. 1997; Yalkowsky 1999; Yalkowsky et al. 1972b; Yalkowsky and Roseman 1981; Yalkowsky et al. 1976) of the cosolvent, while the hydrodynamic efficiency achieved depends on the hydrogeologic heterogeneities of the aquifer (e.g., spatial correlation structure if the hydraulic conductivity); the composition and properties of the NAPL (e.g., singleor multi-component; density; wettability), and the fluid properties (e.g., viscosity, density and NAPL-water interfacial tension) of the solvent mixture used for flushing. Low-molecular-weight $n$-alcohols (e.g., methanol, ethanol, tert-butanol, pentanol, and hexanol) have been used as cosolvents (Brooks et al. 2004; Falta 1998; Falta et al. 1999; Imhoff et al. 1995a; Jawitz 2000; Rao et al. 1997; Ridgway 2001; Sillan et al. 1998). Ethanol flushing was shown to be effective in solubilizing $>85 \%$ of several target contaminants from an light NAPL (LNAPL) source zone at Hill AFB, UT (Rao et al. 1997), and about 60\% of PCE from a source zone at a drycleaner site in Florida (Jawitz et al. 2000). Falta et al's work (1999) at Hill AFB, UT with tert-butanol and hexanol has shown nearly $80 \%$ removal of the total NAPL content from the test cell.

The success of alcohols and surfactants as solubility enhancers for in-situ flushing has been demonstrated in several field studies (Falta et al. 1999; Jawitz et al. 1998b; Jawitz 2000; Ramsburg et al. 2004; Rao et al. 1997), but concerns remain about the regulatory permitting and the risks from residual cosolvents (or surfactants) left in the target remediation zone. Field studies at Hill AFB, UT and in Jacksonville, FL (Jawitz 2000; Rao et al. 1997) involved in-situ flushing with food-grade ethanol, because of concerns with additives or "contaminants" in non- 
food-grade ethanol. Generally, for similar reasons, food-grade surfactants are preferred (ITRC 2003; Ramsburg et al. 2004) for in-situ flushing. For both ethanol and some surfactants, it has been shown that the residual alcohol (or surfactant byproducts) can stimulate microbial activity, and serve as electron donors enhance microbial reductive dechlorination at DNAPL sites (Mravik et al. 2003; Ramsburg et al. 2004).

\section{Benefits of Ethyl Lactate as the Biofriendly Solvent of Choice}

Although ethanol is currently the most common cosolvent for in-situ flushing of NAPL source zones, there is an increasing interest in using the ethyl lactate. Ethyl lactate (ethyl 2hydroxypropionate, EL) is solvent derived from cornstarch or other renewable carbohydrates (NTEC Versol $^{\mathrm{TM}}$, Versol Inc., Mt. Prospect, IL). It is the ethyl ester of natural L (+) lactic acid, produced by fermentation from sugar. It is a clear and colorless liquid of low volatility and is completely miscible with water and most organic solvents. It is nontoxic, hydrolyzes to known biodegradable intermediates and is currently being used as a replacement for a chlorinated solvents used in degreasing metal parts during manufacturing (Trychta et al., 1999). It is also used as a synthetic flavoring for cheese, animal feed, and beer in addition to a solvent degreaser for machine parts. Until recently, EL was too costly to use as a routine solvent; however, an improved purification process developed by Argonne National Labs has made it more economical (Biocycle, 1999 June, page 21). The water soluble ethyl lactate hydrolyzes when water reacts with the ester group; however, this hydrolysis step is generally slow. For example, it takes about 5 days before any drop in $\mathrm{pH}$ is noticeable in a 50/50 mixture of ethyl lactate and water at room temperature. The rate of hydrolysis accelerates with increasing temperature and at $\mathrm{pH}$ values below 5 and above 8 (NTEC Versol).

Once soil flushing has removed the contaminant source material, recovery of the cosolvent is typically needed and is known to be more expensive than the cost of the cosolvent itself (Gannon et al., 1989). Since ethyl lactate is relatively non-toxic, a residual amount of ethyl lactate may be allowed at sites after soil flushing. In addition to the economic benefit, ethyl lactate may serve as a substrate for indigenous microorganisms to induce anaerobic conditions and enhance in-situ reductive dehalogenation. Reductive dehalogenation is the removal of a halogen from a halogenated molecule with concurrent addition of electrons to that molecule. This occurs by the transfer of electrons from an electron donor to an electron acceptor. Microbial-mediated reductive dechlorination involves the step-wise reduction of chlorinated 
solvents to non-toxic end products that is, ethane and ethane by replacing a chlorine atom with a hydrogen atom, and releasing a chloride ion into solution (Fiacco Jr, 2001). Lower substituted ethenes can be oxidized under aerobic conditions; however, more highly substituted ethenes such as PCE and TCE require anaerobic conditions for microbial reductive dehalogenation and halorespiration to occur (Panciera et al., 2001). Reductive dechlorination of TCE and/or PCE using native microorganisms often stalls at dichloroethene (DCE) or vinyl chloride because of a slow reaction rate and/or the lack of appropriate dechlorinating bacteria (Weidemeier et al., 1999). Many investigations have found that many of chlorinated compounds, such as PCE and trichloroethene (TCE), can be degraded by indigenous microorganisms and that dehalogenation upon addition of various carbon sources is enhanced (Panciera et al., 2001). This approach has the potential to increase the naturally-occurring degradation rate at many sites without any longterm operating costs except monitoring (Newell et al., 2001). Therefore, EL residuals after source zone remediation could serve as a substrate for indigenous microorganisms to induce anaerobic conditions and enhance in-situ reductive dehalogenation, but whether or not this process would further facilitate complete mineralization or if it too would stall at undesirable metabolites is unknown.

There is lack of information about the degradation pathway of ethyl lactate by naturally occurring microorganisms; however, the likely path includes hydrolysis of ethyl lactate to lactate and ethanol. Either lactate or ethanol could be indirectly used by halorespiring organisms. Degradation of ethanol and lactate has been previously characterized in anaerobic systems. Lactate is commonly used as an electron donor for reductive dehalogenation (Bagley and Gossett 1990, Ballaprogada et al., 1997; Carr and Hughes 1998; de Bruin et al., 1992; Fennell and Gossett 1997; Pampel and Livingstone 1998; Scholz-Muramatsu et al., 1995). Both ethanol and lactate can be fermented to propionate and then to acetate and hydrogen gas; these fermentation products further enhances reductive dechlorination (Panciera et al., 2001; Ridgway, 2001; Gottschalk, 1986).

\subsection{Research Scope and Approach}

The primary goal of the laboratory experiments is to assess the utility and effectiveness of EL for source zone flushing and subsequent ability of post flushing EL cosolvent residuals to enhance biological removal of contaminant residuals. Results from these lab evaluations involving batch tests and one-dimensional (1-D) and two-dimensional (2-D) flow systems will contribute to assessing the value of this treatment train approach for relevant INDOT sites and to 
developing an effective strategy for using this approach under field conditions. Laboratory batch studies were conducted to characterize the major characteristics of ethyl lactate cosolvent in relation to different contaminant classes including aromatic hydrocarbons, and chlorinated compounds. Additional laboratory batch studies as well as 1-D column and 2-D box flow experiments were conducted to further characterize the behavior of the chlorinated DNAPL PCE, and subsequent effectiveness of EL to remove a PCE source zone through an enhanced dissolution and biological removal treatment train. INDOT sites potentially amenable using this treatment train approach were selected based on input from INDOT staff, and soils for the laboratory studies were collected. Assessment required travel by senior personnel to specific sites to evaluate the nature and extent of contamination. Additional visits to the sites selected were made by research assistants to collect soil samples for laboratory experiments.

\subsection{Objectives and Purpose of the Study}

The primary goal of the laboratory experiments was to assess the utility and effectiveness of ethyl lactate (EL) for source zone flushing of organic contaminant classes representative of contamination at INDOT sites. Towards this goal several physical and chemical parameters relevant to optimizing a remediation design were measured. Toluene and PCE were selected as representative aromatic and chlorinated hydrocarbons, respectively. Solubility of toluene and PCE with increasing \% volume ethyl lactate from 0 to $80 \%$ was measured in laboratory batch studies. The interfacial tension between EL/water solutions and PCE compared to other cosolvent/water solutions was measured. Viscosity and density of EL/water solutions as a function of PCE solubility was measured and compared to other cosolvent/water systems.

Further work was conducted with an emphasis on PCE as a chlorinated DNAPL which universally poses the greatest challenge with regards to achieving remediation goals. To the latter goal, we first assessed how source strength changes during evolution of a PCE source zone in a 2-D box flow experiment. Secondly, we evaluated PCE removal and flow characteristics of ethyl lactate/water solutions in columns packed with PCE contaminated soil towards selecting the optimal ethyl lactate cosolvent content to accelerate removal of PCE without invoking DNAPL mobilization. Lastly, in laboratory batch and 1-D column studies we evaluated the impacts of residual ethyl lactate after in-situ source zone flushing on microbial processes attenuating PCE residuals not removed in the flushing processes. 


\subsection{References}

AATDF, DOD Advanced Applied Technology Demonstration Facility. (1997). "Technology Practices Manual for Surfactants and Cosolvents." TR-97-2.

Bagley, D.M., and Gossett, J.M. (1990). "Tetrachloroethene transformation to trichloroethene and cis-1,2-dichloroethene by sulfate-reducing enrichment culture." Appl. Environ. Microbiol., 56(8), 2511-2516.

Ballapragada, B.S., Stensel, H.D., Puhakka, J.A., and Ferguson, J.F. (1997). "Effect of hydrogen on reductive dechlorination of chlorinated ethenes." Environ. Sci. Technol., 31(6), 17281734.

Banerjee, S., and Yalkowsky, S. H. (1988). "Cosolvent-Induced Solubilization of Hydrophobic Compounds into Water." Analytical Chemistry, 60(19), 2153-2155.

Biocycle, "Ethyl lactate at a Lower Cost." June, 1999, p21.

Brooks, M. C., Annable, M. D., Rao, P. S. C., Hatfield, K., Jawitz, J. W., Wise, W. R., Wood, A. L., and Enfield, C. G. (2004). "Controlled release, blind test of DNAPL remediation by ethanol flushing." Journal of Contaminant Hydrology, 69(3-4), 281-297.

Carr, C.A., and Hughes, J.P. (1998). "Enrichment of high-rate PCE dechlorination and comparative study of lactate, methanol, and hydrogen as electron donors to sustain activity." Environ. Sci. Technol., 32(12), 1817-1824.

De Bruin, W.P., Kotterman, M.J.J., Posthumus, M.A., Schraa, G., and Zehnder, A.J.B. (1992). "Complete biological reductive transformation of tetrachloroethene to ethane." Applied and Environmental Microbiology, 58(6), 1996-2000.

Falta, R. W. (1998). "Using Phase Diagrams to predict the performance of cosolvent floods for NAPL remediation." Ground water monitoring and remediation, 18(3), 94-402.

Falta, R. W., Lee, C. M., Brame, S. E., Roeder, E., Coates, J. T., Wright, C., Wood, A. L., and Enfield, C. G. (1999). "Field test of high molecular weight alcohol flushing for subsurface nonaqueous phase liquid remediation." Water Resources Research, 35(7), 2095-2108.

Fennell, D.E., and Gossett, J.M. (1997). "Comparison of butyric acid, ethanol, lactic acid, and propionic acid as hydrogen donors for the reductive dechlorination of tetrachloroethene." Environmental Science and Technology, 1997(31), 918-926.

Gannon, O.K., Bibring, P., Raney, K., Ward, J.A., Wilson, D.J., Underwood, J.L. and Debelak, K.A., (1989). Sep. Sci. Technol, 24(14), 1073.

Gottschalk, G. (1986). Bacterial Metabolism, Springer-Verlag, New York.

Imhoff, P. T., Gleyzer, S. N., McBride, J. F., Vancho, L. A., Okuda, I., and Miller, C. T. (1995a). "Cosolvent Enhanced Remediation of Residual Reuse Nonaqueous Phase Liquids Experimental Investigation." Environmental Science \& Technology, 1966-1976.

ITRC. (2003). "Assessing the performance of DNAPL source reduction remedies." Interstate technology \& regulatory council, Dense nonaqueous phase liquids team.

Jawitz, J. W., Sillan, R. K., Annable, M. D., Rao, P. S. C., and Warner, K. (2000). "In-situ alcohol flushing of a DNAPL source zone at a dry cleaner site." Environmental Science \& Technology, 34(17), 3722-3729.

Kavanaugh, M. C., and Rao, P. S. C. (2003). "The DNAPL remediation challenge: Is there a case for source depletion?" EPA expert panel.

Kueper, B.H.; E.O.Frind, 1998, “An Overview of Immiscible Fingering in Porous Media.” J. Cont. Hydrology, 2:95-110.

Lowe, D. F.; Oubre, C.L., ; Ward, C.H., Eds. 1999, "Surfactants and Cosolvents for NAPL Remediation.” A Technology Practices Manual, Lewis Publishers : Boca Raton. 
MacDonald, J. A. ; Kavanaugh, M.C. , Environ. Sci. Technol. 1994, 28, 362A-368A.

Mercer, J.W.; R.M. Cohen. (1990), "A Review of Immiscible Fluids in the Subsurface:

Properties, Models, Characterization and Remediation.” J. Cont. Hydrology, 6:107-163.

Middeldorp, P.J.M., Luitjen, M.L.G.C., van de Pas, B.A., van Eekert, M.H.A., Kengen, S.W.M., Schraa, G., and Stams, A.J.M. (1999). "Anaerobic microbial reductive dehalogenation of chlorinated ethenes." Bioremediation Journal, 3(3), 151-169.

Mravik, S. C., Sillan, R. K., Wood, A. L., and Sewell, G. W. (2003). "Field evaluation of the solvent extraction residual biotreatment technology." Environmental Science \& Technology, 37(21), 5040-5049.

Newell, C. J., Aziz, C. E., Haas, P. E., Hughes, J. B., and Khan, T. A., (2001). Two novel methods for enhancing source zone bioremediation: Direct hydrogen addition and electron acceptor diversion, Anaerobic Degradation of Chlorinated Solvent, 19p.

Pampel, L.W.H., and Livingston, A. G. (1998). "Anaerobic dechlorination of perchloroethene in an extractive membrane bioreactor." Applied Microbiology and Biotechnology, 50, 303-308.

Panciera, M. A., Zelennikova, O., Smets, B. F., and Dobbs, G. M., (2001). Differential Stimulation of Haloreduction by Carbon Addition to Subsurface Soils, Anaerobic Degradation of Chloride Solvents, 69p.

Pennell, K.D.; Pope, G.A.; Abriola, L.M. Environ. Sci. Technol. 1996, 30, 1328-1355.

Ramsburg, C. A., Abriola, L. M., Pennell, K. D., Loffler, F. E., Gamache, M., Amos, B. K., and Petrovskis, E. A. (2004). "Stimulated microbial reductive dechlorination following surfactant treatment at the Bachman Road site." Environmental Science \& Technology, 38(22), 5902-5914.

Rao, P. S. C., Annable, M. D., Sillan, R. K., Dai, D. P., Hatfield, K., Graham, W. D., Wood, A. L., and Enfield, C. G. (1997). "Field-scale evaluation of in-situ cosolvent flushing for enhanced aquifer remediation." Water Resources Research, 33(12), 2673-2686.

Ridgway, R.M. (2001). "Anaerobic Reductive Dehalogenation of Trichloroethylene in Unacclimated Freshwater Sediments., Ph. D dissertation, Purdue University, 73p.

Scholz-Muramatsu, H., Neumann, A., Mebmer, M., Moore, E., and Diekert, G. (1995). "Isolation and characterization of Dehalospirillum multivorans gen. nov., sp. Nov., a tetrachloroethene-utilizing, strictly anaerobic bacterium.” Arch. Microbiol., 163, 48-56.

Sillan, R. K., Annable, M. D., Rao, P. S. C., Dai, D. P., Hatfield, K., and Graham, W. D. (1998). "Evaluation of in-situ cosolvent flushing dynamics using a network of spatially distributed multilevel samplers." Water Resources Research, 34(9), 2191-2202.

Trychta, K., Sandburg, D. A., Henry, M., and Datta, R., 1999, "Evaluation of environmentally benign green solvent Versol ethyl lactate for machine shop parts cleaning and degreasing," Argonne National Laboratory.

Weidemeier, T. H., H. S. Rifai, C. J. Newell, and J. T. Wilson. (1999). Natural Attenuation of Fuels and Chlorinated Solvents in the Subsurface, John Wiley \& Sons, Inc., New York, NY.

Yalkowsky, S. H. (1999). "Solubilization by cosolvents." Solubility and solubilization in aqueous media, S. H. Yalkowsky, ed., Oxford University Press, Inc., NY, NY, 180-230.

Yalkowsky, S. H., Flynn, G. L., and Amidon, G. L. (1972b). "Solubilization of nonelectrolytes in polar solvents." Journal of Pharmaceutical Science, 61, 983-984.

Yalkowsky, S. H., Valvani, S. C., and Amidon, G. L. (1976). "Solubilization of nonelectrolytes in polar solvents: IV. Nonpolar drugs in mixed solvents." J. Pharmaceut.1 Sc., 65, 1488-1494. Yalkowsky, S.H. and T. Roseman. 1981, In: Techniques of Solubilization of Drugs, S.H. Yalkowsky(Ed.). Marcel Dekker, Inc., New York, NY, 91-134. 
Chapter 2. Flux-mass Relationship with Sequential DNAPL Release Events

Xihong Zhai, P. Suresh C. Rao, Inez Hua, and Linda S. Lee

\subsection{Introduction}

Dense non-aqueous phase liquid (DNAPL) contaminated sites are characterized by two primary zones: 1) the source zone: the volume of the aquifer (either the vadose zone or the saturated zone) that has had contact with DNAPL and may contain DNAPL at "residual saturation" or as a "pool"; and 2) the plume, which is located down-gradient of the source zone, and contains only the dissolved, adsorbed, or volatilized contaminant. The plume from the source zone results from the mass discharge over time from the source $(\mathrm{M} / \mathrm{T})$, also referred to as source strength, defined as the rate of mass discharge out of the control plane perpendicular to the groundwater flow direction and just down-gradient of the source zone.

Remediation efforts at DNAPL sites have focused on contaminant mass removal at the source zones. It is possible to remove substantial contaminant mass from source zones with aggressive in-situ technologies. However, more recent analyses of available data from field tests indicate that the expectation of achieving maximum contaminant levels (MCLs) in the treated zone is unrealistic, and that a shift towards flux-based evaluation of risks and performance should be evaluated (API, 2002; ITRC, 2003; Kavanaugh and Rao, 2003). In the latter case, the site remediation goal is to remove sufficient DNAPL mass from the source zone to achieve the desired reduction in source strength, which results in either stabilization or shrinkage of the dissolved plume (Kavanaugh and Rao, 2003). The relationship between the amount of DNAPL mass depleted in the source and the resulting reduction in source strength is receiving increasing attention as a performance metric (Falta et al., 2005a; ITRC, 2004; Jawitz et al., 2005; Lemke et al., 2005; Rao et al., 2001; Rao and Jawitz, 2003; Sale and McWhorter, 2001). It is generally recognized that this relationship is a function of several parameters, including the aquifer hydrodynamic heterogeneity, the non-uniformity of DNAPL distribution, the correlation between hydraulic conductivity and DNAPL content, the DNAPL architecture, and the age of the site (the time since contamination event) (Jawitz et al., 2005; Rao et al., 2001; Rao and Jawitz, 2003).

Present studies are focused on the period after which contamination events have terminated at DNAPL sites, and remediation or natural attenuation has been occurring. Both numerical modeling and intensive data collection have been conducted at the field and laboratory 
scales. These studies generally examine the reduction in mass flux in response to reduction in DNAPL mass (Falta et al., 2005b; Lemke et al., 2005). However, most DNAPL sites have evolved since the first spill event. Most industrial sites may have had more than one spill event, or even chronic periodic spills, at various locations. It is of interest to determine how the source strength would change during DNAPL source evolution.

In this study, we used a two-dimensional flow chamber to simulate a confined aquifer, and investigated the formation of a DNAPL source following a sequence of DNAPL spills at multiple locations. The resultant change in DNAPL mass discharge was also measured. The experimental data were modeled with the recently proposed power function that relates source strength to source mass (Falta et al., 2005a; Falta et al., 2005b; Parker and Park, 2004; Rao et al., 2001; Rao and Jawitz, 2003; Zhu and Sykes, 2004), and its implications were discussed.

\subsection{Materials and methods}

Experiments were conducted in rectangular flow chambers $(62 \mathrm{~cm} \times 1.5 \mathrm{~cm} \times 40 \mathrm{~cm})$ similar to those described by Jawitz et al. (1998) using heterogeneous packing of aquifer media. The flow field was contained in two glass plates $(62 \mathrm{~cm} \times 40 \mathrm{~cm})$. Square aluminum tubes $(1.3$ $\mathrm{cm} \times 1.3 \mathrm{~cm}$ ) were used to close the three sides of the flow chamber. The inlet and outlet wells of the flow chamber were made by slotting the vertical section of the aluminum tubes (slot width $0.03 \mathrm{~cm}$; frequency 4 slots per $\mathrm{cm}$ ). The outlet well in the first setting was segmented into seven sections to achieve high resolution of the flow field. The top of the chamber was sealed with bentonite clay to simulate a confined aquifer. Constant hydraulic head was maintained at both inlet and outlet ends so that steady water flow was established. A random, spatially correlated, heterogeneous medium (horizontal correlation length $30 \mathrm{~cm}$; vertical correlation length $3 \mathrm{~cm}$ ) was generated using stochastic methods in the Hydrus-2D model. The correlation lengths were determined based on the dimension of the flow chamber, such that the fine lamina structures would not stretch across the flow domain (i.e. forming layered media). It is to be noted that the random domain generated with Hydrus-2D has low permeability matrix with high permeability inclusions. This permeability scale was reversed such that the domain matrix has higher permeability with lower-permeability inclusions. In such a packing, it was expected that DNAPL could form pools on top of the fine lamina with residual saturated DNAPL above the pools. Three sizes of sands used as received were used to generate the heterogeneous flow domain. The 
matrix was coarse quartz sand (20 to 30 mesh, from Lowes), with Ottawa sand (40 to 50 mesh, from VWR) and fine sand (50 to 60 mesh, from Lowes) lenses placed within the coarse sand matrix while packing the 2-D chamber to generate a lenticular structure. The sand was packed into the flow chamber under water with intermittent vibration to ensure tight packing without air bubbles. The interfaces between different sizes of sand were slightly mixed to avoid abrupt change in permeability. Four DNAPL release points inside the chamber were used to introduce DNAPL at different locations of the domain and to achieve a positive correlation between permeability and DNAPL saturation (Figure 2-1). The injection ports were made from stainless steel tubing terminating at designated depths, connected to a two-way Mininert ${ }^{\circledR}$ valve (VWR).

The hydraulic heads at inlet and outlet were adjusted to achieve a flow rate of 5 $\mathrm{mL} /$ minute. However, due to the negative water head at the outlet end and the extra difficulties encountered in maintaining all seven outlet wells to flow simultaneously, some air bubbles were trapped into the domain through the imperfect sealing, and the flow rate varied from $4 \mathrm{~mL} / \mathrm{min}$ to $5.7 \mathrm{~mL} / \mathrm{min}$. The flow chamber was flushed with $5 \mathrm{mM} \mathrm{CaCl}_{2}$ solution to prevent dispersion of clay particles and to simulate the dilute electrolyte concentration in groundwater. To visually delineate the hydrodynamic characteristic of the flow field and baseline flow pattern, dye tracer tests were performed by injecting $80-\mathrm{mL}$ pulses of $50 \mathrm{mg} / \mathrm{L}$ brilliant blue (erioglaucine sodium salt from Fisher Scientific) solution using a syringe pump at the rate of $8 \mathrm{~mL} / \mathrm{min}$, regardless of the flow rate variation in the domain. A digital camera (Nikon Coolpix 880) was used to capture the movement of the dye pulse every 30 minutes.

The target DNAPL residual saturation value $\left(\mathrm{S}_{\mathrm{N}}\right)$ was 3\%. Given the total pore volume of 1.1 L (estimated from tracer test and verified with dimensions of box and porosity of the sand), the total volume of DNAPL to be injected was $33 \mathrm{~mL}$. Four injection events were designed, with $2 \mathrm{~mL}$ of PCE dyed with Oil-Red-O (from Fisher Scientific) released through each port each time. However, based on DNAPL movement at each release port following each injection event, modification was made to prevent the DNAPL from falling to the base of the domain or to the outlet wells, and three ports were pulled up to a higher position to create release points at the shallow part of the domain. The actual amount of PCE released at each location is given in Table 2-1. The flow rate for DNAPL injection was $0.08 \mathrm{~mL} / \mathrm{min}$, which was slow enough to maintain a low injection pressure thus avoiding leakage of DNAPL from connection points or penetration through low permeability lenses, and to allow sufficient time for DNAPL to migrate freely 
around the injection ports. The principle used in choosing the flow rate for PCE injection is that the Darcy flux should be no more than half of the hydraulic conductivity when the fluid is PCE $\left(q \leq 1 / 2 K_{P C E}\right)$. Based on this criterion, the DNAPL injection rate was set at $0.08 \mathrm{~mL} / \mathrm{min}$. With this flow rate, each injection ports was pumped with pure PCE for 25 minutes (resulting in $2 \mathrm{~mL}$ of PCE into each port), and then with $0.005 \mathrm{M} \mathrm{CaCl}_{2}$ solution for 5 minutes to push out residual PCE left in injection port. Following each DNAPL release, two days of time was given to allow DNAPL to distribute and to establish a steady-state flow.

\subsection{Results and discussion}

\section{PCE distribution}

The downward migration of PCE from the injection ports was visualized using the Oilred-O dye augmented PCE. Thin pink columns formed along the flow path. When DNAPL reached the top of the fine lenses, it mounded up, spread laterally, and formed a red pool. The residual saturation values, $\mathrm{S}_{\mathrm{N}}$, within the DNAPL columns were lower than $\mathrm{S}_{\mathrm{N}}$ in the DNAPL pools. The former are generally referred to as fingers or ganglia (Butcher and Gauthier, 1994; Lemke et al., 2005). At injection port 3, the pool spread from the up-gradient edge of the barrier and sank to the lower part of the domain and formed another pool on top of the next fine layer. No significant difference was found in DNAPL distribution between 3 hours and 16 hours after spill (Figure 2-2a and b); therefore, it was concluded that PCE redistribution was nearly complete within the first 3 hours after release. The pool thicknesses were about $1.8 \mathrm{~cm}$. The horizontal length of the pools depended not only on the amount of PCE injected, but also on the length of the fine barrier available for the pool to spread. If the hydraulic barrier was long enough for $2 \mathrm{~mL}$ PCE to spread, as at port 4, the horizontal length of the pool was $8.8 \mathrm{~cm}$. With these parameters, it can be estimated that the local DNAPL saturation $\left(\mathrm{S}_{\mathrm{N}}\right)$ could be as high as $28 \%$. The $S_{N}$ value at the ganglia area (residual saturated region) was expected to be much lower.

If one assumes the $\mathrm{S}_{\mathrm{N}}$ value remains the same throughout the DNAPL release events, then the sizes of the pool should be proportional to the volume of PCE injected. However, it was not the case in this study (compare Figure 2-2b and Figure 2-2c). The pools appeared to be smaller than expected, indicating that the $\mathrm{S}_{\mathrm{N}}$ in the pools increased as more DNAPL was released. The other reason that might contribute to the smaller sizes of pools is that considerable amount of PCE was lost due to dissolution during flushing with $\mathrm{CaCl}_{2}$ solution between the 
releases. Based on the effluent PCE concentration flow rate measured daily, the total PCE loss from dissolution was $5.5 \mathrm{~mL}$ out of the $28 \mathrm{~mL}$ injected in the 47 days between the first DNAPL injection and the end of this experiment. There was no DNAPL pool on top of fine layer beneath the shallow position of port 4 (Figure 2-1). This position was created by pulling up port 4 before the fourth injection event. The hole left by the steel tubing of the injection port was not well filled by the surrounding sand although gentle vibration was used. This hole made the fine layer fail to perform as a hydraulic barrier and PCE drained through it to the lower part of the aquifer. Estimation of $S_{N}$ value was not possible now since it was hard to tell how much PCE was lost from each pool. It should be noted that although the horizontal length of the DNAPL pools was longer as more PCE was spilled, the thickness of the pool did not increase significantly. This is consistent with the conclusion of Miller et al. (2004) that the equilibrium thickness of a DNAPL pool depends only on the characteristics of the coarse medium. It was reported that the geometry of the pool is determined by the hysteresis between the DNAPL initial wetting curve (imbibition) and the initial drainage curve of the coarse medium (Miller et al., 2004). The leading edge of the DNAPL pool follows the imbibition curve and the other part of the pool follows the drainage curve.

\section{Flux versus mass relationship}

A power function has been proposed to relate the source strength (mass discharge, M/T) to the source mass (Parker and Park, 2004; Hatfield et al., 2001; Rao and Jawitz, 2003; Zhu and Sykes, 2004). The time-dependent source strength $\left(\dot{m}_{t}\right)$ is the product of Darcy flux $(q)$, the crosssectional area $(A)$ of the control plane, and the flux-averaged contaminant concentration $\left(C_{t}\right)$ at time t out of the control plane:

$\dot{m}_{t}=q A C_{t}$

Without much variation in $q$ and $A$, source strength can be represented by the time-dependent contaminant concentration, $C_{t}$.

Thus the power function can be written in term of $C_{t}$ rather than $\dot{m}_{t}$,

$$
\frac{C_{t}}{C_{0}}=\left(\frac{M_{t}}{M_{0}}\right)^{\Gamma}
$$


where $C_{0}$ is the initial flux-averaged contaminant concentration $\left(\mathrm{M} / \mathrm{L}^{3}\right)$ out of the control plane when the source mass is $M_{0}, M_{t}$ is the time-dependent source mass, and $\Gamma$ is an empirical constant (dimensionless), which is a function of the degree of the heterogeneity in the flow domain. Rao et al. (2001) and Rao and Jawitz (2003) have shown through theoretical analyses that the patterns in flux reduction expected with mass reduction are strongly dependent on three factors: (1) the heterogeneity of the hydraulic conductivity and its spatial structure; (2) the DNAPL source zone architecture; and (3) the correlation between these two attributes. Increases in heterogeneity of the hydraulic conductivity and negative correlation of DNAPL content to hydraulic conductivity represent more favorable conditions where $\Gamma>1$, and a significant flux reduction may be anticipated with a small fraction of DNAPL source mass removed. If $\Gamma<1$, a significant reduction in source strength would require most of DNAPL mass to be removed.

Assuming the processes that deplete the mass in source zones are dissolution and firstorder decay through biotic and abiotic degradation, then the mass balance in the source zone can be expressed as,

$$
\frac{d M_{t}}{d t}=-\frac{q A C_{0}}{M_{0}^{\Gamma}} M_{t}^{\Gamma}-\lambda_{s} M_{t}
$$

where $\lambda_{s}$ is the first-order rate constant of the decay process (Falta et al., 2005b). If one neglects the decay in the source zone, $\lambda_{s}=0$, the above equation is simplified and the analytical solution is (Falta et al., 2005b; Parker and Park, 2004; Zhu and Sykes, 2004) as,

$$
M_{t}=\left(\frac{(\Gamma-1) q A C_{0}}{M_{0}^{\Gamma}} t+M_{0}^{1-\Gamma}\right)^{\frac{1}{1-\Gamma}}
$$

and

$$
C_{t}=\frac{C_{0}}{M_{0}^{\Gamma}}\left(\frac{(\Gamma-1) q A C_{0}}{M_{0}^{\Gamma}} t+M_{0}^{1-\Gamma}\right)^{\frac{\Gamma}{1-\Gamma}}
$$

PCE was released to the box in four sequential events. Following each release, an initial concentration $\left(C_{0}\right)$ can be measured and an initial mass $\left(M_{0}\right)$ can be calculated by tracking all of the PCE injected and flushed out because decay in the sand-packed chamber can be neglected. Assuming the $\Gamma$ value does not change from one release to another, the "solver" function in Microsoft Excel can be used to optimize $\Gamma$ value by fixing the four $C_{0}$ and $M_{0}$ values and 
minimizing the sum of squared error (SSE) between the observed $C_{t}, M_{t}$ and the model calculated ones. The fitting result is plotted in Figure 2-3 with the observed values overlaid on the modeled ones. The optimization resulted in a $\Gamma$ value of 2.33 , indicating the favorable PCE elution dynamics in the flow chamber. This is in good agreement with the previous findings based on numerical simulation that a positive correlation between hydraulic conductivity and DNAPL content lead to a more efficient DNAPL source strength reduction as a consequence of mass reduction (Jawitz et al., 2005; Rao and Jawitz, 2003).

By examining Figure 2-3, we noted that the variation between the measured and the modeled values of concentration is more obvious in the last segment of the data, corresponding to the PCE elution after the last spill. This indicates that $\Gamma$ value may have changed as the source zone evolved from one spill event to another. Different $\Gamma$ values (2 and 4) are used to model the observed data and the results are overlaid in Figure 2-3. The power function equation can well describe the PCE elution behavior with $\Gamma$ value varying in this range, indicating that the model is not really sensitive to $\Gamma$ value as long as it falls in the favorable condition category $(\Gamma>1)$. However, it can be seen that the lower $\Gamma$ value fits the data from earlier spill event better, and the higher $\Gamma$ value fits the later spill event better (Figure 2-3).

The reason for this lies in the changing architecture of the DNAPL. There were two kinds of DNAPL structure relative to the flow domain: DNAPL pool above the fine lens with a high $\mathrm{S}_{\mathrm{N}}$ value, and the ganglia (also referred to as DNAPL fingers) above the DNAPL pools with a low $\mathrm{S}_{\mathrm{N}}$. Within one plane perpendicular to the flow direction, the ganglia DNAPL occupies a larger portion of cross-sectional area compared to the DNAPL pool, therefore it contributes more to the PCE flux at the outlet end, since the measured PCE effluent concentration is actually averaged across the cross-sectional area. However, since the $\mathrm{S}_{\mathrm{N}}$ value in the ganglia is much lower compared to the DNAPL pool, it can not last long as a source of PCE flux, i.e. it depletes sooner than DNAPL pool. On the other hand, the DNAPL pools last longer because of higher $\mathrm{S}_{\mathrm{N}}$ values, but they contribute only a small portion to the average PCE effluent concentration. Since DNAPL ganglia were depleted and DNAPL pools were accumulated through the flushing following each spill, the ratio of PCE mass present in DANPL pools to that in DNAPL ganglia became higher and higher.

Lemke et al. (2005) also found out through numerical modeling that as PCE dissolved, the ganglia depleted much faster than the pools, the percentage of PCE mass in ganglia decreased 
and the DNAPL distribution became pool-dominated. PCE dissolution from the ganglia contributes more to the source strength; therefore, a slight reduction of PCE in the ganglia would result in a significant reduction in PCE effluent concentration. Thus, $\Gamma$ value would increase with increasing percentage of PCE mass in the pools. However, when the source zone becomes pooldominated after ganglia are depleted, it is very difficult to achieve further reduction in source strength without removing most of the DNAPL mass, and this represents an unfavorable condition, with $\Gamma<1$ (Jawitz et al., 2005). The PCE effluent concentration will stabilize at a level determined by the thickness of the DNAPL pool. As discussed above, the thickness of the DNAPL pool at equilibrium is a function of the permeability contrast of the fine lens and the surrounding coarse media, not PCE mass. Adding more mass simply extended the length of the pool and increased $\mathrm{S}_{\mathrm{N}}$ value of the pool as discussed above, rather than making it thicker. With this reasoning, the PCE effluent concentration after DNAPL architecture is stabilized following the spill should stay more or less the same unless there are new pools formed.

\subsection{Conclusion}

The PCE DNAPL source formed after a series of PCE spill events at various locations within a 2-D flow chamber used in this study is characterized by DNAPL pools on the lowpermeability hydraulic barrier connected by DNAPL ganglia of residual saturated PCE. The additional spill did not alter the height of the pool but extended its length. The response of DNAPL source strength to mass removal in the source zone as a result of dissolution can be well described by the power function with the power $(\Gamma)$ larger than unity $(\Gamma=2 \sim 4)$, indicating favorable PCE elution dynamics in the flow chamber. In the power function model, $M_{t}$ is not very sensitive to change in $\Gamma$ as shown in Figure 2-3, but $C_{t}$ is sensitive to $\Gamma$. In practice in the field, $C_{t}$ is usually measured and used to estimate $M_{t}$. It is expected based on the above finding that the estimated $M_{t}$ would be fairly robust and close to its true value even with high uncertainty in $C_{t}$ measurement and $\Gamma$ estimation. Figure 2-3 also indicates that lower $\Gamma$ value does fit the data from the early spill event better, and the dissolution behavior following the last spill can be better fitted by higher $\Gamma$ value. This is due to the fact that dissolution removes PCE in the ganglia first, and the DNAPL pool accumulated throughout the spill series. As the ratio of PCE mass in ganglia to that in the pool decreases, $\Gamma$ increases, and the system becomes more efficient in terms of source strength reduction. 


\subsection{References}

API. (2002). "Estimating Mass Flux for Decision-Making: An Expert Workshop." American Petroleum Institute.

AATDF, DOD Advanced Applied Technology Demonstration Facility. (1997). "Technology Practices Manual for Surfactants and Cosolvents." TR-97-2.

Butcher, J. B., and Gauthier, T. D. (1994). "Estimation of Residual Dense NAPL Mass by Inverse Modeling." Ground Water, 32(1), 71-78.

Falta, R. W., Basu, N., and Rao, P. S. (2005a). "Assessing impacts of partial mass depletion in DNAPL source zones: II. Coupling source strength functions to plume evolution." Journal of Contaminant Hydrology, 79(1-2), 45-66.

Falta, R. W., Rao, P. S., and Basu, N. (2005b). "Assessing the impacts of partial mass depletion in DNAPL source zones - I. Analytical modeling of source strength functions and plume response." Journal of Contaminant Hydrology, 78(4), 259-280.

Hatfield, K, Annable MD, Kuhn, S, Rao PSC, and Campbell, T. (2001). "A new method for quantifying contaminant flux at hazardous waste sites." Ground Water Quality, Sheffield, UK, pp 125-127.

ITRC. (2003). "Assessing the performance of DNAPL source reduction remedies." Interstate technology \& regulatory council, Dense nonaqueous phase liquids team.

ITRC, Interstate Technology \& Regulatory Council, Dense Nonaqueous Phase Liquids Team. (2004). "Strategies for monitoring the performance of DNAPL source zone remedies."

Jawitz, J. W., Fure, A. D., Demmy, G. G., Berglund, S., and Rao, P. S. C. (2005). "Groundwater contaminant flux reduction resulting from nonaqueous phase liquid mass reduction." Water Resources Research, 41(10).

Jawitz, J. W., Annable, M. D., Rao, P. S. C., and Rhue, R. D. (1998). "Field implementation of a Winsor type I surfactant/alcohol mixture for in-situ solubilization of a complex LNAPL as a single phase microemulsion." Environmental Science \& Technology, 32(4), 523-530.

Kavanaugh, M. C., and Rao, P. S. C. (2003). "The DNAPL remediation challenge: Is there a case for source depletion?" EPA expert panel.

Lemke, L. D., Abriola, L. M., and Goovaerts, P. (2005). "Dense nonaqueous phase liquid (DNAPL) source zone characterization: Influence of hydraulic property correlation on predictions of DNAPL infiltration and entrapment (Vol 41, art no W06015, 2005)." Water Resources Research, 41(6).

Miller, C. D., Durnford, D. S., and Fowler, A. B. (2004). "Equilibrium nonaqueous phase liquid pool geometry in coarse soils with discrete textural interfaces." Journal of Contaminant Hydrology, 71(1-4), 239-260.

Parker, J. C., and Park, E. (2004). "Modeling field-scale dense nonaqueous phase liquid dissolution kinetics in heterogeneous aquifers." Water Resources Research, 40(5).

Rao, P. S. C., Jawitz, J. J., Enfield, C. G., Falta, R. W. J., Annable, M. D., and Wood, A. L. (2001)."Technology Integration for contaminated site remediation: clean-up goals and performance criteria." Groundwater Quality Conference, Sheffiekd, United Kingdom, 410412.

Rao, P. S. C., and Jawitz, J. W. (2003). "Comment on "Steady state mass transfer from singlecomponent dense nonaqueous phase liquids in uniform flow fields" by T.C. Sale and D.B. McWhorter." Water Resources Research, 39(3). 
Sale, T. C., and McWhorter, D. B. (2001). "Steady state mass transfer from single-component dense nonaqueous phase liquids in uniform flow fields." Water Resources Research, 37(2), 393-404.

USEPA, U.S. Environmental Protection Agency. (2003). "The DNAPL remediation challenge: Is there a case of for source depletion." EPA/600/R-03/143.

Zhu, J. T., and Sykes, J. F. (2004). "Simple screening models of NAPL dissolution in the subsurface." Journal of Contaminant Hydrology, 72(1-4), 245-258. 
Table 2-1. Volumes of PCE released $(\mathrm{mL})$ at each injection ports during each injection event.

\begin{tabular}{|l|c|c|c|c|c|c|c|}
\hline \multirow{2}{*}{} & \multicolumn{2}{|c|}{ Port 1 } & \multicolumn{2}{c|}{ Port 2 } & \multirow{2}{*}{ Port 3 } & \multicolumn{2}{c|}{ Port 4 } \\
\cline { 2 - 5 } \cline { 7 - 9 } & Deep & Shallow & Deep & Shallow & & Deep & Shallow \\
\hline First injection & 2 & & 2 & & 2 & 2 & \\
\hline Second injection & 2 & & 1 & & 3 & 2 & \\
\hline Third injection & & 2 & & & 2 & & 2 \\
\hline Fourth injection & & 2 & & 2 & 2 & & \\
\hline
\end{tabular}

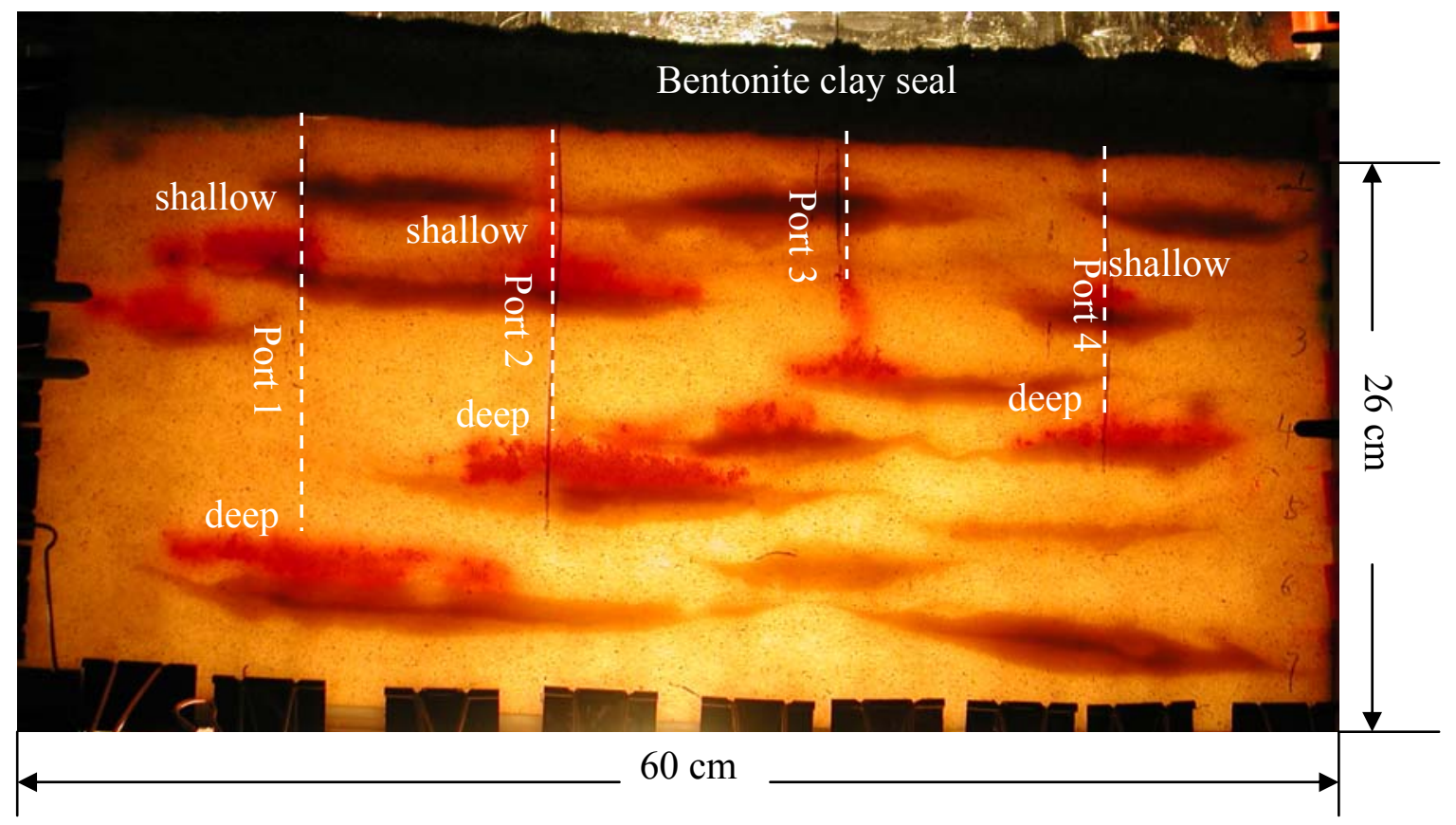

Figure 2-1. Distribution of PCE injection ports in the flow chamber. Picture was taken after the fourth DNAPL spill event. 


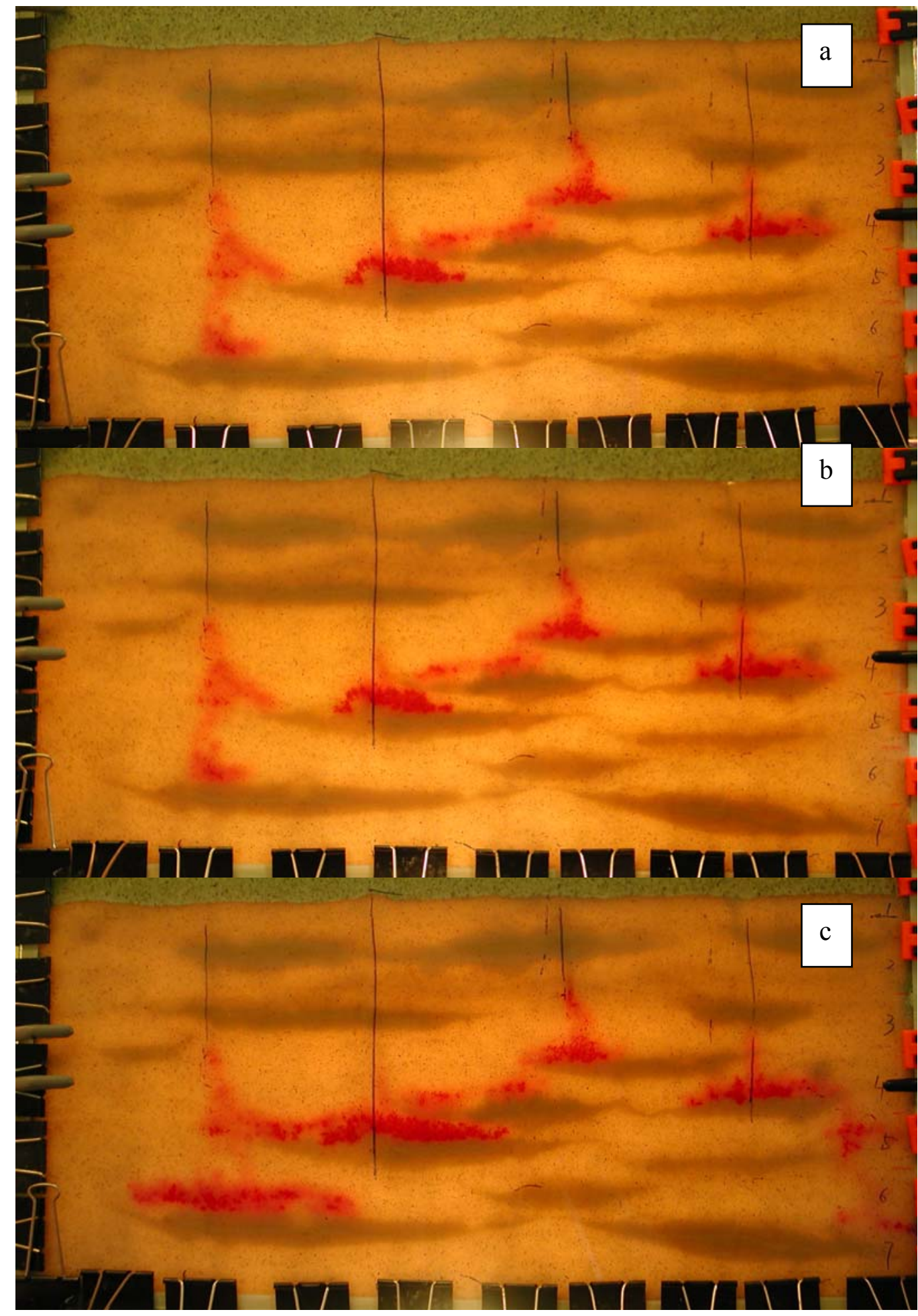

Figure 2-2. PCE DNAPL in the flow chamber a) 3 hours after first spill, b) 16 hours after first spill, and c) one day after second spill. 


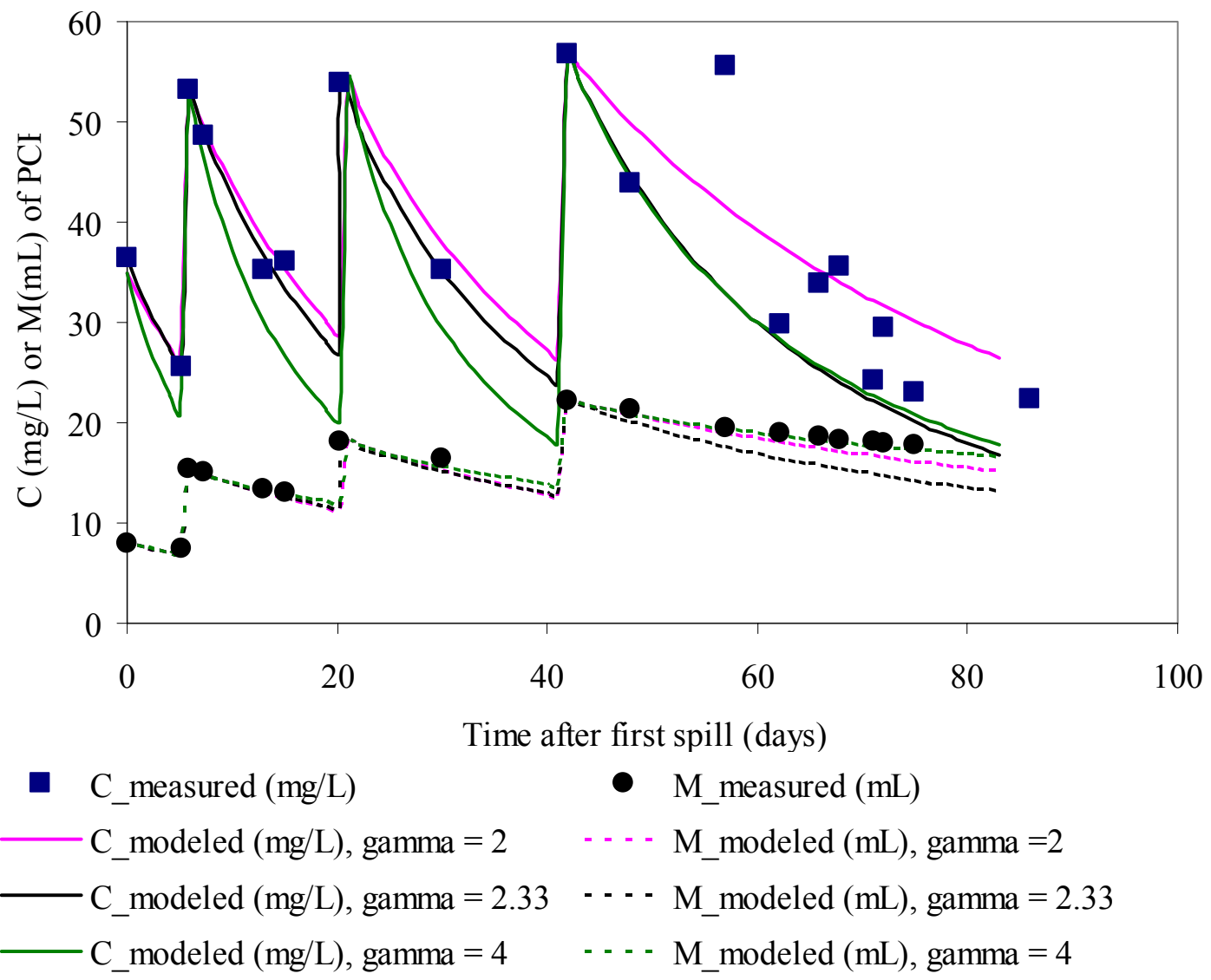

Figure 2-3. PCE effluent concentration and remaining mass versus time after first spill, modeled with power function with $\Gamma=2,2.33$, and 4 . 


\section{Chapter 3. In-Situ Flushing for DNAPL Mass Depletion Using Ethyl lactate}

Xihong Zhai, Jaesun Lee, Linda S. Lee, and P. Suresh C. Rao

\subsection{Introduction}

In-situ cosolvent flushing has been evaluated both under laboratory and field conditions as an effective strategy for enhanced removal of non-aqueous phase liquids (NAPLs) from source zones; NAPL mass depletion is achieved either by solubilization or by mobilization (AATDF, 1997; ITRC, 2003). The NAPL mass recovery effectiveness from insitu flushing in the source zone has been reported to cover a wide range (0 to 99\%) (AATDF, 1997). The maximum efficiency of a cosolvent is a function of the solubilization or cosolvency power (Banerjee and Yalkowsky, 1988; Rao et al., 1997; Yalkowsky, 1999; Yalkowsky et al., 1972b; Yalkowsky and Roseman, 1981; Yalkowsky, et al. 1976) of the cosolvent, while the hydrodynamic efficiency achieved depends on the hydrogeologic heterogeneities of the aquifer (e.g., spatial correlation structure if the hydraulic conductivity); the composition and properties of the NAPL (e.g., single- or multi-component; density; wettability), and the fluid properties (e.g., viscosity, density and NAPL-water interfacial tension) of the solvent mixture used for flushing. Low-molecular-weight $n$-alcohols (e.g., methanol, ethanol, tert-butanol, pentanol, and hexanol) have been used as cosolvents (Brooks et al., 2004; Falta, 1998; Falta et al., 1999; Imhoff et al., 1995a; Jawitz, 2000; Rao et al., 1997; Ridgway, 2001; Sillan et al., 1998b). Ethanol flushing was shown to be effective in solubilizing $>85 \%$ of several target contaminants from an light NAPL (LNAPL) source zone at Hill AFB, UT (Rao et al., 1997), and about $60 \%$ of PCE from a source zone at a drycleaner site in Florida (Jawitz et al., 2000). Falta et al.’s work (1999) at Hill AFB, UT with tertbutanol and hexanol has shown nearly $80 \%$ removal of the total NAPL content from the test cell.

The success of alcohols and surfactants as solubility enhancers for in-situ flushing has been demonstrated in several field studies (Falta et al., 1999; Jawitz et al., 1998b; Jawitz 2000; Ramsburg et al., 2004; Rao et al., 1997), but concerns remain about the regulatory permitting and the risks from residual cosolvents (or surfactants) left in the target remediation zone. Field studies at Hill AFB, UT and in Jacksonville, FL (Sillan et al., 1998a; Rao et al., 1997) involved in-situ flushing with food-grade ethanol, because of concerns with additives or "contaminants" in non-food-grade ethanol. Generally, for similar reasons, food-grade surfactants are preferred (ITRC, 2003; Ramsburg et al., 2004) for in-situ flushing. For both ethanol and some surfactants, it has been shown that the residual alcohol (or surfactant 
byproducts) can stimulate microbial activity, and serve as electron donors enhance microbial reductive dechlorination at DNAPL sites (Mravik et al., 2003; Ramsburg et al., 2004).

Here, we explore the utility of a bio-friendly cosolvent, ethyl lactate (ethyl 2hydroxypropionate), for in-situ flushing of NAPL source zones. Ethyl lactate (NTEC Versol $^{\mathrm{TM}}$, Versol Inc., Mt. Prospect, IL) is an organic solvent made from corn or other renewable carbohydrates. It is the ethyl ester of natural $\mathrm{L}(+)$ lactic acid, produced by fermentation from sugar. It is a clear and colorless liquid of low volatility, is completely miscible with water and most organic solvents, and is non-toxic. Until recently, ethyl lactate was too costly to use as a routine solvent; however, an improved purification process developed by Argonne National Labs has made it more economical (Anonymous, 1999).

PCE was chosen as a representative DNAPL. First, solubilization of PCE by ethyl lactate (EL)/water solutions was measured, and its cosolvency power for PCE estimated and compared to those reported for other binary solvents. Solubility of toluene, as a typical LNAPL contaminant, in EL/water solutions was also measured. Second, various fluid properties, such as viscosity, density and interfacial tension with PCE and toluene of ELwater mixtures were collected and contrasted with other binary solvents. Third, the effectiveness and efficiency of NAPL recovery by solubilization during in-situ flushing with EL-water in column experiments was evaluated.

\subsection{Materials and methods}

\section{Solubility measurement}

Binary mixtures of ethyl lactate and water $(10,20,30,40,50,60,70,80 \%$ ethyl lactate $(\mathrm{v} / \mathrm{v}))$ were prepared by mixing pre-determined volumes of water and ethyl lactate respectively. PCE solubility was measured in EL/water solutions by placing $5 \mathrm{~mL}$ of EL/water solution in 5-mL Teflon-capped vials followed by injection of 1 to $50 \mu \mathrm{L}$ PCE with a gas-tight Hamilton syringe. In order to minimize the potential for cosolvent partitioning into free-phase PCE, PCE was added at approximately twice the expected solubility as estimated from preliminary solubility measurements in which $1 \mathrm{~mL}$ of PCE was mixed with $4 \mathrm{~mL}$ of cosolvent/water solution. The vials were then rotated gently for 5 hours at room temperature on a circular rotator (Glas-Col) at a speed low enough $(20 \mathrm{rpm})$ to avoid formation of emulsions. PCE concentrations were measured directly from the 5-mL vials using a gas chromatograph equipped with a flame ionization detector (GC-FID). 


\section{DNAPL mobilization experiment gradient flushing in 1-D column}

A borosilicate glass column (Western Analytical) with inside diameter of $2.5 \mathrm{~cm}$ and total length of $10 \mathrm{~cm}$ was used for 1-D mobilization experiment (Figure 3-1). Three kinds of media were tested: Oakville soil, medium sand, and Warsaw soil. PCE was dyed with Oilred-O (Fisher) for visual observation. The gradient flushing started with nanopure water, then $10 \%, 20 \%, 30 \%, 40 \%, 50 \%, 60 \%$, and $70 \%$ of ethyl lactate by volume mixed with water. Each composition of EL/water mixture was flushed for at least 1.5 pore volumes to ensure that the solution of current solution was observed in the outlet and didn't cause mobilization. If mobilization did occur, then more pore volumes were flushed until no free phase PCE was observed in the outlet end. The volume of PCE left in column was calculated by tracking the mass of the column after each step of gradient flushing. The flow rate and pore volumes flushed for each volume fraction was detailed in Table 3-1.

\section{Flushing PCE-contaminated 1-D column with $50 \%$ ethyl lactate}

For a lab-scale demonstration, ethyl lactate flushing of PCE was conducted in a borosilicate glass column (Western Analytical, I.D. $=2.5 \mathrm{~cm}$, packing length $=7 \mathrm{~cm}$ ) packed with medium size sand as a representative aquifer material. The column was packed under water (3 $\mathrm{cm}$ of water on the top of the sand) with intermittent vibration to ensure no air entrapment and tight packing. PCE was loaded at the flow of $0.1 \mathrm{~mL} / \mathrm{min}$ for 80 minutes with upward flow. The column was then reversed to facilitate the gravity for PCE to settle for four hours, followed by flushing with nanopure water at $0.5 \mathrm{~mL} / \mathrm{min}$ until no free phase PCE was observed in the column effluent. In total $3.9 \mathrm{~mL}$ PCE was flushed out, resulting in a NAPL saturation $\left(\mathrm{S}_{\mathrm{N}}\right)$ of $40 \%$. Ethyl lactate/water solution (50\%) was used to run cosolvent flushing to recover PCE DNAPL at the flow rate of $0.07 \mathrm{~mL} / \mathrm{min}$. The effluent from the column was connected to a GC-inline sampler and the concentration of PCE was analyzed in real-time.

\subsection{Results and Discussion}

\section{Solubility enhancement with ethyl lactate}

PCE solubility measured in nanopure water, without ethyl lactate, was $218 \mathrm{mg} / \mathrm{L}$ $\left(23^{\circ} \mathrm{C}\right)$, which is similar to the reported aqueous solubility (Broholm et al., 1992). The aqueous toluene solubility measured was $478 \mathrm{mg} / \mathrm{L}\left(23^{\circ} \mathrm{C}\right)$, which is slightly lower than the range of $487 \sim 588 \mathrm{mg} / \mathrm{L}$ (at or close to $25^{\circ} \mathrm{C}$ ) reported in literatures (Brown and Wasik ,1974; Dohanyosova et al., 2001; Poulson et al., 1999; Yany et al.,1997), possibly due to the temperature difference. The coefficients of variation from the replicates were generally less 
than $1 \%$ except for PCE solubilities in $10 \%$ and $20 \%$ ethyl lactate (13\% error). PCE and toluene solubility increased exponentially with the increasing ethyl lactate volume fraction (Figure 3-2). The log-linear model describes these solubilization profiles:

$\log C_{m}^{s a t}=\log C_{w}^{s a t} * \lambda f_{c}$

Eq. 3.1

where $C_{m}{ }^{s}$ and $C_{w}{ }^{s}$ are the solute solubilities in the cosolvent-water mixture and in water, respectively, $\lambda$ is the cosolvent solubilization power for the particular cosolvent-solute system, and $f_{c}$ is the volume fraction of the cosolvent in the aqueous mixture (Banerjee and Yalkowsky, 1988; Schwarzenbach et al., 2002; Yalkowsky et al., 1972a; Yalkowsky et al., 1972b; Yalkowsky and Roseman, 1981).

The slope of the solubilization profile yields an ethyl lactate cosolvency power $(\lambda)$ of 4.37 for PCE and 1.46 for toluene. This difference in $\lambda$ for the two solutes is expected based on the differences in their hydrophobic characters as reflected by their octanol-water partition coefficients $\left(\mathrm{K}_{\mathrm{ow}}\right)$. PCE is more hydrophobic $\left(\log K_{\text {ow }}=2.88\right)$ than toluene $\left(\log K_{\text {ow }}=2.73\right)$; therefore, a larger cosolvency effect is expected. A positive correlation between cosolvency power and $\log K_{o w}$ was observed for various cosolvents and solutes (Li and Yalkowsky, 1998a b; Morris et al., 1988). The PCE cosolvency powers of EL measured in this study are compared in Table 3-3 with those of several other cosolvents reported in the literature (Van Valkenburg and Annable, 2002; Zhai et al., 2005). Ethyl lactate is the strongest cosolvent among those listed. If $50 \%$ of ethyl lactate is to be used, the PCE solubility will be about $40,000 \mathrm{mg} / \mathrm{L}$, which is nearly a 200 -fold increase over the solubility in water.

\section{Fluid Properties of Binary Mixtures}

The interfacial tension (IFT) between water and PCE was 38 dyne/cm and decreased to 2 dyne/cm in EL-water binary mixture with $60 \%$ EL (v/v). A very similar pattern was observed for toluene. In Figure 3-3, log IFT measured for NAPL-water/EL mixtures normalized to that measured for NAPL-water is plotted versus cosolvent volume fraction $\left(f_{c}\right)$. Data trends for both PCE and toluene are very similar with the exception of the data for $60 \%$ ethyl lactate, which is probably related to measurement errors incurred with measuring small IFTs. A single regression line fits the data for both PCE and toluene $\left(\mathrm{R}^{2}=0.92\right)$, indicating the mechanisms of IFT reduction between PCE (a DNAPL) and toluene (an LNAPL) are similar.

The viscosities of EL/water mixtures are generally higher than those of water (Figure $3-4)$ and ranged between 1 and 3.7 cPs with the highest value measured for $70 \%$ EL. The viscosity of several other binary solvent mixtures (Belda et al., 2004; Kipkemboi and Easteal, 
1994; Ovchinnikova, 1982) studied for cosolvent flushing are also shown in Figure 3-4. They all follow a parabolic shape, but with differences in the $f_{c}$ at which the highest viscosity is observed. For acetone and ethanol, the peak viscosity values appear at lower $f_{c}$ values then for ethyl lactate and TBA.

The density of ethyl lactate $(1.042 \mathrm{~g} / \mathrm{mL})$ is slightly larger than that for water, unlike typical alcohol cosolvents, which are significantly lighter than water. This makes the density of the water/EL mixture greater than that of pure water. Figure 3-5 compares the densities of binary solvent mixtures of water with ethyl lactate (this study) and those from the literature on acetone (Ovchinnikova, 1982), TBA (Kipkemboi and Easteal, 1994), and ethanol (Belda et al., 2004). The EL-water system is the only one with densities higher than water among those listed.

\section{NAPL Mobilization \& Total Trapping Number}

Typically cosolvent- or surfactant-enhanced aquifer remediation are designed to promote solubilization rather than mobilization, because the latter can lead to uncontrolled movement and expansion of the NAPL zone (Dawson and Roberts, 1997; Pennell et al., 1996; Ramsburg and Pennell, 2002; Wardlaw and McKellar, 1985). Therefore, one of the important criteria in design of in-situ cosolvent flushing, is achieving maximum solubility enhancement with minimum potential of NAPL mobilization. By coupling interfacial tension effects with those of buoyant and viscous forces, the mobilization of NAPL from a porous media can be described using a Total Trapping Number( $\mathrm{N}_{\mathrm{T}}$ ) (Pennell et al., 1996). Two dimensionless quantities result from balancing buoyant and viscous forces: (1) the capillary number $\left(N_{\mathrm{Ca}}\right)$ is defined in terms of the aqueous flow component in the direction of the pore. $N_{C a}$ relates viscous to capillary forces; (2) The bond number $\left(N_{\mathrm{B}}\right)$ represents the ratio of the buoyancy to capillary forces. The total trapping number, $N_{T}$, is calculated from the Capillary Number, $N_{C a}$, and Bond Number, $N_{B}$. For vertical upward flow, relationship between $N_{T}$ and $N_{C a}, N_{B}$ simplifies to:

$$
\begin{array}{ll}
N_{T}=\left|N_{C_{a}}+N_{B}\right| & \text { Eq. } 3.2
\end{array}
$$

Higher $N_{T}$ values indicate higher potential for NAPL mobilization. Addition of an organic cosolvent to water reduces the NAPL-water IFT and increases the viscosity of the binary system. As indicated in by $N_{C a}, N_{B}$, and $N_{T}$. Lower IFT and higher viscosity lead to higher total trapping number, and consequentially higher tendency to mobilize the residual NAPL. 
From an economic perspective, a high cosolvency power would require less cost of cosolvent, and a small decrease in IFT, and low viscosity would impose lower tendency to mobilize NAPL. Optimization of these three features yields an ideal cosolvent.

Generally, higher volume fraction of cosolvent enhances the solubility more, but also leads to lower IFT. In Figure 3-6, IFT (normalized to that in water) of various binary solutions is plotted in a log-log manner against the corresponding enhanced PCE solubility (scaled to aqueous solubility) for several cosolvents and the surfactant sodium di-hexyl sulfosuccinate. For a comparable solubility enhancement, the IFT values of the surfactant system are much lower than that of the cosolvent/water systems. For the cosolvents, acetone and ethanol appear to be better choices than ethyl lactate based only on the above criteria. In Figure 3-7, measured fluid viscosity is plotted versus $\log$ of normalized solubility. The viscosity curves are generally parabolic with peak values at various $\log \left(C_{m}{ }^{s} / C_{w}{ }^{s}\right)$. If one is targeting at a certain degree of solubility enhancement, say 100 times, $\log \left(C_{m}^{s} / C_{w}^{s}\right)=2$, acetone seems to be the best again. However, it is known that density and viscosity differences between the displacing fluid and the resident fluid may induce fluid override or under-ride, which can decrease the hydrodynamic (sweep) efficiency during cosolvent flushing (Jawitz et al.,1998a; Lake, 1989). Higher viscosity of the displacing fluid has the capacity to penetrate through fine layer in the aquifer and thus mitigate the fluid front nonuniformity caused by hydrodynamic heterogeneity (AATDF, 1997). On the other hand, smaller density difference between the two fluids also favors the formation of more uniform displacing front and thus higher sweep efficiency during cosolvent flushing (Jawitz et al., 1998a; Lake, 1989). Therefore, when sweep efficiency is considered, the EL/water system, with higher viscosity and smaller density differences with water, is a better choice than ethanol/water system.

Critical $N_{T}$ values for mobilization of PCE from homogeneous sands have been estimated in the range of $2 \times 10^{-5}$ to $5 \times 10^{-5}$ (Pennell et al. 1996). Based on the interfacial tension, density, and viscosity values measured in this study, $N_{T}$ was calculated for three media with various permeability values. The results of actual mobilization experiments for these media were plotted against the $N_{T}$ values in Figure 3-8 with \% volume ethyl lactate noted. It can be seen that the critical $N_{T}$ values for the onset of PCE mobilization for the medium sand $\left(5.5 \times 10^{-5}\right)$ was reasonably close to the range reported by Pennell et al (1996). However, for the two soils tested in this study, the onset of PCE mobilization occurred at $N_{T}$ values one order of magnitude lower $\left(2.5 \times 10^{-6}\right.$ for Warsaw soil and $2.8 \times 10^{-6}$ for Oakville soil). Similar critical $N_{T}$ values were observed with soil containing a moderate amount of clay 
(Padgett and Hayden, 1999; Zhai et al., 2005). Padgett and Hayden (1999) attributed this to clay-induced formation of larger multi-pore DNAPL ganglia, which is believed to be mobilized more easily. This reasoning seems to be applicable to the results in this study, since the critical $N_{T}$ values appear to be inversely correlated to \% clay for the three media tested: medium Ottawa sand containing essentially no clay $\left(5.5 \times 10^{-5}\right)>$ Oakville soil containing some clay $\left(2.8 \times 10^{-6}\right)>$ Warsaw soil containing the most clay $\left(2.5 \times 10^{-6}\right)$. The

shape of each curve, especially where $\mathrm{S}_{\mathrm{n}} / \mathrm{S}_{\mathrm{n}}{ }^{\circ}$ starts to drop, is a function of NAPL architect in the porous media, which in turn is dependent on the soil particle distribution. For medium Ottawa sand, the slope of the curve is relatively steep due to a uniform particle size. For the Warsaw and Oakville soils in which a much wider range exists in particle size, $S_{n} / S_{n}{ }^{0}$ values drops gradually with $N_{T}$, since each data point reflects the onset of mobilization with a certain particle size range.

\section{Enhanced PCE Solubilization by Flushing with Ethyl Lactate}

The flushing experiment with isocratic step-wise increases in $f_{c}$ determined that the maximum amount of ethyl lactate that did not cause PCE mobilization was 50\% in the medium sand with a Darcy flux of $0.02 \mathrm{~cm} / \mathrm{min}$. As indicated in Figure 3-9, the PCE concentration in the effluent approached its solubility at 0.8 pore volumes, which coincided with the appearance of a cloudy effluent solution. The same phenomenon was observed by Imhoff and coworkers (1995a,b) when flushing PCE with a $60 \%$ methanol solution. The PCE effluent concentration soon reached enhanced solubility with $50 \%$ ethyl lactate $(40,000$ $\mathrm{mg} / \mathrm{L}$ ) within 2 pore volumes of flushing, and then fluctuated around this value for 13 pore volumes. The calculated PCE residual saturation (average value over the whole column) deceased linearly. At 14.6 pore volumes, $S_{n}$ was reduced to $14.6 \%$, and PCE concentration started to drop, which can be indicative of rate-limited mass transfer process between DNAPL and aqueous phase as exemplified with the rise in concentrations with interruption of flow. Exponential tailing lasted for over 20 pore volumes. The $S_{n}$ values were calculated based on the PCE mass tracked from the column effluent, and therefore, is the average $S_{n}$ over the length of the column. If only water was used to flush the PCE in the column and assuming instantaneous equilibrium dissolution (effluent concentration of $218 \mathrm{mg} / \mathrm{L}$ as measured in this study) about 3000 pore volumes of water would have been needed. Whereas with $50 \%$ ethyl lactate, flushing with 35 pore volumes was sufficient to dissolve nearly all of the DNAPL (PCE) and reduced the effluent concentration to $40 \mathrm{mg} / \mathrm{L}$. 


\section{Modeling of PCE elution with EL/water flushing in the column}

To describe the observed BTC, a non-equilibrium transport model computer code originally developed by Augustijn (1991) and later modified by Jawitz et al (2003) was used, which assumes two-site non-equilibrium dissolution, a model that was originally used for non-equilibrium desorption (Jawitz et al., 2003; Nkedi-Kizza et al., 1984; Vangenuchten and Wierenga, 1976). The two-site model assumes that solute partitioning is instantaneous into some fraction of NAPL and rate-limited into the remaining fraction. The process can be described by the governing partial differential equation in the dimensionless form as follows,

$$
\begin{aligned}
& R_{1} \frac{\partial C_{1}}{\partial T}+\frac{\partial C_{2}}{\partial T}=\frac{1}{P} \frac{\partial^{2} C_{1}}{\partial X^{2}}-\frac{\partial C_{1}}{\partial X} \\
& \frac{\partial C_{2}}{\partial T}=\omega\left[(1-F)(R-1) C_{1}-C_{2}\right]
\end{aligned}
$$

where subscripts 1 and 2 denote the instantaneous and rate-limited fractions. And the dimensionless variables are defined as:

$$
\begin{aligned}
& P=\frac{q L}{D} \\
& T=\frac{q t}{L} \\
& X=\frac{x}{L} \\
& C=\frac{c}{c_{0}} \\
& R=1+\frac{K_{N} S_{N}}{1-S_{N}} \\
& R_{f}=1+\frac{F K_{N} S_{N}}{1-S_{N}} \\
& \omega=\frac{K L}{q}
\end{aligned}
$$

where $P$ is the Peclet number (dimensionless), $t$ is time ( $\mathrm{min}), q$ is darcy velocity $(\mathrm{cm} / \mathrm{min}), D$ is dispersion coefficient $\left(\mathrm{cm}^{2} / \mathrm{min}\right), T$ is pore volumes (dimensionless), $x$ is distance $(\mathrm{cm}), L$ is the length of the column $(\mathrm{cm}), c$ is the solute effluent concentration $(\mathrm{mg} / \mathrm{ml}), c_{0}$ is the solute input concentration $(\mathrm{mg} / \mathrm{ml})$ for desorption and solute solubility for dissolution, $R$ is the retardation factor (dimensionless), $K_{N}$ is the solute partitioning coefficient (dimensionless), $F$ 
is the fraction of the instantaneous site (dimensionless), $\omega$ is the Damkohler number (dimensionless), and $K$ is the first-order kinetic rate constant $\left(\mathrm{min}^{-1}\right)$.

In this computer code, dissolution was modeled as desorption, and the retardation factor, $R$, which describes the desorption process, was utilized to represent the total contaminant mass. The cosolvency effect was taken into account by changing $R$ and $F$. Under saturated conditions, contaminant was presented either in the aqueous phase $\left(C_{w}, \mathrm{mg} / \mathrm{mL}_{\mathrm{aq}}\right)$ or in the NAPL phase $\left(C_{N}, \mathrm{mg} / \mathrm{mL}_{\mathrm{NAPL}}\right)$. So the total contaminant mass relative to the volume of the bulk soil $\left(M, \mathrm{mg} / \mathrm{mL}_{\text {soil }}\right)$ can be expressed as the summation of these two:

$$
M=\left(1-S_{N}\right) C_{W}+S_{N} C_{N}
$$

Assuming the contaminant partitions between NAPL and aqueous phases:

$$
C_{N}=K_{N} C_{W}
$$

then

$$
M=\left(1-S_{N}\right) C_{W}+S_{N} K_{N} C_{W}
$$

and

$$
\frac{M}{\left(1-S_{N}\right) C_{W}}=1+\frac{K_{N} S_{N}}{1-S_{N}}
$$

For a single component NAPL, the aqueous concentration $\left(C_{w}\right)$ can be assumed to equal its pure compound solubility $C_{w}{ }^{s}$. The similarity on the right hand side of equation (9) and equation (15) leads to another expression of retardation factor in water:

$$
R_{w}=\frac{M}{C_{w}^{s}\left(1-S_{N}\right)}
$$

$M$ and $S_{N}$ can be obtained by tracking the mass of PCE injected and flushed out during PCE loading. With the measured $C_{w}{ }^{s}$ value, $R_{w}$ can be calculated using equation (16).

Similar to the log-linear cosolvency effect on solubility, the equilibrium sorption coefficient of hydrophobic organic compounds was also observed to decrease log-linearly in the same manner (Brusseau et al., 1991; Rao et al., 1985; Rao et al., 1990):

$$
K_{N, m}=K_{N, w} \times 10^{-\lambda f}
$$

where $K_{N, m}$ and $K_{N, w}$ are the partition coefficients between NAPL and water (subscript $N, w$ ), and between NAPL and water/cosolvent mixture (subscript $N, m$ ) respectively. Combination of equations (9), and (17) gives the retardation factor in cosolvent/water solution (define $R_{m}$ ): $\log \left(R_{m}-1\right)=\log \left(R_{w}-1\right)-\lambda f$

Eq. 3.18 
The other two parameters that can be impacted by cosolvent are the rate constant, expressed in the form of a Damkohler number, $\omega$, and the fraction of instantaneous sites, $F$. The following equations were used in the model to relate these parameters in water $\left(F_{w}\right)$, and in cosolvent mixture $\left(F_{m}\right)$ (Augustijn et al., 1994; Brusseau et al., 1991):

$\log \omega_{m}=\log \omega_{w}+0.668 \lambda f$

and

$F_{m}=F_{w}-\frac{(F w-0.01)}{0.8}(f-0.2)$ for $\mathrm{f} \geq 0.2$

Both equilibrium and non-equilibrium models were used to assessed the BTC. Peclet number $(\mathrm{P})$ was estimated to be 15 and the retardation factor in water $\left(\mathrm{R}_{\mathrm{w}}\right)$ was calculated to be 4010 in both cases based on the mass of PCE in the column. For nonequilibrium modeling, the modeling result fits the data the best with $\omega_{w}=0.1$, and $F_{w}=0.8$. This corresponds to $\omega_{m}$ $=3.7$ and $F_{m}=0.5$ indicating that the dissolution of PCE into EL/water solution was very close to equilibrium, as can be seen on Figure 3-9 where non-equilibrium and equilibrium modeling gave similar results. The Damkohler number in EL/water solution $\left(\omega_{m}\right)$ of 3.7 is translated to a first-order dissolution constant of 0.026 , which is comparable with the values reported in a previous study (Jawitz et al., 2003) for ethanol/water solution and surfactant solution.

\section{Mass Transfer Constraints for PCE Solubilization}

Under 1-D no flow condition, like during flow interruption, the mass transfer process can be described as,

$\frac{\partial\left(\theta S_{w} C\right)}{\partial t}=K\left(C_{e}-C\right)$

where $\theta$ is the porosity, $C$ is the PCE concentration in fluid phase, $S_{w}=\left(1-S_{n}\right)$ is the aqueous phase saturation, $K$ is the mass transfer rate coefficient $\left(\mathrm{min}^{-1}\right)$, which is the product of the mass transfer coefficient $(k, \mathrm{~cm} / \mathrm{min})$, and specific interfacial area $\left(\alpha, \mathrm{cm}^{2} / \mathrm{cm}^{3}\right)$ between DNAPL and the fluid phase $(K=k \alpha)$, and $C_{e}$ is the equilibrium concentration (which is usually the solubility limit). The last term represents dissolution of PCE from a stagnant DNAPL, which uses the generally accepted single-film model.

Assuming that partitioning of water or ethyl lactate into PCE is negligible, and that the flow interruption duration is long enough so that the variation of initial concentration along the column is negligible as well, then $K$ can be simply calculated as (Abriola et al., 1993): 


$$
K=\frac{\theta S_{w}}{\Delta t} \ln \left[\frac{C_{e}-C_{b}}{C_{e}-C_{a}}\right]
$$

where $\Delta t$ is the duration of the flow interruption, $C_{b}$ and $C_{a}$ are the PCE concentrations before and after flow interruption, respectively.

There are also several empirical power-law equations developed to estimate $K$ for a given flow condition (Imhoff et al., 1995b; Imhoff et al., 1994; Miller et al., 1990; Powers et al., 1992; 1994). The general form is

$$
S h=\beta_{0} R_{e}^{\beta_{1}} S_{n}^{\beta_{2}} S c^{\beta_{3}}
$$

where $S h=K d_{50}{ }^{2} / D_{a}$ is the Sherwood number, $R_{e}=d_{50} v_{a} / v_{a}$ is the Reynolds number, $S c=$ $v_{a} / D_{a}$ is the Schmidt number, $d_{50}$ is the median grain size $(\mathrm{cm}), D_{a}=1.32 \times 10^{-5} /\left(\mu^{1.14} \overline{V i}^{0.589}\right)$ is the molecular diffusion coefficient $\left(\mathrm{cm}^{2} / \mathrm{min}\right)$ in the aqueous phase (Schwarzenbach et al., 2002), $v_{a}$ is the interstitial aqueous phase velocity, $v_{a}$ is the aqueous phase kinetic viscosity, $\mu$ is the dynamic viscosity $(\mathrm{cP})$ of the solution $\left(10^{-2} \mathrm{~g} / \mathrm{cm} / \mathrm{s}\right), \overline{V i}$ is the molar volume of PCE $\left(\mathrm{cm}^{3} / \mathrm{mol}\right)$, and $\beta_{0}, \beta_{1}, \beta_{2}$, and $\beta_{3}$ are empirical constants. Reported $\beta$ values in the literature vary considerable depending on experimental conditions. The latter of Imhoff et al. (1995) were most similar to this study; therefore, their $\beta$ values were used in model simulations: $\beta_{0}=$ $4.79, \beta_{1}=0.75, \beta_{2}=1.03, \beta_{3}=0.5$.

The values of $K$ were estimated using both equation (3-22) and equation (3-23) for the two flow interruptions and results are summarized Table 3-4. Equation 3-23 with the Sherwood number estimated about a one order-of-magnitude higher $K$ value than equation 322. This difference can be attributed to several approximations that may not be valid. First, the Imhoff et al. (1995) experimental conditions, although similar, were not identical to these experimental conditions in our study; therefore, the actual $\beta$ values needed in eq. 3-23 may be somewhat different. Second, errors can arise from the estimation of molecular diffusion coefficient, $D_{a}$, and median grain size, $d_{50}$. Third, and most importantly, the mass transfer process can be enhanced by the advective flux of the bulk fluid past the interface, so the power-law equation, which applies to a flow condition, should result in a higher $K$ value than the no-flow condition (Abriola et al., 1993). Note that the $K$ values for the first flow interruption estimated with both methods are about 3 times that for the second flow interruption, which is proportional to the $S_{n}$ values for the two flow interruptions. This positive correlation is expected based on both equations. 


\subsection{References}

AATDF, DOD Advanced Applied Technology Demonstration Facility. (1997). "Technology Practices Manual for Surfactants and Cosolvents." TR-97-2.

Abriola, L. M., Dekker, T. J., and Pennell, K. D. (1993). "Surfactant-Enhanced Solubilization of Residual Dodecane in Soil Columns .2. Mathematical-Modeling." Environmental Science \& Technology, 27(12), 2341-2351.

Annable, M., and Rao, P. S. C. (2005). "Personal communication."

Anonymous. (1999). "Ethyl lactate at a Lower Cost." Biocycle, 40(6), 21.

Augustijn, D. C. M., Jessup, R. E., Rao, P. S. C., and Wood, A. L. (1994). "Remediation of Contaminated Soils by Solvent Flushing." Journal of Environmental Engineering-Asce, $120(1), 42-57$.

Banerjee, S., and Yalkowsky, S. H. (1988). "Cosolvent-Induced Solubilization of Hydrophobic Compounds into Water." Analytical Chemistry, 60(19), 2153-2155.

Belda, R., Herraez, J. V., and Diez, O. (2004). "Rheological study and thermodynamic analysis of the binary system (water/ethanol): Influence of concentration." Physics and Chemistry of Liquids, 42(5), 467-479.

Bradley, P. M. (2003). "History and Ecology of Chloroethene Biodegradation: A Review." Bioremediation Journal, 7(2), 81-109.

Broholm , K., Cherry, J. A., and Feenstra, S. (1992). "Dissolution of heterogeneously distributed solvents residuals." Subsurface Restoration Conference, Third International Conference On Groundwater Quality Research, Dallas, Texas, 21-24.

Brooks, M. C., Annable, M. D., Rao, P. S. C., Hatfield, K., Jawitz, J. W., Wise, W. R., Wood, A. L., and Enfield, C. G. (2004). "Controlled release, blind test of DNAPL remediation by ethanol flushing." Journal of Contaminant Hydrology, 69(3-4), 281-297.

Brown, R. L., and Wasik, S. P. (1974). "Method of Measuring Solubilities of Hydrocarbons in Aqueous-Solutions." Journal of Research of the National Bureau of Standards Section a-Physics and Chemistry, A 78(4), 453-460.

Brusseau, M. L., Wood, A. L., and Rao, P. S. C. (1991). "Influence of Organic Cosolvents on the Sorption Kinetics of Hydrophobic Organic-Chemicals." Environmental Science \& Technology, 25(5), 903-910.

Dawson, H. E., and Roberts, P. V. (1997). "Influence of viscous, gravitational, and capillary forces on DNAPL saturation." Ground Water, 35(2), 261-269.

Dohanyosova, P., Fenclova, D., Vrbka, P., and Dohnal, V. (2001). "Measurement of aqueous solubility of hydrophobic volatile organic compounds by solute vapor absorption technique: Toluene, ethylbenzene, propylbenzene, and butylbenzene at temperatures from $273 \mathrm{~K}$ to 328 K." Journal of Chemical and Engineering Data, 46(6), 1533-1539.

Falta, R. W. (1998). "Using Phase Diagrams to predict the performance of cosolvent floods for NAPL remediation." Ground water monitoring and remediation, 18(3), 94-402.

Falta, R. W., Lee, C. M., Brame, S. E., Roeder, E., Coates, J. T., Wright, C., Wood, A. L., and Enfield, C. G. (1999). "Field test of high molecular weight alcohol flushing for subsurface nonaqueous phase liquid remediation." Water Resources Research, 35(7), 2095-2108.

Gerritse, J., Renard, V., Visser, J., and Gottschal, J. C. (1995). "Complete Degradation of Tetrachloroethene by Combining Anaerobic Dechlorinating and Aerobic Methanotrophic Enrichment Cultures." Applied Microbiology and Biotechnology, 43(5), 920-928.

Gibson, S. A., and Sewell, G. W. (1992). "Stimulation of Reductive Dechlorination of Tetrachloroethene in Anaerobic Aquifer Microcosms by Addition of Short-Chain Organic-Acids or Alcohols." Applied and Environmental Microbiology, 58(4), 13921393. 
Imhoff, P. T., Gleyzer, S. N., McBride, J. F., Vancho, L. A., Okuda, I., and Miller, C. T. (1995a). "Cosolvent Enhanced Remediation of Residual Reuse Nonaqueous Phase Liquids - Experimental Investigation." Environmental Science \& Technology, 1966-1976.

Imhoff, P. T., Gleyzer, S. N., McBride, J. F., Vancho, L. A., Okuda, I., and Miller, C. T. (1995b). "Cosolvent Enhanced Remediation of Residual Reuse Nonaqueous Phase Liquids - Experimental Investigation." Environmental Science \& Technology, 29(8), 1966-1976.

Imhoff, P. T., Jaffe, P. R., and Pinder, G. F. (1994). "An Experimental-Study of Complete Dissolution of a Nonaqueous Phase Liquid in Saturated Porous-Media." Water Resources Research, 30(2), 307-320.

ITRC, Interstate Technology \& Regulatory Council, Dense Nonaqueous Phase Liquids Team. (2003). "Technical and Regulatory Guidance for Surfactant/Cosolvent Flushing of DNAPL Source Zones." Washington, DC.

Jawitz, J. W., Annable, M. D., and Rao, P. S. C. (1998a). "Miscible fluid displacement stability in unconfined porous media: Two-dimensional flow experiments and simulations." Journal of Contaminant Hydrology, 31(3-4), 211-230.

Jawitz, J. W., Annable, M. D., Rao, P. S. C., and Rhue, R. D. (1998b). "Field implementation of a Winsor type I surfactant/alcohol mixture for in-situ solubilization of a complex LNAPL as a single phase microemulsion." Environmental Science \& Technology, 32(4), 523-530.

Jawitz, J. W., Dai, D. P., Rao, P. S. C., Annable, M. D., and Rhue, R. D. (2003). "Ratelimited solubilization of multicomponent nonaqueous-phase liquids by flushing with cosolvents and surfactants: Modeling data from laboratory and field experiments." Environmental Science \& Technology, 37(9), 1983-1991.

Jawitz, J. W., Sillan, R. K., Annable, M. D., Rao, P. S. C., and Warner, K. (2000). "In-situ alcohol flushing of a DNAPL source zone at a dry cleaner site." Environmental Science \& Technology, 34(17), 3722-3729.

Jawitz, J.W., Dai, D.P., Rao, P.S.C, et al. Rate-limited solubilization of multicomponent nonaqueous-phase liquids by flushing with cosolvents and surfactants: Modeling data from laboratory and field experiments. Environmental Science \& Technology, 37(9), 1983-1991.

Kastner, M. (1991). "Reductive Dechlorination of Trichloroethylenes and Tetrachloroethylenes Depends on Transition from Aerobic to Anaerobic Conditions." Applied and Environmental Microbiology, 57(7), 2039-2046.

Kipkemboi, P. K., and Easteal, A. J. (1994). "Densities and Viscosities of Binary Aqueous Mixtures of Nonelectrolytes - Tert-Butyl Alcohol and Tert-Butylamine." Canadian Journal of Chemistry-Revue Canadienne De Chimie, 72(9), 1937-1945.

Lake, L. W. (1989). Enhanced oil recovery, Prentice Hall.

Li, A., and Yalkowsky, S. H. (1998a). "Predicting cosolvency. 1. Solubility ratio and solute $\log \mathrm{K}_{\mathrm{ow}} . "$ Industrial \& Engineering Chemistry Research, 37(11), 4470-4475.

Li, A., and Yalkowsky, S. H. (1998b). "Predicting cosolvency. 2. Correlation with solvent physicochemical properties." Industrial \& Engineering Chemistry Research, 37(11), 4476-4480.

Miller, C. T., Poirier-Mcneill, M. M., and Mayer, A. S. (1990). "Dissolution of Trapped Nonaqueous Phase Liquids - Mass-Transfer Characteristics." Water Resources Research, 26(11), 2783-2796.

Morris, K. R., Abramowitz, R., Pinal, R., Davis, P., and Yalkowsky, S. H. (1988). "Solubility of Aromatic Pollutants in Mixed-Solvents." Chemosphere, 17(2), 285-298. 
Mravik, S. C., Sillan, R. K., Wood, A. L., and Sewell, G. W. (2003). "Field evaluation of the solvent extraction residual biotreatment technology." Environmental Science \& Technology, 37(21), 5040-5049.

Nkedi-Kizza, P., Biggar, J. W., Selim, H. M., Vangenuchten, M. T., Wierenga, P. J., Davidson, J. M., and Nielsen, D. R. (1984). "On the Equivalence of 2 Conceptual Models for Describing Ion-Exchange During Transport through an Aggregated Oxisol." Water Resources Research, 20(8), 1123-1130.

Ovchinnikova, R. A. (1982). "Density and Viscosity of the Water Acetone System." Journal of Applied Chemistry of the USSR, 55(8), 1737-1739.

Padgett, P. K., and Hayden, N. J. (1999). "Mobilization of residual tetrachloroethylene during alcohol flushing of clay-containing porous media." Journal of Contaminant Hydrology, 40(3), 285-296.

Pennell, K. D., Pope, G. A., and Abriola, L. M. (1996). "Influence of viscous and buoyancy forces on the mobilization of residual tetrachloroethylene during surfactant flushing." Environmental Science \& Technology, 1328-1335.

Poulson, S. R., Harrington, R. R., and Drever, J. I. (1999). "The solubility of toluene in aqueous salt solutions." Talanta, 48(3), 633-641.

Powers, S. E., Abriola, L. M., and Weber, W. J. (1992). "An Experimental Investigation of Nonaqueous Phase Liquid Dissolution in Saturated Subsurface Systems - Steady-State Mass-Transfer Rates." Water Resources Research, 28(10), 2691-2705.

Powers, S. E., Abriola, L. M., and Weber, W. J. (1994). "An Experimental Investigation of Nonaqueous Phase Liquid Dissolution in Saturated Subsurface Systems - Transient MassTransfer Rates." Water Resources Research, 30(2), 321-332.

Ramsburg, C. A., Abriola, L. M., Pennell, K. D., Loffler, F. E., Gamache, M., Amos, B. K., and Petrovskis, E. A. (2004). "Stimulated microbial reductive dechlorination following surfactant treatment at the Bachman Road site." Environmental Science \& Technology, 38(22), 5902-5914.

Ramsburg, C. A., and Pennell, K. D. (2002). "Density-modified displacement for dense nonaqueous-phase liquid source-zone remediation: Density conversion using a partitioning alcohol." Environmental Science \& Technology, 2082-2087.

Rao, P. S. C., Annable, M. D., Sillan, R. K., Dai, D. P., Hatfield, K., Graham, W. D., Wood, A. L., and Enfield, C. G. (1997). "Field-scale evaluation of in-situ cosolvent flushing for enhanced aquifer remediation." Water Resources Research, 33(12), 2673-2686.

Rao, P. S. C., Hornsby, A. G., Kilcrease, D. P., and Nkedi-Kizza, P. (1985). "Sorption and Transport of Hydrophobic Organic-Chemicals in Aqueous and Mixed-Solvent Systems Model Development and Preliminary Evaluation." Journal of Environmental Quality, 14(3), 376-383.

Rao, P. S. C., Lee, L. S., and Pinal, R. (1990). "Cosolvency and Sorption of Hydrophobic Organic-Chemicals." Environmental Science \& Technology, 24(5), 647-654.

Ridgway, R. M. (2001). "Anaerobic Reductive Dehalogenation of Trichloroethylene in Unacclimated Freshwater Sediments," PhD Dissertation, Purdue University.

Sabatini, D. A., Knox, R. C., Harwell, J. H., and Wu, B. (2000). "Integrated design of surfactant enhanced DNAPL remediation: efficient supersolubilization and gradient systems." Journal of Contaminant Hydrology, 45(1-2), 99-121.

Schwarzenbach, R. P., Gschwend, P. M., and Imboden, D. M. (2002). Environmental Organic Chemistry, Wiley, John \& Sons, Incorporated.

Sillan, R.K., M.D. Annable, and P.S.C. Rao. (1998a). In-situ Cosolvent Flushing for Enhanced Solubilization of a Complex LNAPL: Comprehensive Field Scale Evaluation. USEPA-SERDP-Air Force Project Final Report. 
Sillan, R. K., Annable, M. D., Rao, P. S. C., Dai, D. P., Hatfield, K., and Graham, W. D. (1998b). "Evaluation of in-situ cosolvent flushing dynamics using a network of spatially distributed multilevel samplers." Water Resources Research, 34(9), 2191-2202.

Vangenuchten, M. T., and Wierenga, P. J. (1976). "Mass-Transfer Studies in Sorbing PorousMedia .1. Analytical Solutions." Soil Science Society of America Journal, 40(4), 473-480.

Van Valkenburg, M. E., and Annable, M. D. (2002). "Mobilization and entry of DNAPL pools into finer sand media by cosolvents: two-dimensional chamber studies." Journal of Contaminant Hydrology, 59(3-4), 211-230.

Wardlaw, N. C., and McKellar, M. (1985). "Oil Blob Populations and Mobilization of Trapped Oil in Unconsolidated Packs." Canadian Journal of Chemical Engineering, 63(4), 525-532.

Yalkowsky, S. H. (1999). "Solubilization by cosolvents." Solubility and solubilization in aqueous media, S. H. Yalkowsky, ed., Oxford University Press, Inc., New York, NY, 180-230.

Yalkowsky, S. H., Amidon, G. L., Zogfari, G., and Flynn, G. L. (1972a). "Solubilization of nonelectrolytes in polar solvents: III. Alkyl p-aminobenzoates in polar and mixed solvents." Journal of Pharmaceutical Science, 64, 48-52.

Yalkowsky, S. H., Flynn, G. L., and Amidon, G. L. (1972b). "Solubilization of nonelectrolytes in polar solvents." Journal of Pharmaceutical Science, 61, 983-984.

Yalkowsky, S. H., and Roseman, T. J. (1981). "Solubilization of drugs by cosolvents." Techniques of solubilization of drugs, S. H. Yalkowsky, ed., Dekker, New York, NY, 91134.

Yalkowsky, S. H., Valvani, S. C., and Amidon, G. L. (1976). "Solubilization of nonelectrolytes in polar solvents: IV. Nonpolar drugs in mixed solvents." Journal of Pharmaceutical Science, 65, 1488-1494.

Yany, Y., Miller, D. J., and Hawthorne, S. B. (1997). "Toluene solubility in water and organic partitioning from gasoline and diesel fuel into water at elevated temperatures and pressures." Journal of Chemical and Engineering Data, 42(5), 908-913.

Zhai, X., Hua, I., Rao, P. S. C., and Lee, L. S. (2005). "Cosolvent enhance chemical oxidation of perchloroethylene by potassium permangnanate." Journal of Contaminant Hydrology (corrected proof, in press). 
Table 3-1. Experimental parameters of PCE mobilization in 1-D column

\begin{tabular}{|c|c|c|c|}
\hline Packing material & $\begin{array}{c}\text { Hydraulic conductivity } \\
(\mathrm{cm} / \mathrm{min})\end{array}$ & $\begin{array}{c}\text { Pore volume } \\
(\mathrm{mL})\end{array}$ & $\begin{array}{c}\text { Darcy Flow rate } \\
(\mathrm{cm} / \mathrm{min})\end{array}$ \\
\hline Medium Ottawa sand & 2.52 & 13.4 & 0.02 \\
\hline Oakville soil & 0.08 & 11.3 & 0.04 \\
\hline Warsaw soil & 0.01 & 10 & 0.02 \\
\hline
\end{tabular}

Table 3-2. Experimental conditions for PCE dechlorination in 1-D columns

\begin{tabular}{|c|c|c|c|c|}
\hline $\begin{array}{c}\text { Column } \\
\text { ID }\end{array}$ & $\begin{array}{c}\text { Pore volume } \\
(\mathrm{mL})\end{array}$ & $\begin{array}{c}\text { Residence } \\
\text { time (days) }\end{array}$ & \multicolumn{2}{|c|}{$\begin{array}{c}\text { Composition of feeding solution prepared with } \\
\text { groundwater }\end{array}$} \\
\cline { 4 - 5 } & 29 & 2.22 & Electron donor & None \\
\hline NoED & 35 & 2.60 & $\begin{array}{c}1.21 \mathrm{mM} \mathrm{EL} \\
(143 \mathrm{mg} / \mathrm{L})\end{array}$ & $\begin{array}{c}\text { PCE 0.04 mM to 0.18 mM } \\
\text { (See Figure 121) }\end{array}$ \\
\hline EtOH & 33 & 3.19 & $\begin{array}{c}2.41 \mathrm{mM} \mathrm{Ethanol} \\
(111 \mathrm{mg} / \mathrm{L})\end{array}$ & \\
\hline
\end{tabular}

Table 3-3. PCE solubilization power of several cosolvents for PCE

\begin{tabular}{|c|c|c|}
\hline Cosolvent & Cosolvency power, $\sigma$ & Source \\
\hline Methanol & 2.67 & Imhoff et al, 1995 \\
\hline Ethanol & 3.62 & Van Valkenberg and Annable, 2002 \\
\hline Tertiary butyl alcohol & 3.85 & Zhai et al., 2005 \\
\hline Acetone & 3.22 & Zhai et al., 2005 \\
\hline Ethyl lactate & 4.37 & This work \\
\hline
\end{tabular}

Table 3-4. Calculated and model fitted mass transfer rate constants

\begin{tabular}{|c|c|c|c|c|c|}
\hline Flow & $\Delta t$ & $\mathrm{~S}_{\mathrm{n}}$ & \multicolumn{3}{|c|}{ Mass transfer rate coefficient $K(1 / \mathrm{min})$} \\
\cline { 4 - 5 } interruptions & $(\mathrm{min})$ & & $K=\frac{\theta S_{w}}{\Delta t} \ln \left[\frac{C_{e}-C_{b}}{C_{e}-C_{a}}\right]$ & $S h=\beta_{0} \operatorname{Re}^{\beta_{1}} S_{n}^{\beta_{2}} S c^{\beta_{3}}$ & $\begin{array}{c}\text { Model } \\
\text { fitting }\end{array}$ \\
\hline First & 2418 & $3.6 \%$ & $7.6 \times 10^{-4}$ & $6.2 \times 10^{-3}$ & \multirow{2}{*}{0.026} \\
\hline Second & 3840 & $1.2 \%$ & $2.8 \times 10^{-4}$ & $2.0 \times 10^{-3}$ & \multirow{2}{*}{} \\
& & &
\end{tabular}




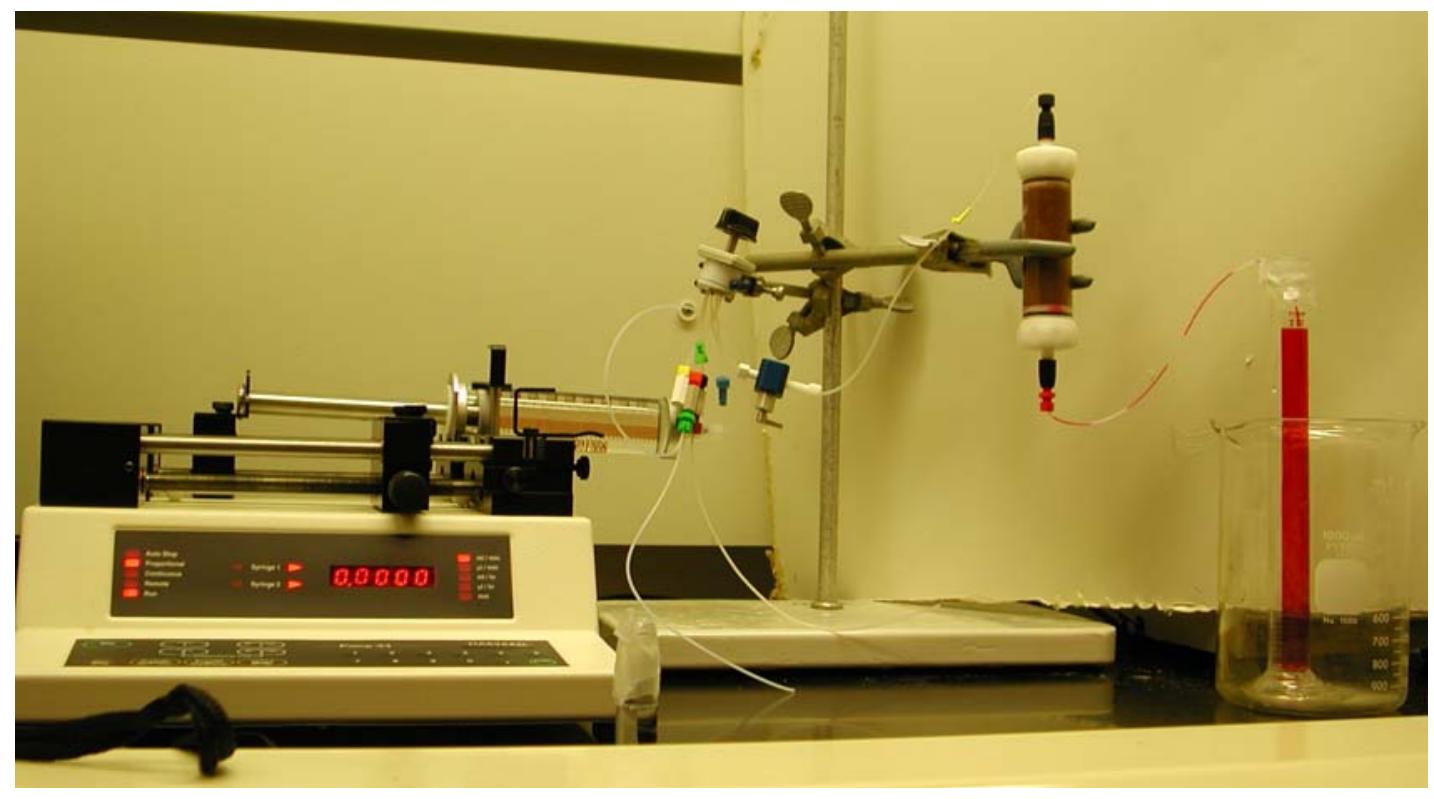

Figure 3-1. Experimental set up for PCE mobilization in a 1-D column

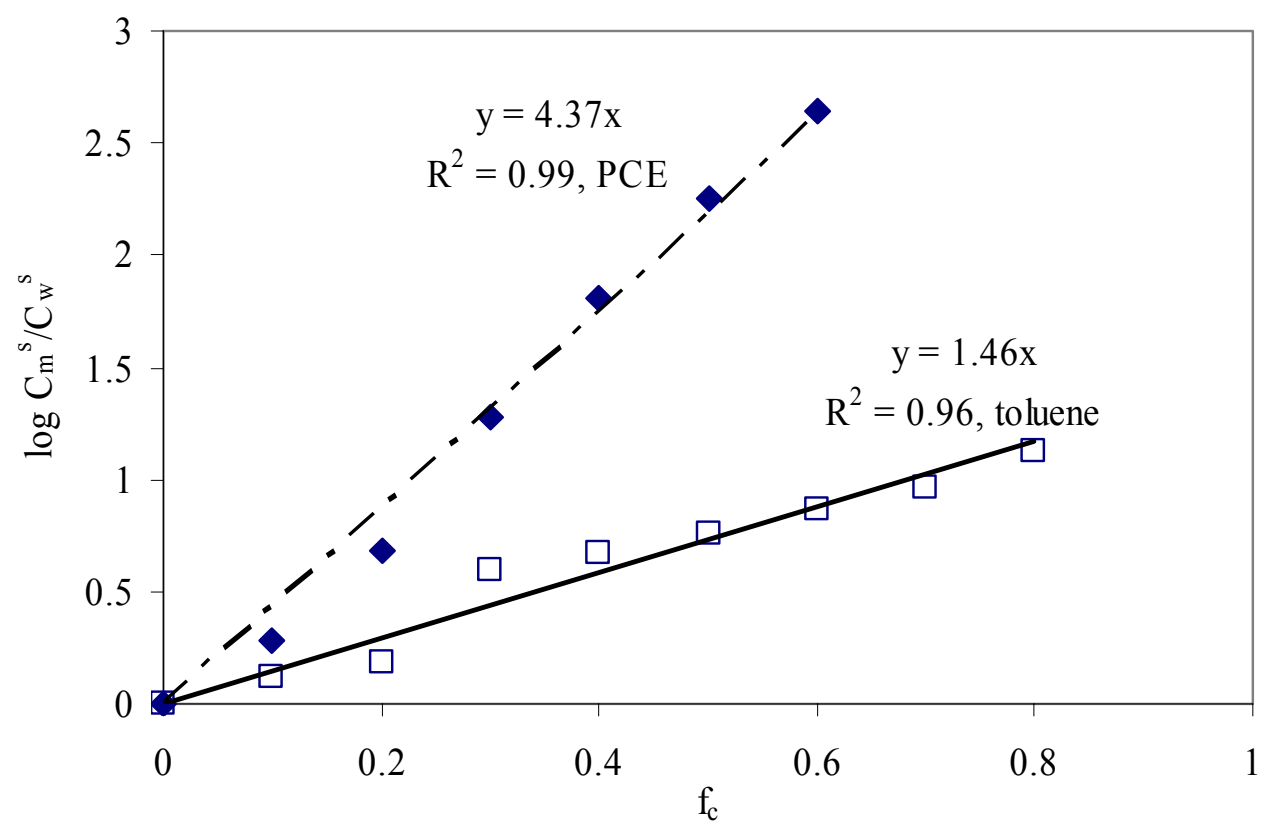

Figure 3-2. Log normalized solubility $\left(C_{m}{ }^{s} / C_{w}{ }^{s}\right)$ versus ethyl lactate cosolvent fraction $\left(\mathbf{f}_{\mathbf{c}}\right)$. 


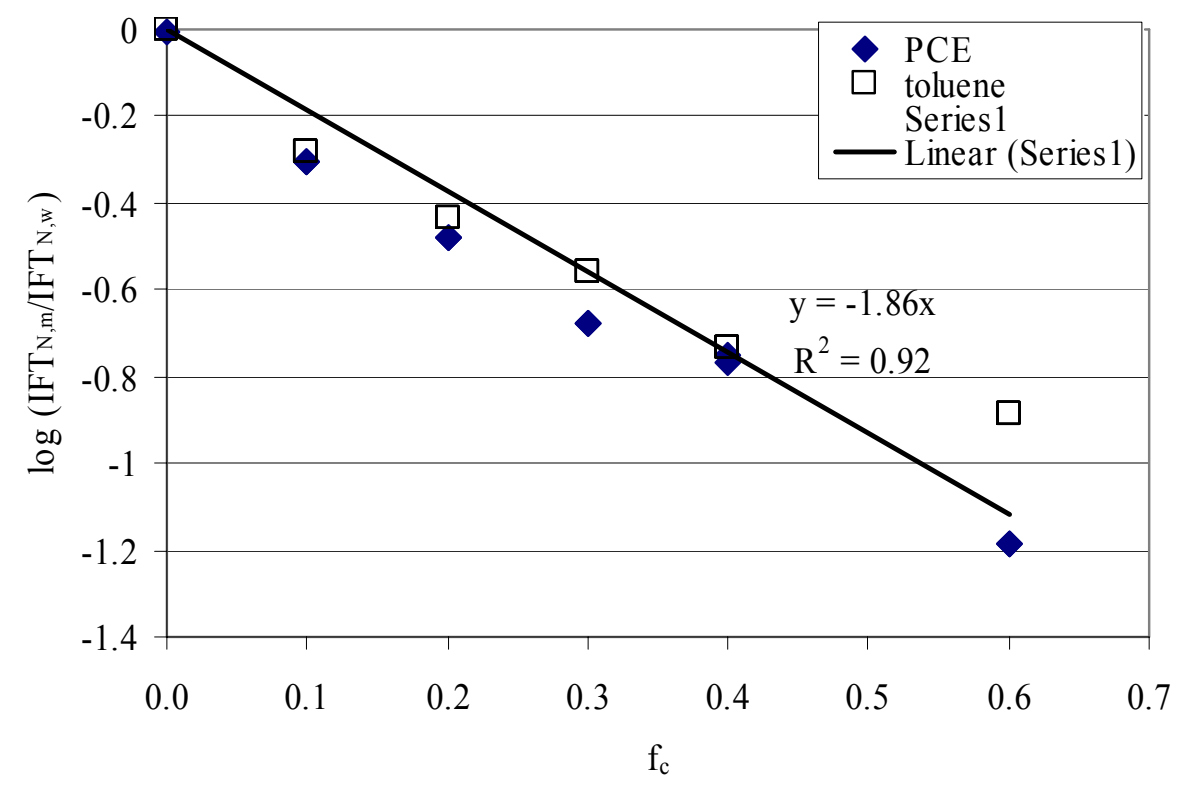

Figure 3-3. Log normalized interfacial tension (IFT ${ }_{\mathrm{N}, \mathrm{m}} /$ IFT $\left._{\mathrm{N}, \mathrm{w}}\right)$ between ethyl lactate $(E L) /$ water mixture and NAPL (PCE and toluene) versus EL volume fraction $\left(f_{c}\right)$.

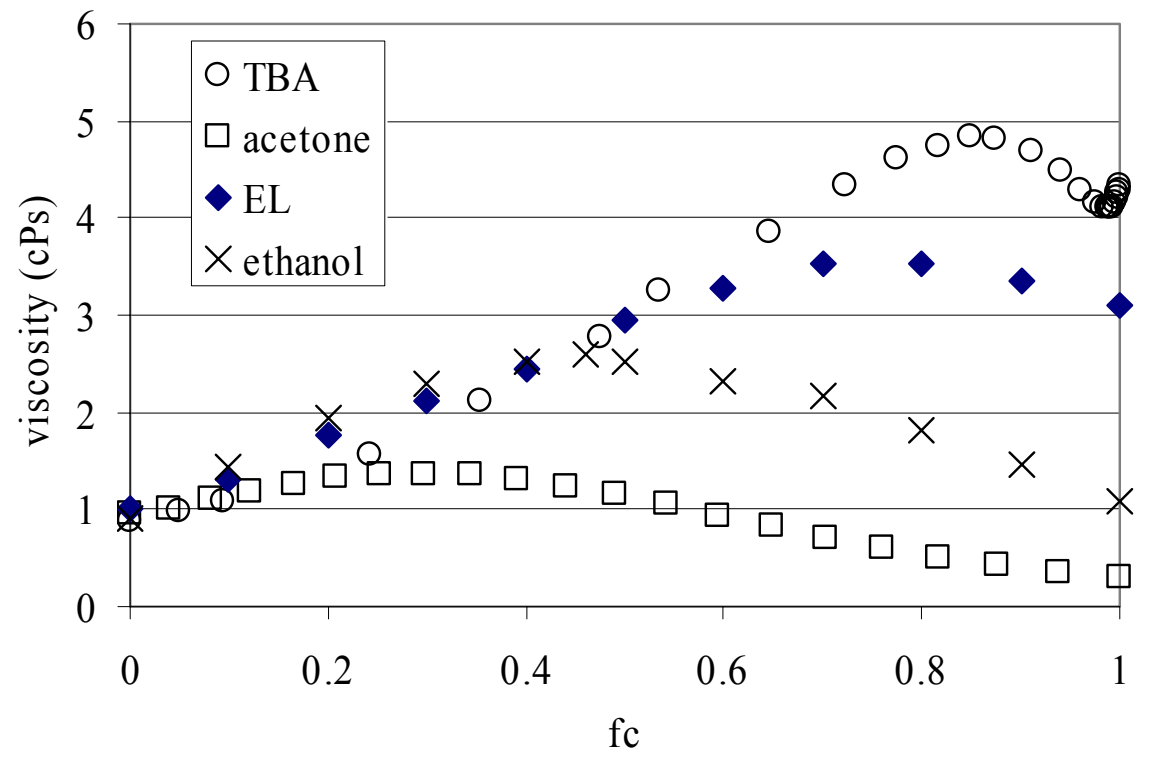

Figure 3-4. Viscosity of binary solvent systems of water and TBA (Kipkemboi and Easteal, 1994), acetone (Ovchinnikova, 1982), EL (this study), or ethanol (Belda et al., 2004) as a function of organic cosolvent volume fraction $\left(f_{c}\right)$. 


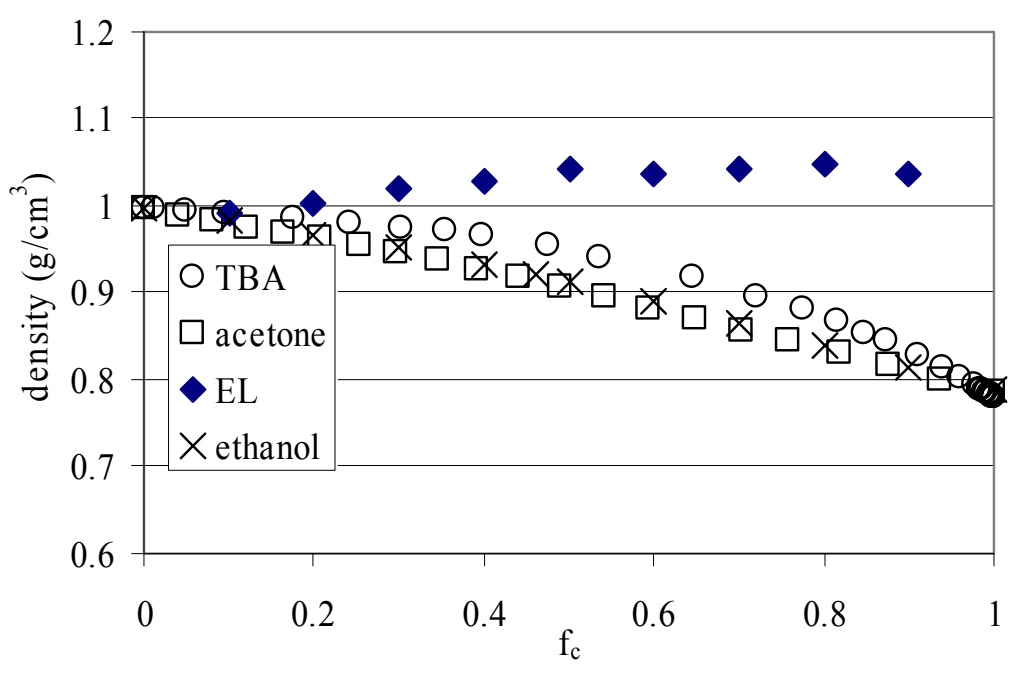

Figure 3-5. Density of binary solvent systems of water and TBA (Kipkemboi and Easteal, 1994), acetone (Ovchinnikova, 1982), EL (this study), or ethanol (Belda et al., 2004) as a function of organic cosolvent volume fraction $\left(f_{c}\right)$.

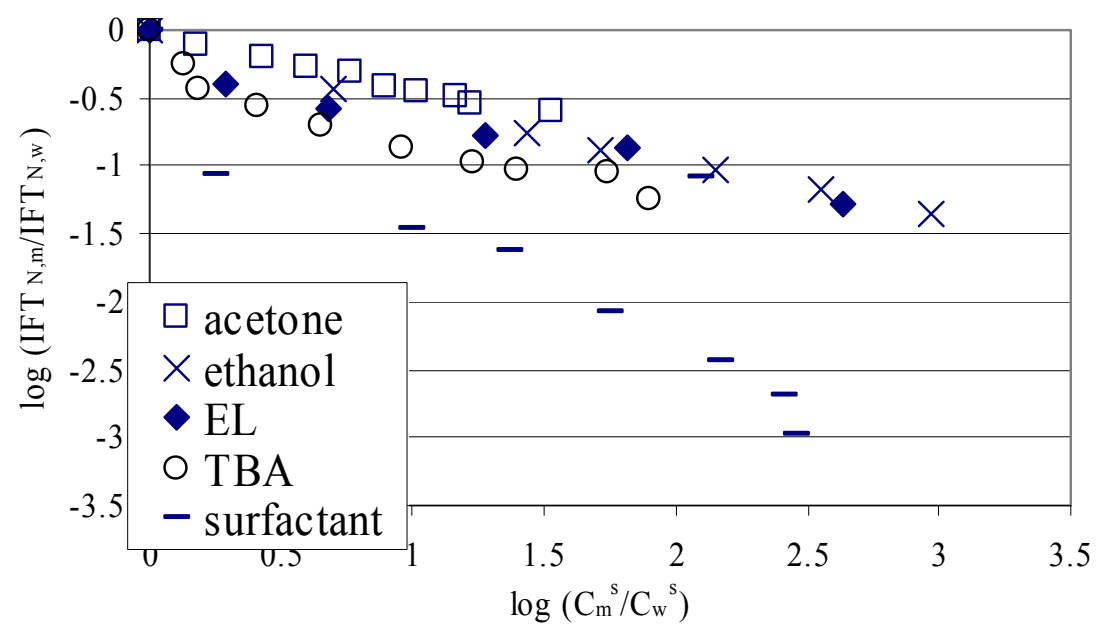

Figure 3-6. Inverse relationship between log normalized interfacial tension (IFT,, $\mathrm{m} /$ IFT $\left._{N}, w\right)$ versus $\log$ normalized solubility $\left(C_{m}{ }^{s} / C_{w}{ }^{s}\right)$ of PCE in different binary solvent systems. TBA and acetone data are from Zhai et al. (2005), ethanol data are from Van Valkenburg and Annable (2002), surfactant data are from Sabatini et al. (2000). 


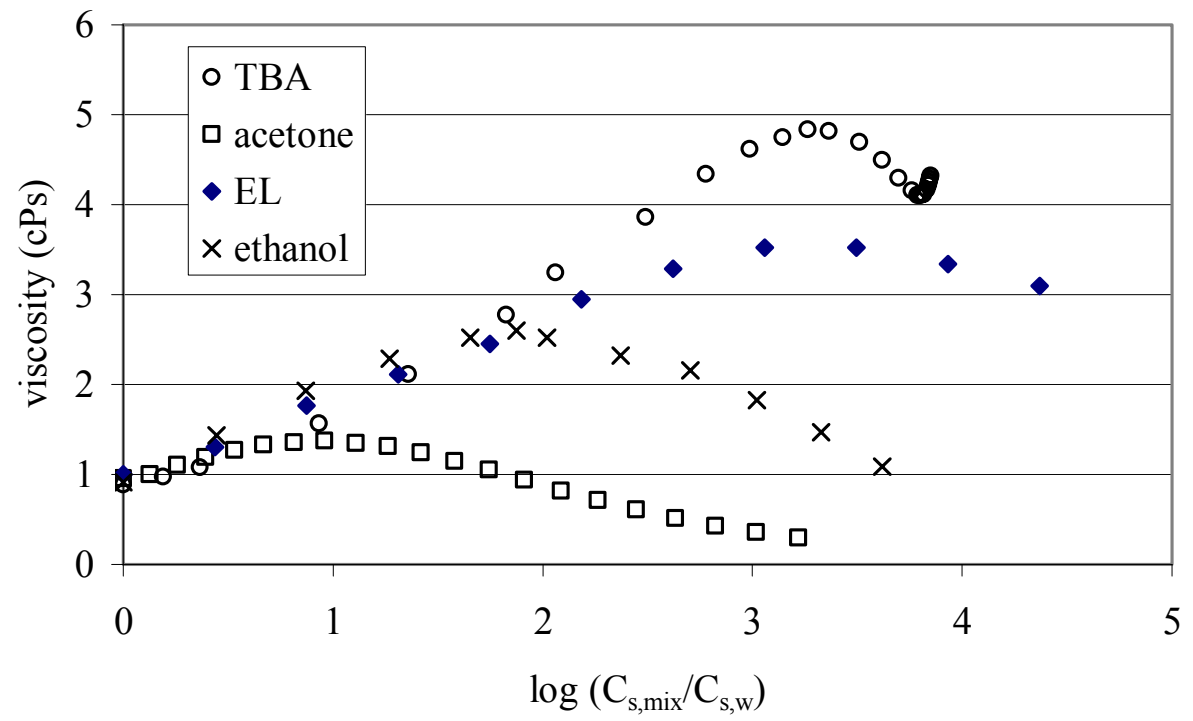

Figure 3-7. Viscosity of binary solvent systems of water and TBA (Kipkemboi and Easteal, 1994), acetone (Ovchinnikova, 1982), EL (this study), or ethanol (Belda et al., 2004) versus the $\log$ normalized solubility $\left(\mathrm{C}_{\mathrm{m}}{ }^{\mathrm{s}} / \mathrm{C}_{\mathrm{w}}{ }^{\mathrm{s}}\right)$.

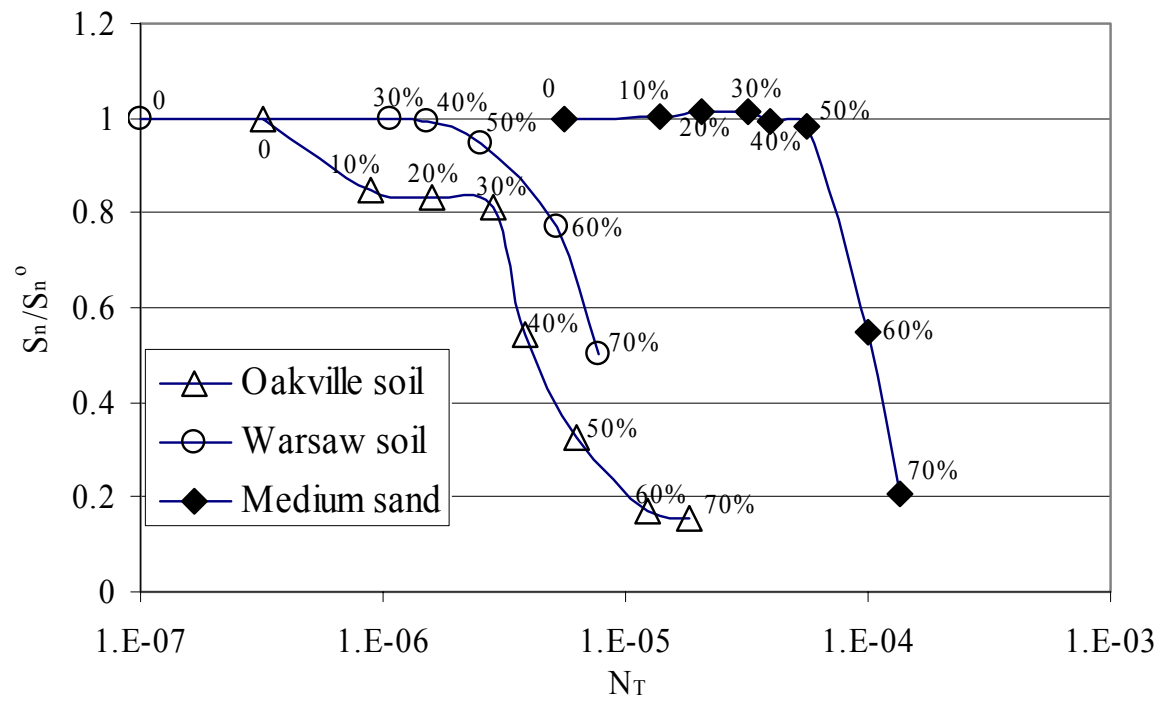

Figure 3-8. PCE residual saturation after flushing relative to initial PCE residual saturation $\left(S_{n} / S_{n}{ }^{0}\right.$, ) versus total trapping number $\left(N_{T}\right)$ with different volume fraction (data label) of ethyl lactate for three media. 


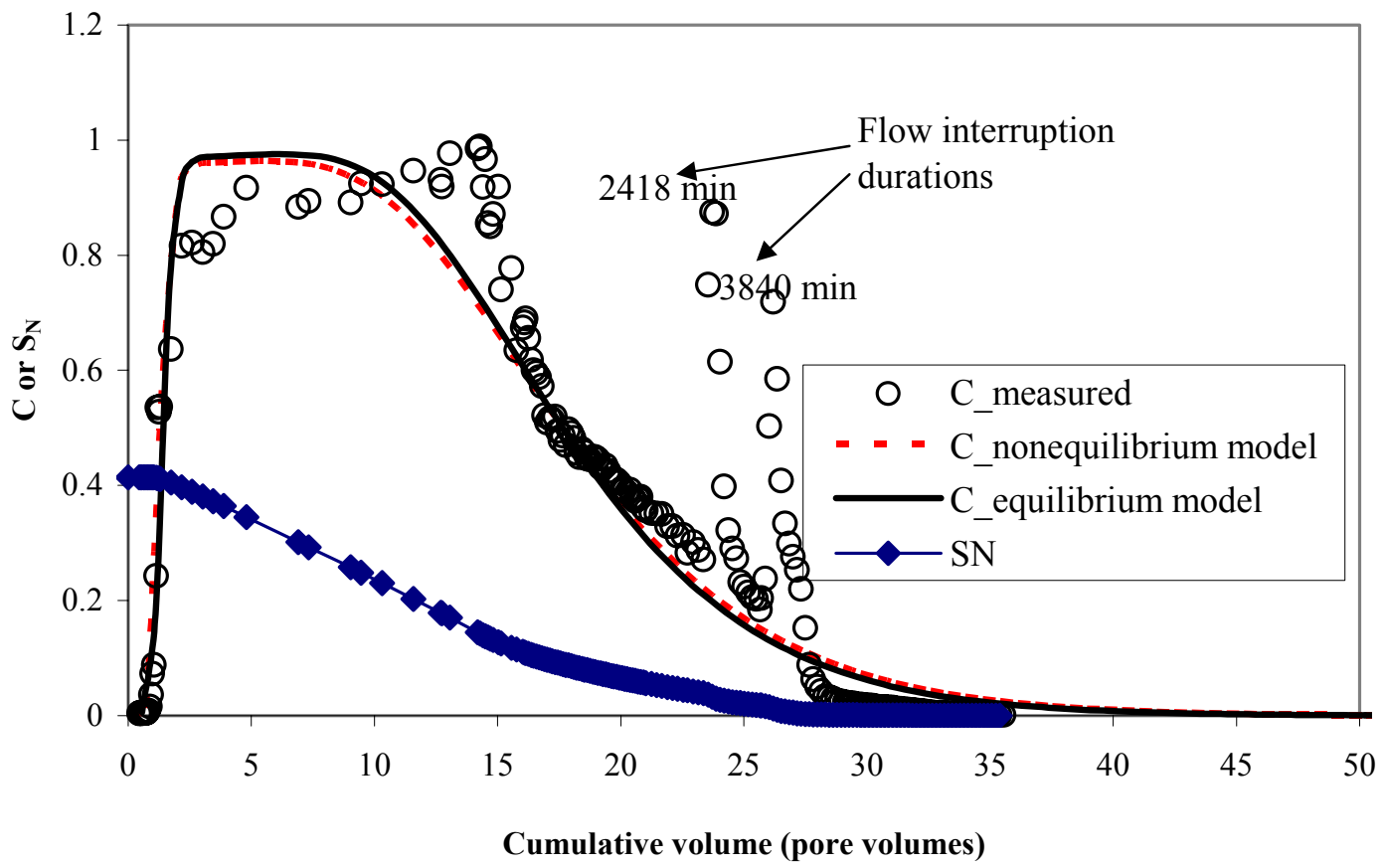

Figure 3-9. PCE concentration relative to solubility in $50 \%$ ethyl lactate $\left(C / C_{m}{ }^{s}\right)$ and average PCE residual saturation ( $S_{n}$ calculated based on PCE mass) during cosolvent flushing. 


\section{Chapter 4. Impact of Ethyl Lactate Residuals on Biodegradation of a PCE Plume}

Xihong Zhai, Jaesun Lee, Linda S. Lee, Larry Nies, and P. Suresh C. Rao,

\subsection{Introduction}

The success of alcohols and surfactants as solubility enhancers for in-situ flushing has been demonstrated in several field studies (Falta et al. 1999; Jawitz et al. 1998b; Jawitz 2000; Ramsburg et al. 2004; Rao et al. 1997), but concerns remain about the regulatory permitting and the risks from residual cosolvents (or surfactants) left in the target remediation zone. Field studies at Hill AFB, UT and in Jacksonville, FL (Sillan et al., 1998; Rao et al., 1997) conducted in-situ flushing with food-grade ethanol, because of concerns with additives or "contaminants" in non-food-grade ethanol. Generally, for similar reasons, food-grade surfactants are preferred (ITRC, 2003; Ramsburg et al., 2004) for in-situ flushing. For both ethanol and some surfactants, it has been shown that the residual alcohol (or surfactant byproducts) can stimulate microbial activity, and serve as electron donors to enhance microbial reductive dechlorination at DNAPL sites (Mravik et al., 2003; Ramsburg et al., 2004).

Although ethanol is currently the most common in-situ flushing cosolvent for NAPL source zones, there is increasing interest in using ethyl lactate. Ethyl lactate (ethyl 2hydroxypropionate, EL) is derived from cornstarch or other renewable carbohydrates (NTEC Versol $^{\mathrm{TM}}$, Versol Inc., Mt. Prospect, IL). It is the ethyl ester of natural L (+) lactic acid, produced by fermentation from sugar. It is a clear and colorless liquid of low volatility and is completely miscible with water and most organic solvents. It is nontoxic, hydrolyzes to known biodegradable intermediates and is currently being used as a replacement for a chlorinated solvents used in degreasing metal parts during manufacturing (Trychta et al., 1999). It is also used as a synthetic flavoring for cheese, animal feed, and beer in addition to a solvent degreaser for machine parts. Until recently, EL was too costly to use as a routine solvent; however, an improved purification process developed by Argonne National Labs has made it more economical (Biocycle, 1999 June, page 21). The ester group in EL hydrolyzes in water; however, this hydrolysis step is generally slow. For example in a 50/50 EL/water at room temperature, it takes about 5 days before any drop in $\mathrm{pH}$, which would be induced by the production of an acid during hydrolysis, is noticeable. The rate of hydrolysis accelerates with increasing temperature and at $\mathrm{pH}$ values below 5 and above 8 (NTEC Versol).

Work on the degradation pathway of ethyl lactate by naturally occurring microorganisms is sparse; however, the likely path starts with the hydrolysis of EL to lactate 
and ethanol (Figure 4-1). Either lactate or ethanol could be indirectly used by halorespiring organisms. Degradation of ethanol and lactate has been previously characterized in anaerobic systems. Lactate is commonly used as an electron donor for reductive dehalogenation (Bagley and Gossett, 1990, Ballaprogada et al., 1997; Carr and Hughes, 1998; de Bruin et al., 1992; Fennell and Gossett, 1997; Pampel and Livingstone, 1998; Scholz-Muramatsu et al., 1995). Both ethanol and lactate can be fermented to propionate and then to acetate and hydrogen gas; these fermentation products are known to further enhance reductive dechlorination (Panciera et al., 2001; Ridgway, 2001; Gottschalk, 1986).

Given that EL is nontoxic, residual amounts may be left in the subsurface after source zone flushing. Residual EL and its metabolites may serve as a substrate for indigenous microorganisms to induce anaerobic conditions and enhance in-situ reductive dehalogenation. Reductive dehalogenation is the removal of a halogen from a halogenated molecule with concurrent addition of electrons to that molecule. This occurs by the transfer of electrons from an electron donor to an electron acceptor. Microbial-mediated reductive dechlorination involves the step-wise reduction of chlorinated solvents to non-toxic end products that is, ethane and ethane by replacing a chlorine atom with a hydrogen atom, and releasing a chloride ion into solution (Fiacco Jr. et al, 2001). Reductive dehalogenation of perchloroethene (PCE a/k/a tetrachloroethene), one of the most commonly studied chlorinated contaminant, is well defined. PCE is dehalogenated to trichloroethene (TCE), then anaerobic TCE degradation occurs and sequentially reduces to the dichloroethene (DCE) isomers, chloroethene (CE, or VC), and ethene in microbial systems (Figure 4-2). Lower substituted ethenes can be oxidized under aerobic conditions; however, more highly substituted ethenes such as PCE and TCE require anaerobic conditions for microbial reductive dehalogenation and halorespiration to occur (Panciera et al., 2001). Reductive dechlorination of TCE and/or PCE using native microorganisms often stalls at dichloroethene (DCE) or vinyl chloride because of a slow reaction rate and/or the lack of appropriate dechlorinating bacteria (Weidemeier et al., 1999). Many investigations have found that many chlorinated compounds, such as PCE and trichloroethene (TCE), can be degraded by indigenous microorganisms and that dahalogenation upon addition of various carbon sources is enhanced (Panciera et al., 2001). This approach has the potential to increase the naturallyoccurring degradation rate at many sites without any long-term operating costs except monitoring (Newell et al., 2001). Recently, Jayaraj et al. (2004) showed that EL did promoted microbial dechlorination of PCE in static laboratory-scale microcosms, but not to complete mineralization. North et al. (2001) injected a time-release source of lactic acid 
$\left(\mathrm{HRC}^{\mathrm{TM}}\right)$ into a plume of PCE-contaminated ground water in a shallow aerobic aquifer beneath a dry cleaning facility. This resulted in a significant increase in the rate of biologically-mediated degradation of PCE and its daughter products and a greater than $95 \%$ reduction in PCE concentration near the source area in 12 months. They also found that the injection of a lactic acid source created an anaerobic and nutrient-rich environment, thus accelerating reductive dechlorination. Results indicate that accelerated degradation of contaminants can be achieved although the exact degradation pathway for lactate by dechlorinating microorganisms is unknown. Whether or not leaving EL residuals under dynamic conditions would ultimately yield complete mineralization or if it too would stall at undesirable metabolites within a targeted timeframe are still unknown.

As previously noted, highly chlorinated organic compounds are not utilized by aerobes. Several research groups have focused on the isolation of reductive dehalogenating bacteria in pure and mixed cultures and several bacterial species have been isolated (Gerritse et al., 1999; Gerritse et al., 1996; Holliger et al., 1993; Krumholz et al., 1996; Maymo-Gatell et al., 1997; Scholz-Muramatsu et al., 1995). The number of enriched culture of anaerobic bacteria that can dechlorinate PCE and TCE have been reported by Mangnuson et al. (2000), and research on isolated microorganisms and molecular biological studies of dechlorination enzyme system is ongoing. Tables 4-1 and 4-2 summarize the reductive dechlorinating species isolated in pure culture and mixed culture. As shown, the complete dehalogenation of PCE to ethene is not likely happen in most pure cultures, suggesting that different microbial community would be responsible for each dehalogenation reaction $(\mathrm{PCE} \rightarrow \mathrm{TCE} \rightarrow \mathrm{DCE} \rightarrow$ $\mathrm{VC} \rightarrow$ ethene).

The level of understanding of the microbiology of reductive dehalogenation has evolved over a relatively recent period. This has provided the basis for utilizing reductive dehalogenation for monitored natural attenuation, permeable barriers, passive treatment systems, and active remediation systems for migration of chlorinated solvents outside source area (Norris, 2001). The natural attenuation or reductive dehalogenation processes, in which the chlorinated compounds serve as electron acceptors, require or are favored by microorganisms specific to the desired degradation pathway, the near absence of dissolved oxygen, low redox potential, near neutral $\mathrm{pH}$, presence of sufficient electron donors, low to moderate levels of dissolved hydrogen, low nitrate, and maybe low sulfate (Norris et al., 2001). Enhanced bioremediation of chlorinated solvents is based on enhancing or creating these conditions. It has generally been regarded that microbial methods are only effective in 
treating the resulting plume from DNAPL dissolution rather than the DNAPL itself (Cherry et al., 1996; NRC, 1999), because saturated aqueous concentrations of PCE of TCE are likely to be toxic to dehalogenating bacteria (Lee et al., 1998; Distefano et al., 1992).

We propose that ethyl lactate is an optimal cosolvent choice for remediation of DNAPL-contaminated sites. The advantages of using ethyl lactate include the following: (1) ethyl lactate is classified as a non-toxic, non-hazardous product by OSHA; (2) ethyl lactate is completely miscible in all proportions with water; and (3) ethyl lactate breakdown yields biodegradable products that are generally nontoxic to microorganisms, and therefore a residual amount of solvent remaining the flushed zone may also serve as a substrate to induce microorganisms for enhanced reductive dehalogenation (Gerritse et al., 1995; Gibson and Sewell, 1992; Kastner, 1991; Ridgway, 2001). In Chapter 3, we demonstrated the effectiveness of ethyl lactate at solubilizing DNAPL and reducing DNAPL mass in a source zone. In this chapter, we investigate the effect of residual ethyl lactate on biodegradation of PCE compared to ethanol (currently the most commonly used cosolvent) in batch microcosm studies and in the columns packed with soil from an old dry-cleaner site now owned by INDOT.

\subsection{Material and Methods}

\section{Microcosm study}

A preliminary microcosm study was conducted prior to the 1-D column biodegradation experiment. Soil samples were taken at 1.3-2.7 $\mathrm{m}$ (4 8 feet) below ground from a former dry cleaner site (primary contaminant of concern is PCE) in Crawfordsville, $\mathrm{IN}$, and stored at $4^{\circ} \mathrm{C}$. Microcosms were set up in 160-mL serum bottles sealed with Teflonfaced septa caps. Each serum bottle contained $50 \mathrm{~mL}$ of $\mathrm{pH}$ buffer solution $(1000 \mathrm{mg} / \mathrm{L}$ $\mathrm{K}_{2} \mathrm{HPO}_{4}, 500 \mathrm{mg} / \mathrm{L} \mathrm{KH}_{2} \mathrm{PO}_{4}, 100 \mathrm{mg} / \mathrm{L} \mathrm{NH}_{4} \mathrm{Cl}$, and several drops of $\mathrm{NaOH}$ to adjust $\mathrm{pH}$ to 7.2), about $60 \mathrm{~g}$ of soil, purged with nitrogen, and amended with $\sim 5 \mathrm{mg}$ of PCE. Bottles had approximately $84 \mathrm{~cm}^{3}$ of nitrogen-filled head space after additions of soil and solution. Three sets of microcosms were prepared in anaerobic chamber: (1) Control: autoclaved soil $+\mathrm{pH}$ buffer solution + PCE; (2) no EL: soil + pH buffer solution + PCE; and (3) $0.5 \mathrm{~mL}$ ethyl lactate $(1 \%)+$ soil + pH buffer solution + PCE.

Upon adding PCE, the bottles were covered with aluminum foil to avoid exposure to light, and shook vigorously $(220 \mathrm{rpm})$ for 5 hours to facilitate PCE distribution between phases, and stored in the dark upside down with caps merged in water. All sets were prepared 
in triplicate. Samples were taken every two days with a $2.5-\mathrm{mL}$ glass syringe (Hamilton gastight) and 22 gauge sterilized needle. One $\mathrm{mL}$ of aliquot was taken out of each bottle and passed through a 0.45 PTFE syringe filter into a $250-\mu \mathrm{L}$ glass insert within a $2-\mathrm{mL}$ autosampler vial. Samples were then analyzed on GC-FID for PCE, TCE, cis-DCE, and VC.

\section{PCE biodegradation in 1-D column}

Three sets of columns were set up in parallel to compare the impact of residual EL or ethanol on PCE biodegradation. Two autoclaved borosilicate glass columns (Western Analytical) were coupled together for each column set up, which allowed easy sampling at the adjoining points (schematic shown in Figure 4-3). Soil taken from a former dry-cleaner site in Crawfordsville, IN was stored at $4^{\circ} \mathrm{C}$ prior to use, and dry-packed into the columns in nitrogen-filled anaerobic chamber. Three different solutions (Table 4.3) (made with local groundwater filtered with $0.2 \mu \mathrm{m}$ filter) were flushed through the three sets of columns, respectively. Two syringe pumps with three $50-\mathrm{mL}$ gas-tight syringes were used to deliver the solutions at the flow rate of $0.01 \mathrm{~mL} / \mathrm{min}$. The pore volumes of the three columns sets were between $29 \mathrm{~mL}$ and $35 \mathrm{~mL}$ (see Table 4-3), as determined by a partitioning tracer test performed at the beginning of the experiment, which allowed estimates of the residence time within each column system of 2.2 days to 3.5 days (Table 4-3). The columns were covered with aluminum foil to avoid exposure to light. After column flushing for 15 days, gas bubbles were observed in the outlet tubing, which caused the in-line sampling system to collect gas rather than liquid samples. Samples were then collected manually a placed in a $100-\mu \mathrm{L}$ glass insert within 2-mL GC auto-sample vials. Results from a test where in-line sampling was done simultaneously with manual sampling showed similar results within less than $10 \%$.

Columns were flushed for a total of 28 days followed by extraction of the column soils with methanol to recover the chlorinated compounds in both the pore water and sorbed to soil. To get a higher resolution, each column couple was sectioned into five segments, with 2 segments in the first column and 3 segments in the second one (Figure 4-3). Each soil segment was homogenized in beakers and subsampled for methanol extraction and DGGE (Denaturing gradient gel electrophoresis) analysis to look for differences in bacteria type and diversity that may have evolved from the different solutions. 


\subsection{Results and Discussion}

\section{Microcosm Biodegradation Study}

The batch microcosm was conducted to qualitatively assess the bioactivity of the soil to be used in the 1-D column studies. The microcosms that were amended with an aqueous solution of $1 \%$ EL had significant production of cis-DCE starting on day 4 with a concentration plateau on day 5 . By day $8,84.7 \%( \pm 2.9 \%)$ of total PCE added to the microcosms was captured as $c i s-\mathrm{DCE}$ with the $1 \%$ EL amendment. In the autoclaved control microcosms and those without any electron donor, no chlorinated solvent other than PCE was detected. Measured aqueous phase concentrations, the Henry's constants, and the sorption coefficients of PCE and cis-DCE were used to calculate total PCE and DCE mass in the serum bottle. The total mass within each serum bottle compared with the initial PCE mass on day 8 are shown in Figure 4-4. Good mass balance $(101.5 \% \pm 16.2 \%)$ was observed in all microcosms. The microcosm study suggested that there are native microbial communities amenable to reductive dechlorination in the soil if sufficient electron donor (EL in this case) is available.

\section{PCE dechlorination in 1-D columns}

The PCE concentration in the feeding solutions decreased over time (Figure 4-5) to simulate the diminishment of the source zone mass flux as DNAPL is depleted (Falta et al., 2005). A pressure build-up was noted in the columns as evidence of eruptible flow into the vials immediately after switching the three-way valve between the two columns to sample the middle port. The possible gas product may be methane and/or hydrogen (Jayaraj et al., 2004; Ridgway, 2001). No quantitative measurement of gas pressure was attempted.

TCE was detected sporadically in samples from all three column sets at concentrations below the calibration limit (1 20 mg/L), thus considered negligible for inclusion in mass balance calculations. It is generally agreed that the transformation from TCE to cis-DCE is fairly fast so that no significant appearance of TCE can be observed during biodechlorination of PCE (Bradley, 2003; Christ et al., 2005). The breakthrough curve of cis-DCE and PCE at the middle sampling ports and at the end of all three column sets are shown in Figure 4-6. In the column couple fed without electron donor, cis-DCE was only detected occasionally in both the middle and the end sampling ports and at very low concentrations $(0.003 \mathrm{mM})$ (Figure 4-6a and d). For the EL-fed column couple, cis-DCE appeared consistently in both of the middle and end sampling ports, with the concentration measured for the middle and end ports stabilizing around $0.04 \mathrm{mM}$ (Figure 4-6b) and 0.05 
$\mathrm{mM}$, respectively (Figure 4-6e). The highest $c i s$-DCE concentration of $0.102 \mathrm{mM}$ was observed at the end of the EL column after 5.8 pore volumes (Figure 4-6e) in response to the higher PCE concentration in the feeding solution (Figure 4-6b). In the ethanol-fed column couple, $c i s-\mathrm{DCE}$ was consistently detected in the middle sampling port with concentrations increasing gradually from $0.01 \mathrm{mM}$ to $0.028 \mathrm{mM}$ (Figure 4-6c), and eventually began to appear at the end port at low concentrations $(0.003 \mathrm{mM})$ (Figure 4-6f). By comparing the BTC of cis-DCE in the middle and the end ports of all three column sets, it is clear that the low concentration of EL $(1.21 \mathrm{mM})$ promoted the bioactivity in the soil considerably with enhanced dechlorination of PCE to cis-DCE. Ethanol at equivalent concentrations can also enhance PCE biodechlorination, but not as efficient as EL; reasons include the possible need for a longer acclimation time (Ridgway, 2001).

There are two possible reasons as to why further dechlorination after cis-DCE was not observed. First, the hydraulic residence time may not have been sufficient to allow reduce. Zheng et al (2001) studied the influence of hydraulic retention time on extent of PCE dechlorination and found out that it stopped at $c i s$-DCE when the residence time was 2.9 days, which is about the same as in this study, and that vinyl chloride (VC) and ethane were detected as end product when the residence time was 11 days. However, our batch microcosm study lasted over three weeks, and cis-DCE was still found to be the only dechlorination product. Therefore, insufficient residence time is unlikely to be the cause of incomplete dechlorination of PCE in our study. Secondly, the soil may lack the right bacteria species needed to completely transform DCE to ethene. It has been commonly observed that the dechlorination of PCE in many field sites ends up with accumulation of cis-DCE. Major et al. (2002) study concluded that only when dehalococcoides was present did complete dechlorination of PCE or TCE to ethane occur in natural systems.

The PCE effluent concentrations at the end of all three column couples were similar, although a significant fraction of PCE in the EL column was transformed to cis-DCE. This is likely due to the large retardation factor of PCE (10, See Table 4-3), which caused most of the PCE to be sorbed to soil with only a small fraction existing in the aqueous phase such that the dechlorination within the column did not lead to an obvious change in PCE effluent concentrations (Figure 4-7 and Figure 4-8). The PCE effluent concentration was further complicated by the variation in concentration of the feeding solution.

The chlorinated solvents recovered through extraction of the column soils included cis-DCE and PCE, and very small amount (less than 0.001 mmole) of TCE in both EL and EtOH columns (Figure 4-7b and c), whereas only PCE was seen in the NoED column (Figure 
4-7a). This is in good agreement with the retardation factor of the three compounds (Table 43 ) and the dechlorination process in three column sets: stronger biodegradation activity resulted in transformation of the more highly retarded PCE to the less retarded cis-DCE. The mass of each compound recovered at the end sampling ports and extracted from the soil in each column couple is summarized in Figure 4-9a and $b$. The fraction of the total chlorinated solvents recovered from the column effluent is positively correlated to the amount of cisDCE produced since cis-DCE has a much smaller retardation factor than PCE. In the NoED column, there was basically no dechlorination, and PCE was the only chlorinated constituent detected, thus with PCE's large retardation factor, 2/3 of the total mass resided in the soil phase. In the EL column, strong bioactivity transformed about 2/3 of total PCE injected into cis-DCE, therefore more than $2 / 3$ of the total chlorinated solvents were recovered in the column effluent. As for the EtOH column, less than half of the total mass of chlorinated solvents was recovered in the column effluent.

EL and ethanol concentrations were also monitored in the feeding solution and the middle and end sampling ports (Figure 4-8). EL hydrolyzes into ethanol and lactate, resulting in considerable amount of ethanol $(0.623 \mathrm{mM})$ detected in the feeding solution of EL column. But ethanol soon disappeared in the middle sampling ports in both EL and EtOH columns, indicating that ethanol was consumed by the bacteria very quickly. On the other hand, EL concentrations decreased gradually from the feeding solution to the middle, and still appeared at the end of the EL column. It was argued that through a slow hydrolysis process, EL releases ethanol and lactate gradually (Haselow, 2005) enabling it to sustain some bioactivity throughout all three coupled columns. In the ethanol-fed columns, most likely only bacteria in the first column had ethanol to utilize as an energy source with the next two columns having to use acetate, which is a potential ethanol metabolite (Ridgway, 2001) that was not monitored in our study, or have no energy source. Previous research indicated that the predominant ethanol degradation pathway is through the production of propionate through succinate using the hydrogen released from the oxidation of acetate, which has a no net-yield of reducing equivalents (Ridgway, 2001; Schink et al., 1985).

At the end of the experiments, both the EL and EtOH columns were black and the NoED column was a grayish brown (Figure 4-10). During sampling of the soil from the columns, a strong pungent $\mathrm{H}_{2} \mathrm{~S}$-like odor was noted in the EL and EtOH columns. The black color may be a reduced manganese precipitate or a sulfide precipitate, but no metal analysis was performed for confirmation. The DGGE analysis of the soil samples from all three 
columns indicated that the microbial populations did evolve differently among these three column sets with the EL column exemplifying the most diversity (Figure 4-11).

\subsection{References}

Bagley, D.M., and Gossett, J.M. (1990). "Tetrachloroethene transformation to trichloroethene and cis-1,2-dichloroethene by sulfate-reducing enrichment culture." Appl. Environ. Microbiol., 56(8), 2511-2516.

Ballapragada, B.S., Stensel, H.D., Puhakka, J.A., and Ferguson, J.F. (1997). "Effect of hydrogen on reductive dechlorination of chlorinated ethenes." Environ. Sci. Technol., 31(6), 1728-1734.

Biocycle, "Ethyl lactate at a Lower Cost." June, 1999, p21.

Carr, C.A., and Hughes, J.P. (1998). "Enrichment of high-rate PCE dechlorination and comparative study of lactate, methanol, and hydrogen as electron donors to sustain activity." Environ. Sci. Technol., 32(12), 1817-1824.

De Bruin, W.P., Kotterman, M.J.J., Posthumus, M.A., Schraa, G., and Zehnder, A.J.B. (1992). "Complete biological reductive transformation of tetrachloroethene to ethane." Applied and Environmental Microbiology, 58(6), 1996-2000.

DiStefano, T.D., Gossett, J.M., and Zinder, S.H. (1992). "Hydrogen as an electron donor for dechlorination of tetrachloroethene by an anaerobic mixed culture." Applied and Environmental Microbiology, 58(11), 3622-3629.

Falta, R. W., Lee, C. M., Brame, S. E., Roeder, E., Coates, J. T., Wright, C., Wood, A. L., and Enfield, C. G. (1999). "Field test of high molecular weight alcohol flushing for subsurface nonaqueous phase liquid remediation." Water Resources Research, 35(7), 2095-2108.

Fennell, D.E., and Gossett, J.M. (1997). "Comparison of butyric acid, ethanol, lactic acid, and propionic acid as hydrogen donors for the reductive dechlorination of tetrachloroethene." Environmental Science and Technology, 1997(31), 918-926.

Fiacco, Jr. R. J., Demers, G. A., Brown, R. A., Skladany, G., and Robinson, D., (2001). A comparison of chemical oxidation and biological reductive dechlorination technologies for the treatment of chlorinated solvents, Anaerobic Degradation of Chlorinated Solvents, $45 \mathrm{p}$.

Gerritse, J., Drzyzga, O., Kloetstra, G., Keijmel, M., Wiersum, L.P., Hutson, R., Collins, M.D., and Gottschal, J.C. (1999). "Influence of different electron donors and acceptors on dehalorespiration of tetrachloroethene by Desulfitobacterium frappieri TCE1." Applied and Environmental Microbiology, 65(12), 5212-5221.

Gerritse, J., Renard, V., Gomes, T.M.P., Lawson, P.A., and Gottschal, J.C. (1996).

"Desulfitobacterium sp. Strain PCE1, an anaerobic bacterium that can grow by reductive dechlorination of tetrachloroethene of ortho-chlorinated phenols." Arch Microbiol, 165, 132-140.

Gerritse, J., Renard, V., Visser, J., and Gottschal, J. C. (1995). "Complete Degradation of Tetrachloroethene by Combining Anaerobic Dechlorinating and Aerobic Methanotrophic Enrichment Cultures." Applied Microbiology and Biotechnology, 43(5), 920-928.

Gibson, S. A., and Sewell, G. W. (1992). "Stimulation of Reductive Dechlorination of Tetrachloroethene in Anaerobic Aquifer Microcosms by Addition of Short-Chain Organic-Acids or Alcohols." Applied and Environ. Microbiology, 58(4), 1392-1393.

Gibson, S.A., and Sewell, G.W. (1992). "Stimulation of reductive dechlorination of tetrachloroethene in anaerobic aquifer microcosms by addition of short-chain organic acids or alcohols.” Applied and Environmental Microbiology, 58(4), 1392-1393. 
Gottschalk, G. (1986). Bacterial Metabolism, Springer-Verlag, New York.

Haselow, J. (2005). "Personal communication."

Holliger, C., Scraa, G., Stams, A.J.M., and Zehnder, A.J.B. (1993). "A highly purified enrichment culture couples the reductive dechlorination of tetrachloroethene to growth." Applied and Environ. Microbiology, 59(9), 2991-2997.

ITRC, Interstate Technology \& Regulatory Council, Dense Nonaqueous Phase Liquids Team. (2003). "Technical and Regulatory Guidance for Surfactant/Cosolvent Flushing of DNAPL Source Zones." Washington, DC.

Jawitz, J. W., Annable, M. D., Rao, P. S. C., and Rhue, R. D. (1998b). "Field implementation of a Winsor type I surfactant/alcohol mixture for in-situ solubilization of a complex LNAPL as a single phase microemulsion." Environ. Sci. \& Technology, 32(4), 523-530.

Kastner, M. (1991). "Reductive Dechlorination of Trichloroethylenes and Tetrachloroethylenes Depends on Transition from Aerobic to Anaerobic Conditions." Applied and Environmental Microbiology, 57(7), 2039-2046.

Krumholz, L. R., Sharp, R., and Fishbain, S.S. (1996). "A freshwater anaerobe coupling acetate oxidation to tetrachloroethylene dehalogenation." Applied and Environmental Microbiology, 62(11), 4108-4113.

Lee, M.D., Odum, J.M., and Buchanan, R.J., Jr. (1998). 52, 423-452.

Mangnuson, J.K., Romine, M.F., Burris, D.R. and Kingsley, M.T., (2000). Appl. Environ. Microbiol. 66, 5141-5147.

Maymó-Gatell, X., Chien, Y. T., Gossett, J.M., and Zinder, S.H. (1997). "Isolation of a bacterium that reductively dechlorinates tetrachloroethene to ethane." Science, 276(June), 1568-1571.

Middeldorp, P.J.M., Luitjen, M.L.G.C., van de Pas, B.A., van Eekert, M.H.A., Kengen, S.W.M., Schraa, G., and Stams, A.J.M. (1999). "Anaerobic microbial reductive dehalogenation of chlorinated ethenes." Bioremediation Journal, 3(3), 151-169.

Mravik, S. C., Sillan, R. K., Wood, A. L., and Sewell, G. W. (2003). "Field evaluation of the solvent extraction residual biotreatment technology." Environmental Science \& Technology, 37(21), 5040-5049.

National Research Council (NRC), (1999), In Groundwater and soil cleanup: improving management of persistent contaminants; National Academy Press: Washington, D.C, pp 113-174.

Newell, C. J., Aziz, C. E., Haas, P. E., Hughes, J. B., and Khan, T. A., (2001). Two novel methods for enhancing source zone bioremediation: Direct hydrogen addition and electron acceptor diversion, Anaerobic Degradation of Chlorinated Solvent, 19p.

North, R. W., Burkett, S. E., and Sincock, J., (2001). Effective enhancement of biological degradation of tetrachloroethene (PCE) in ground water, Anaerobic Degradation of Chlorinated Solvents, 189p.

Pampel, L.W.H., and Livingston, A. G. (1998). "Anaerobic dechlorination of perchloroethene in an extractive membrane bioreactor." Applied Microbiology and Biotechnology, 50, 303-308.

Panciera, M. A., Zelennikova, O., Smets, B. F., and Dobbs, G. M., (2001). Differential Stimulation of Haloreduction by Carbon Addition to Subsurface Soils, Anaerobic Degradation of Chloride Solvents, 69p.

Ramsburg, C. A., Abriola, L. M., Pennell, K. D., Loffler, F. E., Gamache, M., Amos, B. K., and Petrovskis, E. A. (2004). "Stimulated microbial reductive dechlorination following surfactant treatment at the Bachman Road site." Environmental Science \& Technology, 38(22), 5902-5914. 
Rao, P. S. C., Annable, M. D., Sillan, R. K., Dai, D. P., Hatfield, K., Graham, W. D., Wood, A. L., and Enfield, C. G. (1997). "Field-scale evaluation of in-situ cosolvent flushing for enhanced aquifer remediation." Water Resources Research, 33(12), 2673-2686.

Ridgway, R. M. (2001). "Anaerobic Reductive Dehalogenation of Trichloroethylene in Unacclimated Freshwater Sediments," PhD Dissertation, Purdue University.

Schink, B., Phelps, T. J., Eichler, B., and Zeikus, J. G. (1985). "Comparison of Ethanol Degradation Pathways in Anoxic Fresh-Water Environments." Journal of General Microbiology, 131(MAR), 651-660.

Scholz-Muramatsu, H., Neumann, A., Mebmer, M., Moore, E., and Diekert, G. (1995).

"Isolation and characterization of Dehalospirillum multivorans gen. nov., sp. Nov., a tetrachloroethene-utilizing, strictly anaerobic bacterium." Arch. Microbiol., 163, 48-56.

Sillan, R.K., M.D. Annable, and P.S.C. Rao. (1998a). In-situ Cosolvent Flushing for Enhanced Solubilization of a Complex LNAPL: Comprehensive Field Scale Evaluation. USEPA-SERDP-Air Force Project Final Report.

Trychta, K., Sandburg, D. A., Henry, M., and Datta, R. (1999). "Evaluation of environmentally benign green solvent Versol ethyl lactate for machine shop parts cleaning and degreasing." Argonne National Laboratory. 
Table 4-1. Summary of PCE reductive dehalogenation of pure cultures (Modified from Ridgway, 2001)

\begin{tabular}{|c|c|c|c|}
\hline Species & e- donor used & e- acceptor used & Dechlorination \\
\hline $\begin{array}{l}\text { Dehalobacter } \\
\text { restrictus }\end{array}$ & $\mathrm{H}_{2}$ & $\begin{array}{c}\text { 1.1.1.1.1.1. PCE, } \\
\text { TCE } \\
\left(\mathrm{O}_{2}, \mathrm{NO}_{3}^{-}, \mathrm{NO}_{2}{ }^{-}, \mathrm{SO}_{4}{ }^{2-}\right. \\
, \mathrm{SO}_{3}{ }^{2-}, \mathrm{S}_{2} \mathrm{O}_{3}{ }^{2-}, \mathrm{S} \\
\left.\mathrm{CO}_{2}\right)\end{array}$ & $\begin{array}{l}\text { 1.1.1.1.1.2. PCE } \\
->\text { cis-DCE }\end{array}$ \\
\hline $\begin{array}{c}\text { 1.1.1.1.3. Dehalo } \\
\text { bacter } \\
\text { (Strain TEA) }\end{array}$ & $\begin{array}{c}\mathrm{H}_{2} \\
\text { (glucose, pyruvate, } \\
\text { lactate, acetate, } \\
\text { formate) }\end{array}$ & $\begin{array}{c}\text { 1.1.1.1.1.4. PCE, } \\
\text { TCE }\end{array}$ & PCE ->cis-DCE \\
\hline $\begin{array}{l}\text { Dehalospirilum } \\
\text { multivorans }\end{array}$ & $\begin{array}{c}\mathrm{H}_{2}, \text { pyruvate, lactate, } \\
\text { ethanol, formate, } \\
\text { glycerol, acetate }\end{array}$ & $\begin{array}{l}\text { PCE, fumarate, nitrate } \\
\text { (sulfate) }\end{array}$ & PCE ->cis-DCE \\
\hline $\begin{array}{l}\text { 1.1.1.1.5. Desulfit } \\
\text { obacterium } \\
\text { Frappieri } \mathrm{TCE} 1\end{array}$ & $\begin{array}{c}\mathrm{H}_{2} \text {, lactate, formate, } \\
\text { pyruvate, butyrate, } \\
\text { crotonate, ethanol, } \\
\text { serine }\end{array}$ & $\begin{array}{l}\text { PCE, TCE, nitrate, } \\
\text { sulfite, fumarate, } \\
\text { thiosulfate }\end{array}$ & PCE ->cis-DCE \\
\hline $\begin{array}{l}\text { Desulfitobacterium } \\
\text { Sp. Strain PCE } 1\end{array}$ & $\begin{array}{c}\text { L-lactate, formate, } \\
\text { pyruvate, butyrate, } \\
\text { succinate, ethanol } \\
\left(\mathrm{H}_{2}\right)\end{array}$ & $\begin{array}{c}\text { PCE, ortho- } \\
\text { chlorinated phenols, } \\
\text { sulfilte, thiosulfate, } \\
\text { fumarate }\end{array}$ & PCE -> TCE \\
\hline $\begin{array}{l}\text { Eurobacterium } \\
\text { Strain }\end{array}$ & $\mathrm{H}_{2}$ & PCE, TCE, 1,2-DCE & PCE -> VC \\
\hline $\begin{array}{l}\text { Desulfuromonas } \\
\text { chloroethenica }\end{array}$ & $\begin{array}{c}\text { 1.1.1.1.1.6. Acetate, } \\
\text { pyruvate }\end{array}$ & PCE, TCE & PCE ->cis-DCE \\
\hline
\end{tabular}


Table 4-2. Dehalogenation of PCE in mixed cultures

\begin{tabular}{|c|c|c|c|c|}
\hline Dechlorination & e- donor & Culture & Conditions & Reference \\
\hline $\mathrm{PCE} \rightarrow$ ethane & lactate $(1 \mathrm{mM})$ & $3: 1$ mixture of anaerobic sediment & fixed bed column $(25 \mathrm{~cm} \mathrm{~L}$ & de Bruin et al. 1992 \\
\hline cis DCE, $\mathrm{VC} \rightarrow$ ethene & acetate, & PCE contaminated soil + cell & Batch study carried out in & Rosner et al. 1997 \\
\hline $\mathrm{PCE} \rightarrow$ ethane & methanol & Digested sludge from wastewater & Suspended, PCE repeatedly & DiStefano et al. \\
\hline $\mathrm{PCE} \rightarrow$ ethane & methanol & - & suspended & Tandoi et al. 1994 \\
\hline $\mathrm{PCE} \rightarrow$ ethene & methanol & sludge & suspended & Freedman and \\
\hline $\mathrm{PCE} \rightarrow$ ethane & anaerobic basal & anaerobic digester sludge & column & Kaseros et al. 2000 \\
\hline PCE $\rightarrow$ ethane & yeast extract & contaminated aquifer & Suspended (CSTR) & Yang et al. 2000 \\
\hline $\mathrm{PCE} \rightarrow$ ethane & organic/oxygen, & contaminated aquifer & continuous flow column & Kao et al. 2003 \\
\hline $\mathrm{PCE} \rightarrow$ ethane & methanol, yeast & anaerobic digester/coarse silica & continuous flow column & Isalou et al. 1998 \\
\hline $\mathrm{PCE} \rightarrow$ ethane & methanol, lactate & contaminated sediment & continuous flow column & Drzyzga et al. 2002 \\
\hline $\mathrm{PCE} \rightarrow$ ethane & methanol & anaerobic digested sludge & fixed bed reactor & Cabirol et al. 1998 \\
\hline $\mathrm{TCE} \rightarrow$ ethane & methanol & contaminated sediment & batch & Bloom et al. 2000 \\
\hline $\mathrm{PCE} \rightarrow$ ethane & lactate, methanol, & Anaerobic granular & column & Carr et al. 1998 \\
\hline
\end{tabular}


Table 4-3. Summary of PCE dechlorination in 1-D columns

\begin{tabular}{|c|c|c|c|c|c|c|c|c|c|}
\hline Column ID & \multicolumn{3}{|c|}{ EL } & \multicolumn{3}{|c|}{$\mathrm{EtOH}$} & \multicolumn{3}{|c|}{ NoED } \\
\hline Compounds & PCE & TCE & $c i s-\mathrm{DCE}$ & PCE & TCE & $c i s-\mathrm{DCE}$ & PCE & TCE & cis-DCE \\
\hline $\begin{array}{c}\text { Total PCE injected }{ }^{\mathrm{a}} \\
\text { (mmole) }\end{array}$ & 0.0234 & & & 0.0233 & & & $\begin{array}{c}0.026 \\
2\end{array}$ & & \\
\hline $\begin{array}{c}\text { Recovered at the end } \\
\text { sampling ports }{ }^{\mathrm{b}} \text { (mmole) }\end{array}$ & 0.0068 & $\begin{array}{c}9.88 \mathrm{E}- \\
05\end{array}$ & 0.0147 & 0.0084 & $\begin{array}{c}3.15 \mathrm{E}- \\
05\end{array}$ & 0.0009 & $\begin{array}{c}0.007 \\
9\end{array}$ & $0.00 \mathrm{E}+00$ & 0.0002 \\
\hline $\begin{array}{l}\text { Extracted from the soil }{ }^{\mathrm{c}} \\
\qquad(\mathrm{mmole})\end{array}$ & 0.0034 & $\begin{array}{c}1.53 \mathrm{E}- \\
04\end{array}$ & 0.0053 & 0.0073 & $\begin{array}{c}6.80 \mathrm{E}- \\
04\end{array}$ & 0.0041 & $\begin{array}{c}0.017 \\
1\end{array}$ & $0.00 \mathrm{E}+00$ & 0.0000 \\
\hline $\begin{array}{l}\text { Total chlorinated solvents } \\
\text { recovered }^{\mathrm{d}} \text { (mmole) }\end{array}$ & \multicolumn{3}{|c|}{0.030} & \multicolumn{3}{|c|}{0.021} & \multicolumn{3}{|c|}{0.025} \\
\hline Recovery mass balance $^{\mathrm{e}}$ & \multicolumn{3}{|c|}{$130.2 \%$} & \multicolumn{3}{|c|}{$91.9 \%$} & \multicolumn{3}{|c|}{$95.9 \%$} \\
\hline $\begin{array}{l}\text { PCE First-order decay } \\
\text { constant }(1 / \mathrm{yr})\end{array}$ & \multicolumn{3}{|c|}{-153.41} & \multicolumn{3}{|c|}{-32.54} & \multicolumn{3}{|c|}{-1.27} \\
\hline Retardation factor & 10 & 3 & 2 & 10 & 3 & 2 & 10 & 3 & 2 \\
\hline
\end{tabular}

Notes: ${ }^{\mathrm{a}}$ integration of the curves in Figure $4-5 ;{ }^{\mathrm{b}}$ integration of the curves in Figure 4-6d, e, and $\mathrm{f} ;{ }^{\mathrm{c}}$ integration of the curves in Figure $4-7 ;{ }^{\mathrm{d}}$ summation of row 4 and row $5 ;{ }^{\mathrm{e}}$ row 6 over row 3. 


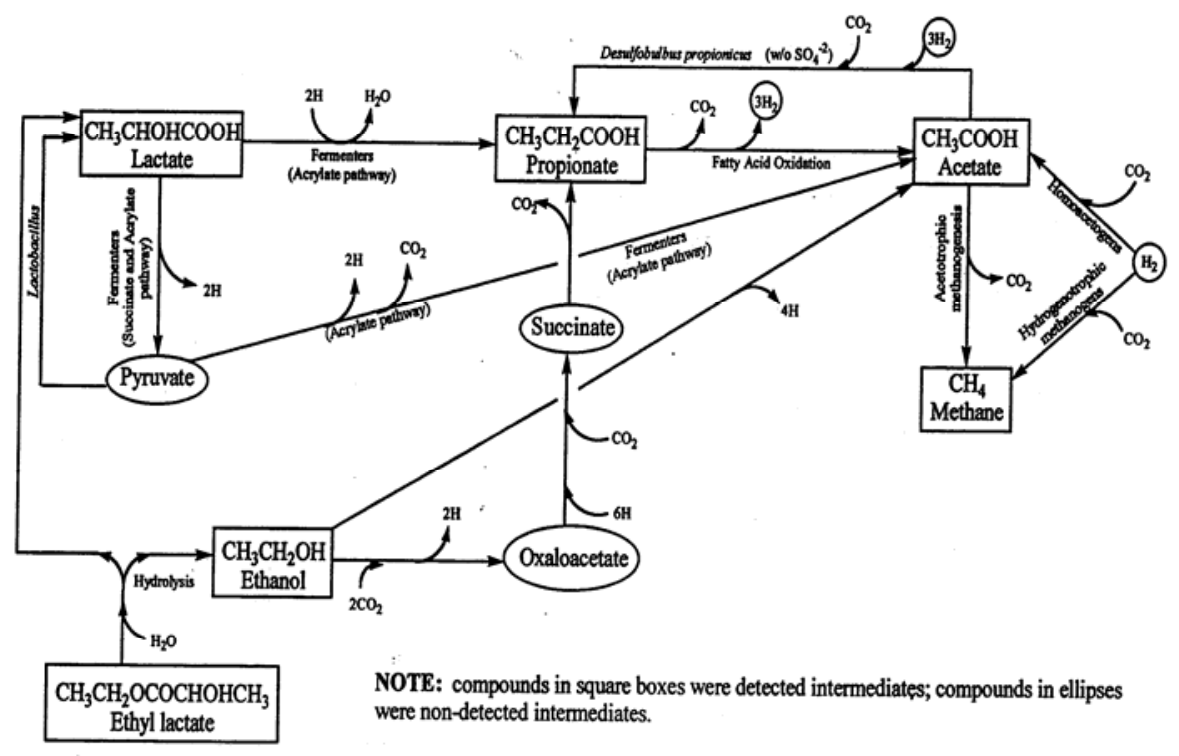

Figure 4-1. Metabolic pathway for the anaerobic degradation of ethyl lactate (Ridgway, 2001)

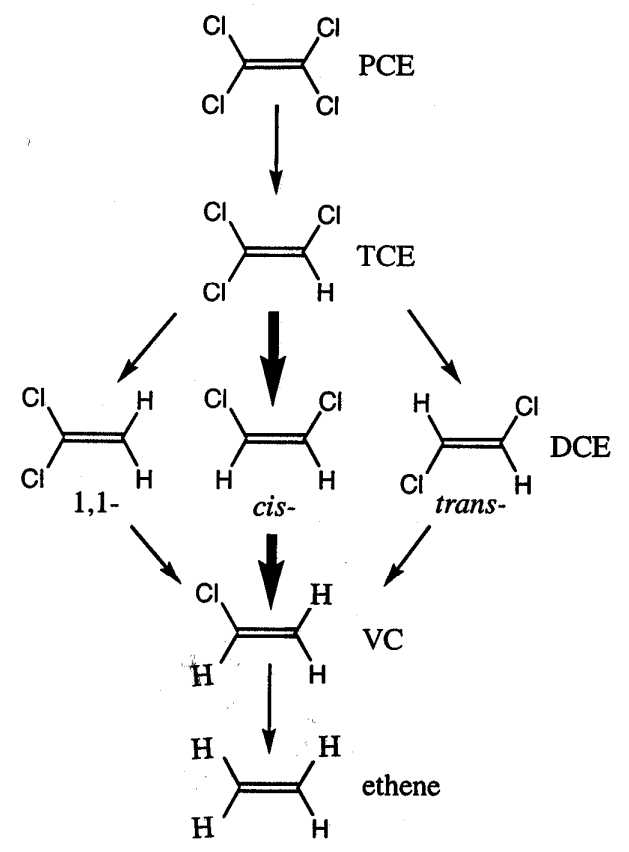

Figure 4-2. Microbial Dechlorination Pathway of PCE to Ethene (Middeldorp et al., 1999) 


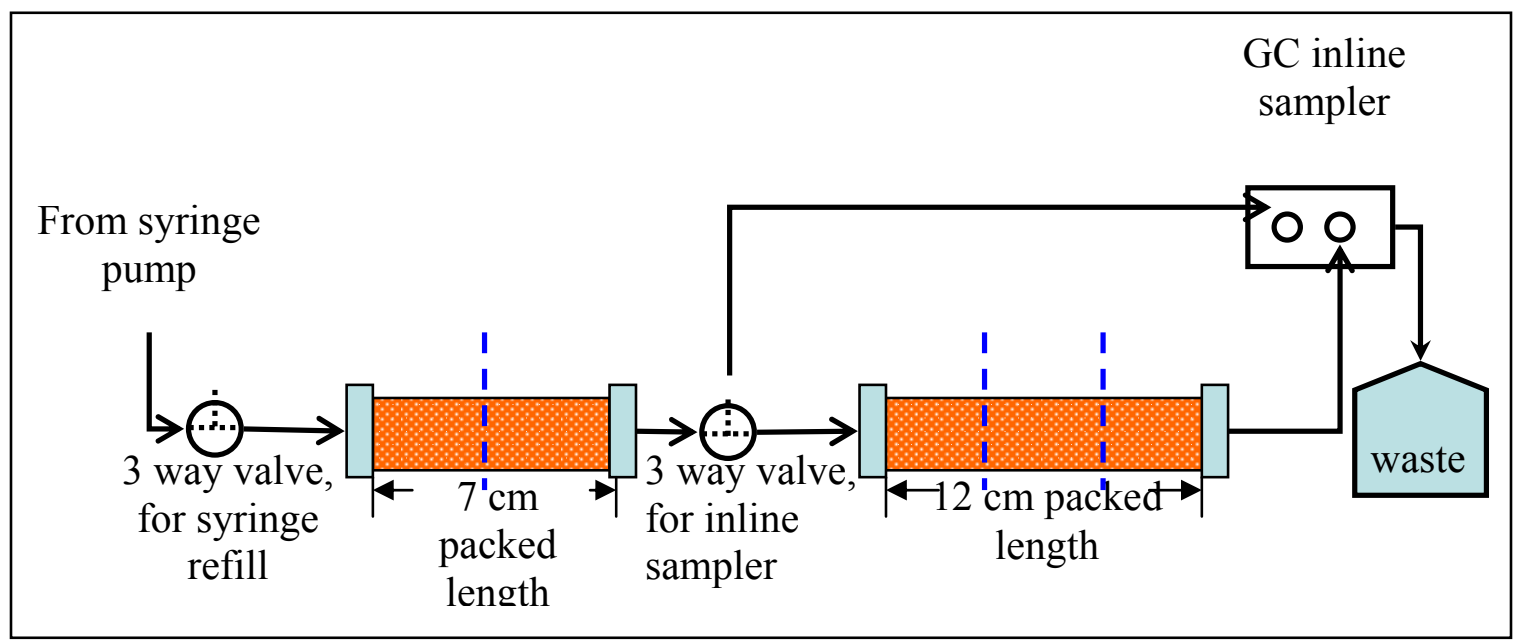

Figure 4-3. Schematic of 1-D column biodegradation experiment set up. Blue dashed lines indicate the sectioning scheme of the columns at the end of the experiment.

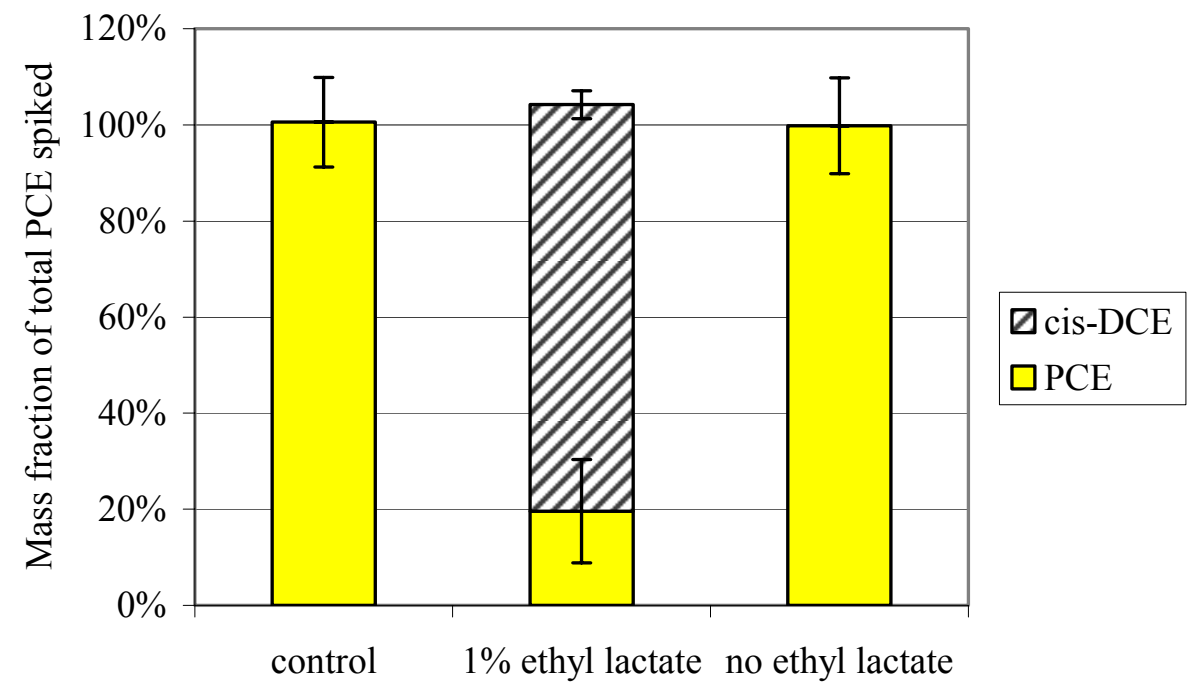

Figure 4-4. Mass distribution of chlorinated solvents after 8 days in soil microcosms. 

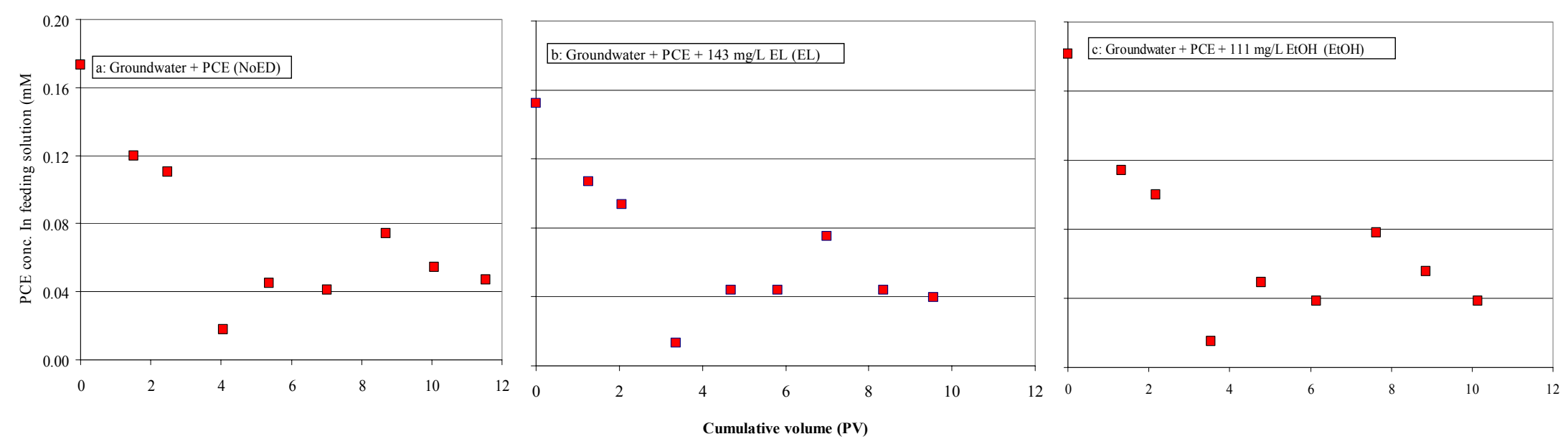

Figure 4-5. Concentration of PCE in the feeding solution in (a) NoED column, (b) EL column, and (c) EtOH column. 

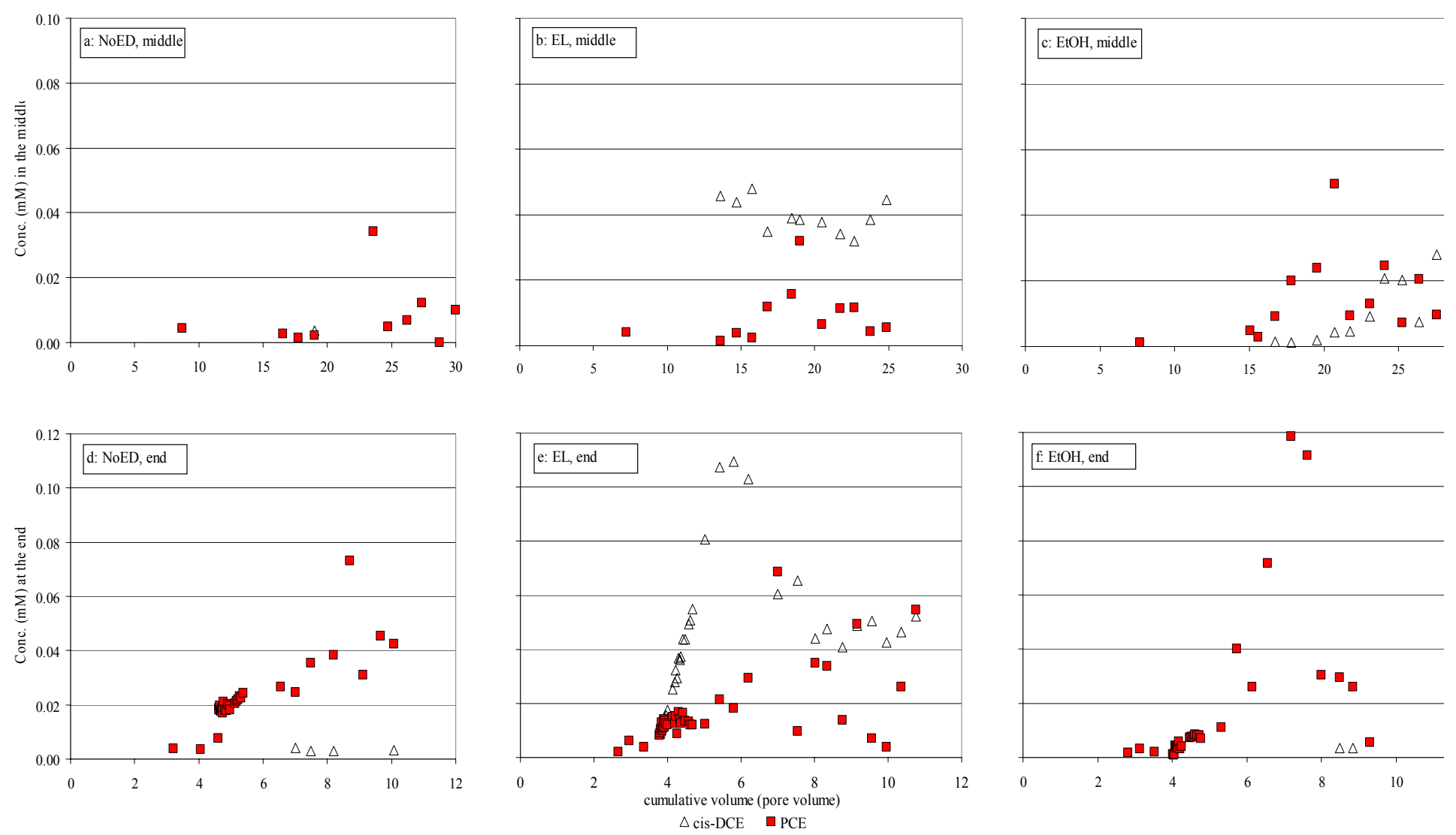

Figure 4-6. Breakthrough of cis-DCE (open triangles) and PCE (filled squares) in the middle sampling ports of (a) ${ }^{\cdots}$ D column, (b) EL column, and (c) EtOH column, and at the end sampling ports of (d) NoED column, (e) EL column, f) EtOH column 

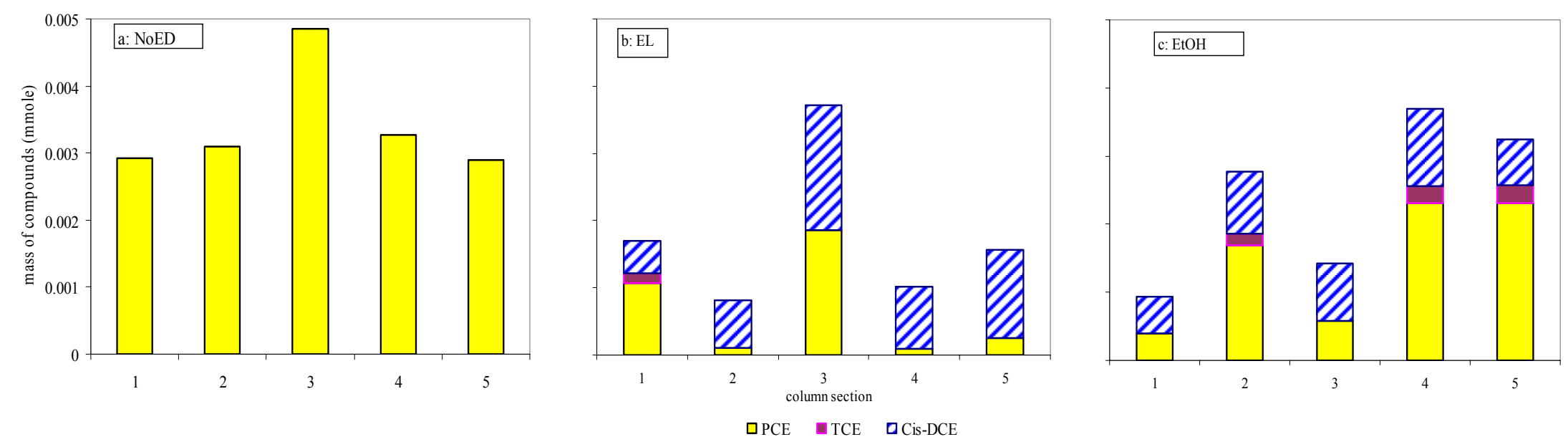

Figure 4-7. Mass of cis-DCE, TCE, and PCE extracted from the soil in a) NoED column, b) EL column, and c) EtOH column. 

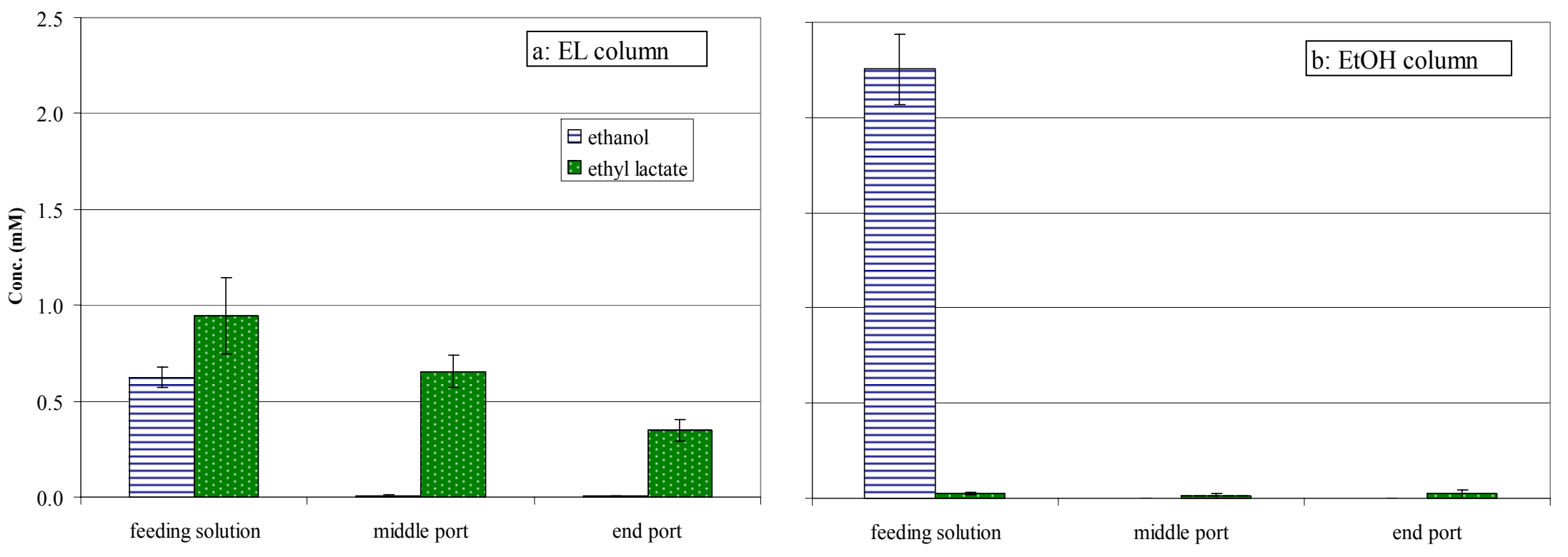

Figure 4-8. Ethanol and ethyl lactate concentration (average over time) in (a) EL column and (b) EtOH column, error bars show one standard deviation. 

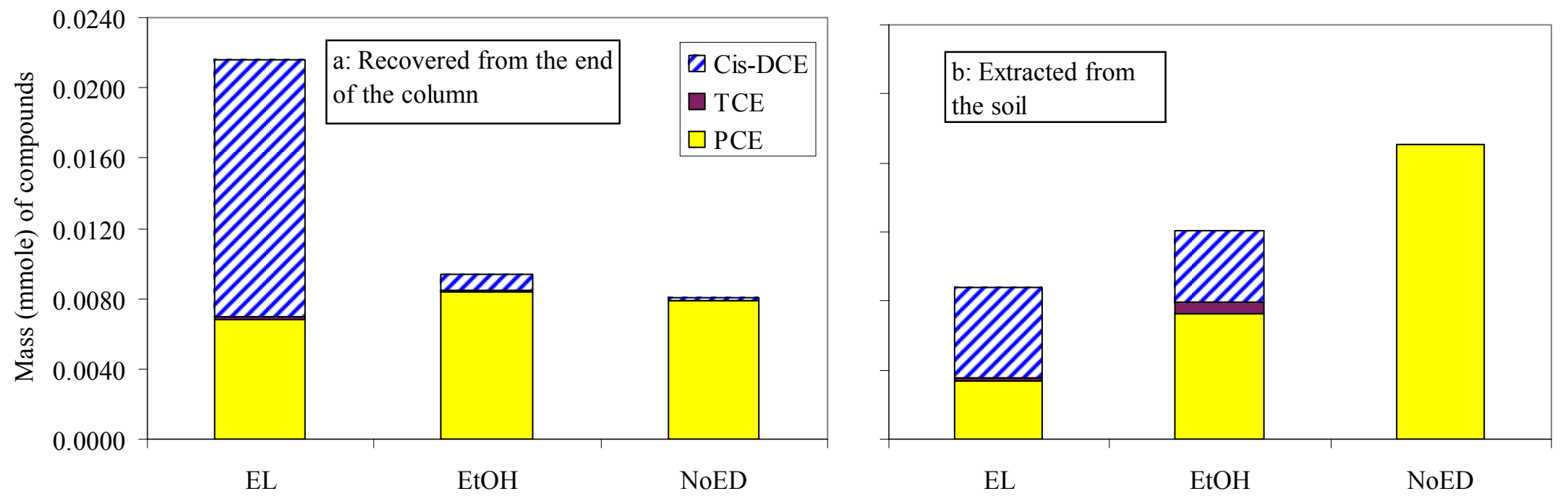

Figure 4-9. Mass of cis-DCE, TCE and PCE as (a) recovered in the aqueous phase at the end sampling ports (integration of area under the curve in Figure 4-6 d, e and f), and (b) extracted from the soil (summation of Figure 4-7 a, b and c). 


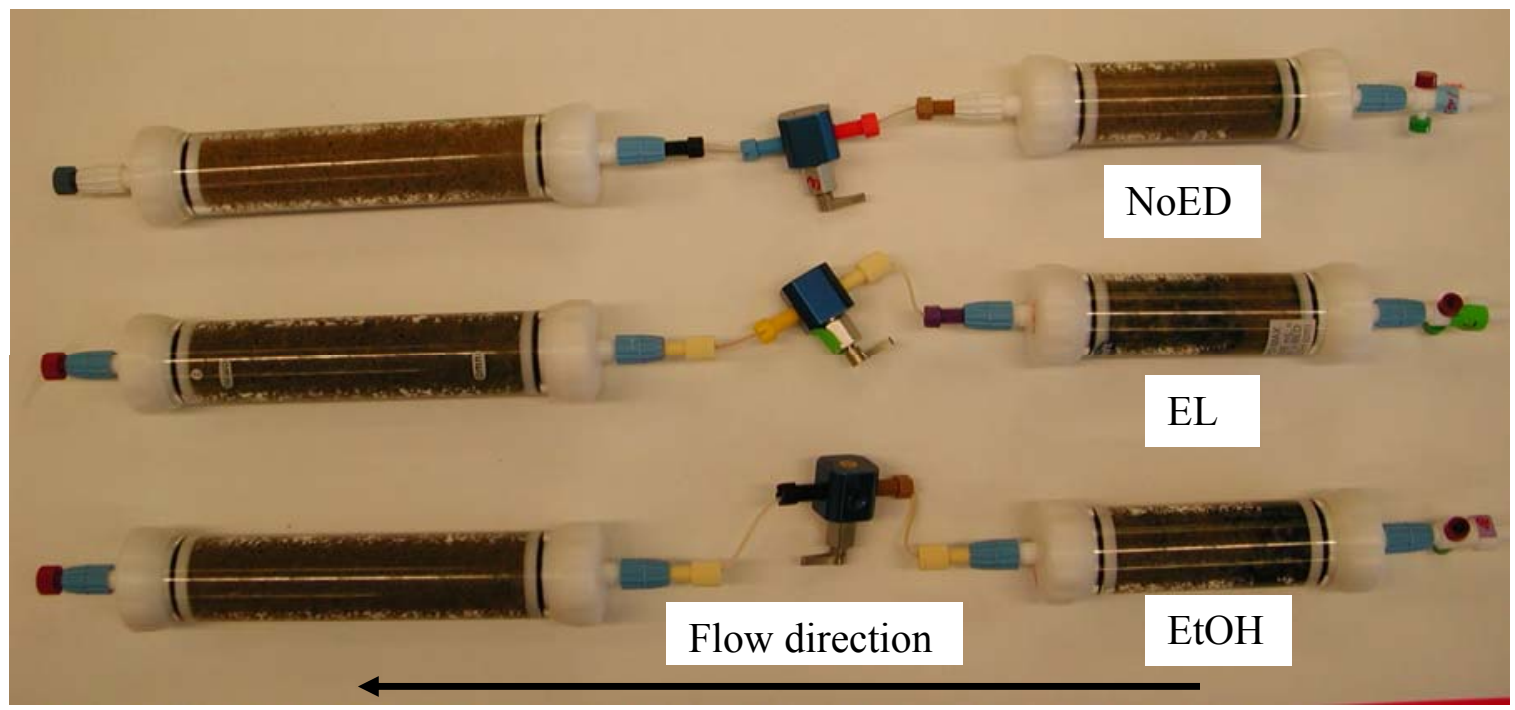

Figure 4-10. Appearance of the three column couples post-biodechlorination.

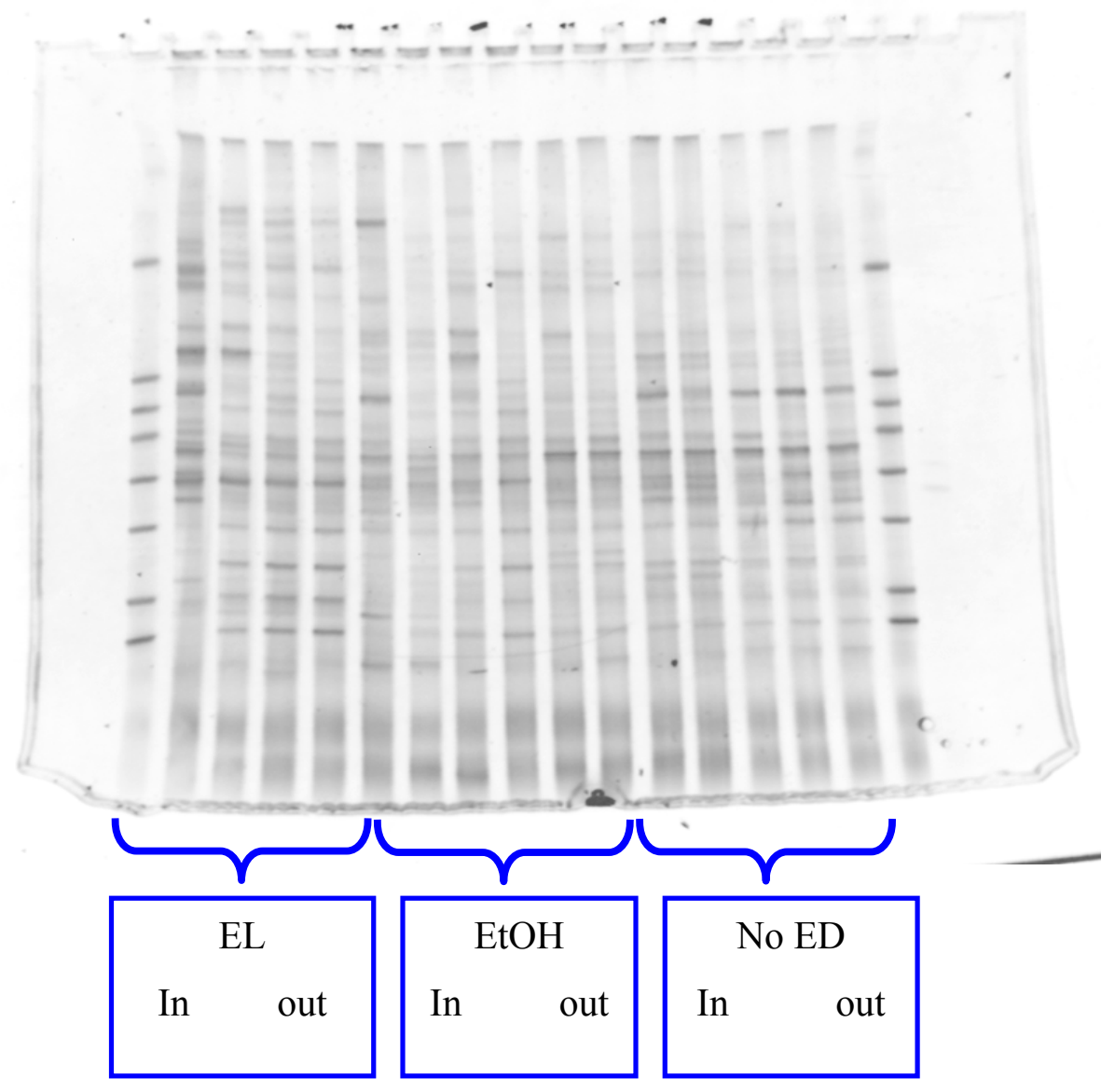

Figure 4-11. DGGE analysis of the soil from the three column couples at the end of the biodegradation experiment. 


\section{Chapter 5: Field Site Assessments and Visits}

Linda S. Lee, Inez Hua, and P. Suresh C. Rao

Project staff visited the Warsaw Sub-district site on March 23, 2002. After discussions with INDOT, further information was requested regarding site characteristics. In response to the request, additional sampling (by ATC Associates, Inc.) and site characterization was conducted on May 15, 2002. Inez Hua, Linda Lee, and Ben Lawrence were also present at the site that day. Soil and groundwater samples were collected for analysis. The groundwater samples were analyzed for benzene, toluene, ethylbenzene, xylene (BTEX) and methyl tert-butyl ether (MTBE). The soil samples were tested for Total Petroleum Hydrocarbons (TPH) in the gasoline range. Contaminants in all samples were reported non-detectible. ATC also performed a slug test.

Investigations related to these sites include the current JTRP/INDOT-funded project on the use of ethyl lactate in a coupled process involving in-situ flushing followed by enhanced biodegradation with residual ethyl lactate (EL-treatment train), another JTRP/INDOT-funded SPR-2623 project entitled "Remediation of Soils and Ground Water Contaminated by Aromatic and Chlorinated Hydrocarbons and Metals" in which in-situ chemical oxidation (ISCO is the remediation option being investigated, and another project focused on innovative technologies for accelerated groundwater clean-up and remediation performance assessment at contaminated sites, which complements both of the JTRP in-situ remediation projects. The Purdue PIs are Suresh Rao, Inez Hua, Linda Lee, and Chad Jafvert; additionally, there are numerous off-campus collaborators.

Sites were screened and selected based upon both hydrogeologic and contaminant criteria. Optimal geologic formations include coarse geologic parent material with high intrinsic permeability, less than 50 feet $(15 \mathrm{~m})$ deep, and underlain by a low permeability fine textured material serving as the confining geologic unit. Sites contaminated with dense non-aqueous liquids (DNAPLs), with an identified source zone and an extended dissolved plume in the groundwater were preferred. Access to the site, a site owner who is willing to provide in-kind services and who plans to implement some site remediation is also important.

Some of the potential sites are being considered for demonstrating a new technology for measuring contaminant fluxes (allowing for an estimation of the DNAPL source strength) before 
and after site/source remediation. This would require installation of a set of transect wells perpendicular to the mean flow of the dissolved plume and just down gradient from the source area. This method is being tested at a number of sites outside Indiana, and flux measurements will become an increasingly common component of site characterization and assessment.

Second, the sites are being evaluated for field scale testing of innovative remediation techniques for source cleanup, solvent flushing and chemical oxidation.

Table 5-1. Potential Sites for the EL-Treatment Train Field Test/Study in Indiana

\begin{tabular}{||l|l|l||}
\hline Location & Status & Future Tasks \\
\hline $\begin{array}{l}\text { Warsaw } \\
\text { (INDOT) }\end{array}$ & $\begin{array}{l}\text { Visited site twice; on the basis of consultant } \\
\text { reports and further characterization of } \\
\text { groundwater and soil- declined as potential site }\end{array}$ & Not applicable \\
\hline $\begin{array}{l}\text { Alexandria } \\
\text { (INDOT) }\end{array}$ & $\begin{array}{l}\text { Site investigation concluded; remediation work } \\
\text { bid out. Site declined for field study. }\end{array}$ & Not applicable \\
\hline $\begin{array}{l}\text { Crawfordsville } \\
\text { (INDOT) }\end{array}$ & $\begin{array}{l}\text { Aerial photos received. Site visit and meeting } \\
\text { with INDOT staff on January 13, 2004. }\end{array}$ & \\
\hline $\begin{array}{l}\text { Winamac } \\
\text { (INDOT) }\end{array}$ & $\begin{array}{l}\text { Received and analyzed facility log for this site. } \\
\text { Decision pending. }\end{array}$ & \\
\hline $\begin{array}{l}\text { Dyer } \\
\text { (INDOT) }\end{array}$ & $\begin{array}{l}\text { Well-log and groundwater concentrations map } \\
\text { received. Decision pending. }\end{array}$ & \\
\hline $\begin{array}{l}\text { Anderson } \\
\text { (General Motors) })\end{array}$ & $\begin{array}{l}\text { Site visit and meeting with IDEM planned for } \\
\text { January 28, 2004. }\end{array}$ & \\
\hline
\end{tabular}




\section{Chapter 6. Conclusions and Implementation Suggestions}

Linda S. Lee, Inez Hua, and Ben Lawrence

\subsection{Conclusions}

The primary goal of this research was to investigate ethyl lactate (EL) as a solvent for insitu flushing of NAPL source zones, and its potential to enhance biodegradation of contaminants in the down-gradient plume. Research examined in a series of laboratory studies a number of inter-connected issues pertinent to enhanced remediation of DNAPL source zones. First, the evolution of a DNAPL source zone from multiple releases and the resulting relationship between source strength (mass discharge, M/T) and DNAPL mass in the source zone was examined in 2D flow systems. Next, the role of EL as a cosolvent for depletion of DNAPL from the source zone was investigated in batch and column studies. Lastly, additional batch and column experiments were conducted to examine how residual cosolvent (EL and ethanol) serve as electron donors to promote the reductive dechlorination of DNAPL constituents in the dissolved plume. Perchloroethene (PCE) was used as a model DNAPL throughout this study. Additional work done with a toluene, a representative LNAPL, was limited to laboratory batch studies on quantifying physical and chemical characteristics relevant to assessing the use of EL for solubilizing an LNAPL source zone. Since there are alternate methods preferred over in-situ cosolvent flushing for LNAPL-type source zones relevant to INDOT sites, e.g., gasoline and diesel fuel contaminated sites, further work to explore effectiveness of EL for these source zones was not pursued.

The contaminant mass discharge (or source strength) out of DNAPL source zone is a function of the DNAPL mass present in the source zone. There are two types of DNAPL architecture in the source zone: DNAPL "pools" with high residual saturation, and ganglia with low residual saturation. Ganglia contribute more to mass discharge. When the DNAPL mass in the source zone is depleted by dissolution, it depletes the mass associated with the ganglia at a much faster rate than the mass in pools, so that the source strength decreases quickly at the beginning. As DNAPL sites are aged, the percentage of contaminant mass residing in the zones with ganglia decreases and the source architecture becomes pool-dominated; it is very difficult to achieve reduction in source strength without removing most of the contaminant mass in the 
pools. An innovative in-situ flushing technique using EL for enhanced removal of a DNAPL was evaluated in the current project.

In-situ flushing, with either cosolvent or surfactant, has been practiced over the past decade for cleanup of DNAPL sites (Falta et al. 1999; Jawitz et al. 1998; Jawitz 2000; Ramsburg et al. 2004; Rao et al. 1997). It has been one of the goals to use food-grade, or bio-friendly, cosolvents (Jawitz et al. 2000; Mravik et al. 2003) or surfactants (Ramsburg et al. 2004; Shiau et al. 1996) to eliminate the necessity to completely recover the flushing agent. An additional benefit of in-situ flushing can be derived if the flushing agent can be used as an electron donor by the microbes in the down-gradient plume to degrade contaminants as may be the case with EL. EL was found out to have the highest cosolvency power toward solubilization of PCE among several commonly used cosolvents, including methanol, ethanol, acetone, tertiary-butyl (TBA) etc. The physicochemical properties of EL/water binary solutions, including viscosity, density, and DNAPL interfacial tension, indicated that EL poses a lower DNAPL mobilization potential. Therefore, EL is a very efficient cosolvent for extracting DNAPL mass through in-situ flushing. Another advantage of EL making it a much better choice than other cosolvents, is its ability to serve as an excellent electron donor and promote biodegradation. Upon dissolving into water, EL slowly hydrolyzes into ethanol and lactate, which can both be utilized by microbes to carry out reductive dehalogenation of chlorinated solvents. In the column studies, the mechanism of slow hydrogen release was verified by the gradually decreased concentration along the column in the biodegradation experiments. When fed with low concentration of EL $(0.21 \mathrm{mM})$, microbes indigenous in a PCE-contaminated site were able to convert $\sim 80 \%$ of PCE to cis-DCE within 2.5 days of residence time. Compared to ethanol fed at the concentration with equivalent hydrogen donated $(0.41 \mathrm{mM})$, the microbes required less time to adapt to EL solution. Although EL did enhance the degradation of PCE, column residence time was not long enough to assess if PCE would be completely degraded to nonchlorinated metabolites, which is the desired target.

\subsection{Implementation Suggestions}

A cosolvent approach is most useful at sites where solubility is a limiting factor, such as at chlorinated hydrocarbon sites, including dry cleaner sites. In-situ flushing as with many in-situ remediation strategies is most easily implemented at moderate to high-permeability sites. EL is an effective flushing cosolvent for the mass reduction of a DNAPL initially through enhanced 
dissolution followed by enhancing dehalogenation of chlorinated compounds. Therefore, in-situ flushing with ethyl lactate is most applicable at moderate to high-permeability sites where the primary contaminants of concern are halogenated compounds, such as PCE and TCE. INDOT should consider the use of such techniques when standard excavation of contaminated source soil would not be practical or cost-effective. The latter may be due to the depth of the source (especially with DNAPLs) or proximity to utilities, buildings, or a roadway. Ideally INDOT would have ownership or unlimited access rights to the prospective property. This would simplify investigation and implementation of the chosen remedial option.

Geologically, porous soil would help in injecting a cosolvent and improving access to the contaminated area. The "ideal" situation would consist of a small, concentrated source zone (especially if free-phase NAPL is present) that feeds a large, relatively dilute plume. Plumes composed of chlorinated compounds would be most useful for the study. They are less mobile (and therefore easier to gain regulatory approval for unconventional treatment methods) and traditionally more limited in treatment options compared to more volatile gasoline constituents.

As with any of the techniques described in this report, regulatory approval at an early stage is critical to the success of such a remediation approach.

EL did enhance the degradation of PCE; however, the column studies conducted were not long enough to assess if PCE would be completely degraded to the desired target of nonchlorinated metabolites. The present of EL residuals will likely invoke anaerobic conditions near the flushed zone, which is needed to enhance dechlorination from the highly chlorinated compounds to the less chlorinated compounds. Subsequently, an aerobic zone is desirable; based on our findings and what is known in the literature, we know that the lower chlorinated compounds can be degraded aerobically by several microbial populations. In a field scenario, sufficient dissolved oxygen will likely be present at some distance downgradient of the flushed zone. However, if this distance is not within the site boundaries, an additional step in the treatment train involving aeration downfield of the flushing zone may be needed. A small pilot scale study or additional laboratory-scale work may be warranted before a full field demonstration to further probe these issues. 


\subsection{References}

Falta, R. W., Lee, C. M., Brame, S. E., Roeder, E., Coates, J. T., Wright, C., Wood, A. L., and Enfield, C. G. (1999). "Field test of high molecular weight alcohol flushing for subsurface nonaqueous phase liquid remediation." Water Resources Research, 35(7), 2095-2108.

Jawitz, J. W., Annable, M. D., Rao, P. S. C., and Rhue, R. D. (1998). "Field implementation of a Winsor type I surfactant/alcohol mixture for in-situ solubilization of a complex LNAPL as a single phase microemulsion." Environmental Science \& Technology, 32(4), 523-530.

Jawitz, J. W., Sillan, R. K., Annable, M. D., Rao, P. S. C., and Warner, K. (2000). "In-situ alcohol flushing of a DNAPL source zone at a dry cleaner site." Environmental Science \& Technology, 34(17), 3722-3729.

Mravik, S. C., Sillan, R. K., Wood, A. L., and Sewell, G. W. (2003). "Field evaluation of the solvent extraction residual biotreatment technology." Environmental Science \& Technology, 37(21), 5040-5049.

Ramsburg, C. A., Abriola, L. M., Pennell, K. D., Loffler, F. E., Gamache, M., Amos, B. K., and Petrovskis, E. A. (2004). "Stimulated microbial reductive dechlorination following surfactant treatment at the Bachman Road site." Environmental Science \& Technology, 38(22), 5902-5914.

Rao, P. S. C., Annable, M. D., Sillan, R. K., Dai, D. P., Hatfield, K., Graham, W. D., Wood, A. L., and Enfield, C. G. (1997). "Field-scale evaluation of in-situ cosolvent flushing for enhanced aquifer remediation." Water Resources Research, 33(12), 2673-2686.

Shiau, B. J., Sabatini, D. A., Harwell, J. H., and Vu, D. Q. (1996). "Microemulsion of mixed chlorinated solvents using food grade (edible) surfactants." Environmental Science \& Technology, 30(1), 97-103. 